$$
\begin{gathered}
\text { Universidade de São Paulo } \\
\text { Instituto de Química de São Carlos } \\
\text { Programa de Pós Graduação em Físico-Química }
\end{gathered}
$$

Estudo das interações entre o corante catiônico azul de metileno e partículas de argila em suspensão aquosa. Processos de migração entre partículas.

\title{
Tatiana Batista
}

Dissertação apresentada ao
Instituto de Química de São Carlos
da Universidade de São Paulo,
como um dos requisitos para
obtenção do título de mestre em
Ciências (Físico-Química)

Orientador: Prof. Dr. Fergus Gessner

São Carlos 
Aos meus pais Nelson $e$ Sandra pelo carinho, oportunidade, apoio e incentivo. 
Ao Vagner pelo amor companheirismo, atenção $e$, paciência. 


\section{Agradecimentos}

Ao Prof. Dr. Fergus Gessner, pela orientação, paciência e amizade.

Ao Prf. Dr. Miguel Guilhermo Neumann, pela infra-estrutura do laboratório disponibilizada.

À Carla pela amizade, paciência e cuidado com o laboratório.

Ao Laboratório de Bioquímica e ao Laboratório de Química Analítica pela ajuda na liofilização das argilas.

À Alessandra pela organização do laboratório e ajuda.

Aos amigos do laboratório de fotoquímica, pela colaboração e amizade.

Aos meus amigos, Josy, Kátia, Ana Paula, Alessandra, Márcia, Lisbeth, Jorge, Miriam, Avelardo, Raquel e outros por estarem sempre presentes, pela sinceridade e confiança.

À Silvia e Andréia , da sessão de pós gradução, pelo apoio e paciência.

Ao pesssoal da biblioteca e à Eliana pela correção das referências bibliográficas.

Ao Instituto de Química de São Carlos.

À Capes pela bolsa de estudos. 


\section{Índice}

Índice $i$

Lista de Figuras iii

Lista de Tabelas vii

Resumo viii

Abstract ix

1. Introdução

1.1 Argilas 1

1.1.2 Estrutura e classificação dos argilominerais 2

1.1.3 Propriedades 5

1.1.3.1 Capacidade de troca de cátions

1.1.3.2 Inchamento (Swelling) 6

1.1.4 Colóides Liofóbicos e Liofilicos 8

1.2 Corantes catiônicos 11

1.3.1. Estudo de corantes em argila em suspensão aquosa 13

2. Revisão da Literatura 18

$\begin{array}{lr}\text { 3. Objetivos } & 25\end{array}$

4. Parte Experimental 26

4.1 Reagentes 26

4.1.1 Corante 26

4.1.2 Argilominerais 26

4.2 Equipamentos Utilizados 28

4.3 Procedimentos experimentais $\quad 28$

4.3.1 Purificação das argilas 28

4.3.2 Preparação das suspensões e soluções $\quad 29$

4.3.3 Experimentos com membrana de diálise 30

4.4 Espectros dos corantes em suspensões de argila 31

4.5 Espectros diferença 21

5. Resultados e Discussões

5.1 Estudo do sistema SWy-1/AM 32

5.2 Estudo do sistema Laponita B/AM 37

5.3 Estudo do sistema SAz-1/AM 41

5.4 Estudo do sistema SWy-1/AM com adição de SWy-1 45

5.5 Estudo do sistema SAz-1/AM com adição de SAz-1

5.6 Estudo do sistema Laponita - B /AM com adição de Laponita - B

5.7. Estudo do sistema SAz-1/AM com adição de SWy-1 57

5.8 Estudo do sistema SWy-1/AM com adição de SAz-1 63

5.9 Estudo do sistema Lap B/AM com adição de SWy-1 69

5.10 Estudo do sistema SW/AM com adição de Lap B 73 
5.11 Estudo do sistema SAz-1/AM com adição de Lap-B

5.12 Experimentos com diálise

6. Considerações Finais

7. Conclusões

94

8. Referências Bibliográficas 


\section{Lista de Figuras}

Figura 1: (a) Representação de um tetraedro constituído de um átomo de silício central e quatro átomos de oxigênio nos vértices. (b) Representação da folha tetraédrica vista de lado.

Figura 2: (a) Representação de um octaedro constituído de um átomo de alumínio, que pode ser substituído por ferro ou magnésio central e seis hidroxilas nos vértices. (b) Representação da folha octaédrica vista de lado.

Figura 3: Representação da estrutura de uma partícula de argila do tipo 2:1. (a) forma tridimensional (b) forma esquemática.

Figura 4: Dispersão da argila e formação de tactóides suspensão aquosa.(a) argila com alta densidade de carga, (b) argila com baixa densidade de carga.

Figura 5: Curvas de energia repulsiva (r), atrativa (a) e resultante (R) em função da distância entre as partículas

Figura 6: Distribuição dos cátions trocáveis em volta das partículas de argila. (a) modelo descrito por Helmholtz e (b) modelo proposto por Gouy e Chapman.

Figura 7: Variação do potencial elétrico em função do aumento da distância da superfície da partícula.

Figura 8: Espectros de azul de metileno para três concentrações diferentes em

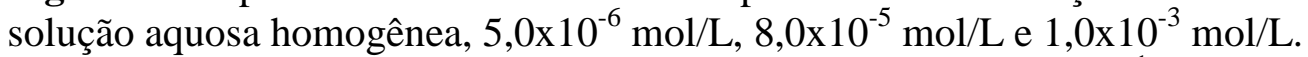

Figura 9: Espectro do azul de metileno em solução de $\mathrm{HCl} 3 \mathrm{~mol} . \mathrm{L}^{-1}$.

Figura 10: Esquema do rearranjo das moléculas de corante na superfície de uma partícula de argila em suspensão

Figura 11: Esquema proposto para descrever as interações entre moléculas de corante e partículas de argila.

Figura 12 : Espectros da suspensão de (a) SWy-1 0,11g.L $\mathrm{L}^{-1}$ e $[\mathrm{AM}]=6 \times 10^{-6} \mathrm{~mol}$. $\mathrm{L}^{-1}$ e (b) Laponita - B 0,11g.L $\mathrm{L}^{-1}$ e $[\mathrm{AM}]=6 \times 10^{-6} \mathrm{~mol} . \mathrm{L}^{-1}$

Figura 13: Espectros da suspensão de $S W y-10,11 \mathrm{~g} \cdot \mathrm{L}^{-1} 1$ (a) $[\mathrm{AM}]=1 \times 10^{-6} \mathrm{~mol} \cdot \mathrm{L}^{-}$ ${ }^{1}$ (b) $[\mathrm{AM}]=6 \times 10^{-6} \mathrm{~mol} \cdot \mathrm{L}^{-1}$, (c) $[\mathrm{AM}]=2 \times 10^{-5} \mathrm{~mol} \cdot \mathrm{L}^{-1}$, (d) $[\mathrm{AM}]=4 \times 10^{-5} \mathrm{~mol} \cdot \mathrm{L}^{-}$

1 . Os tempos t estão em minutos e $\mathrm{d}$ em dias.

Figura 14: Variação do comprimento de onda correspondente ao máximo de absorção para os agregados de AM em função da concentração de corante adicionada, no tempo inicial.

Figura 15: Variação da absorbância em função do tempo para as diferentes espécies de AM. (a) Agragados, (b) monômeros e (c) monômeros protonados

Figura 16: Espectros da suspensão de Laponita B $0,11 \mathrm{~g} \cdot \mathrm{L}^{-1} 1(\mathrm{a})[\mathrm{AM}]=2 \times 10^{-6}$ mol. $\mathrm{L}^{-1},(\mathrm{~b})[\mathrm{AM}]=6 \times 10^{-6} \mathrm{~mol} \cdot \mathrm{L}^{-1}$, (c) $[\mathrm{AM}]=4 \times 10^{-5} \mathrm{~mol} . \mathrm{L}^{-1}$. Os tempos t estão expressos em minutos e $\mathrm{d}$ em dias.

Figura 17: Variação do comprimento de onda correspondente ao máximo de absorção para os agregados de AM em função da concentração de corante adicionada, no tempo inicial

Figura 18: Variação da absorbância em função do tempo para as diferentes espécies de AM. (a) Agregados, (b) monômeros e (c) monômeros protonados

Figura 19 Espectros da suspensão de SAz-1 $0,11 \mathrm{~g} \cdot \mathrm{L}^{-1} 1$ (a) $[\mathrm{AM}]=1 \mathrm{x} 10^{-6} \mathrm{~mol} . \mathrm{L}^{-1}$ (b) $[\mathrm{AM}]=6 \times 10^{-6} \mathrm{~mol} \cdot \mathrm{L}^{-1}$, (c) $[\mathrm{AM}]=2 \times 10^{-5} \mathrm{~mol} \cdot \mathrm{L}^{-1}$, (d) $[\mathrm{AM}]=4 \times 10^{-5} \mathrm{~mol} \cdot \mathrm{L}^{-1}$. Os tempos t estão expressos em minutos e $\mathrm{d}$ em dias. 
Figura 20: Variação do comprimento de onda correspondente ao máximo de absorção para os agregados de AM em função da concentração de corante adicionada, no tempo inicial.

Figura 21: (a) Variação da razão $A_{\text {agre }} / A_{\text {mon }}$ em suspensões de $S A z-1$ e função da concentração de AM, no tempo inicial. Variação da absorbância em função do tempo para as diferentes espécies de AM. (b) Agregados, (c) monômeros e (d) monômeros protonados

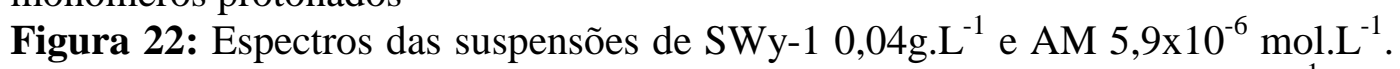
(a) Adição de água. (b) Adição de $S W y-1$, concentração final de $0,01 \mathrm{~g} \cdot \mathrm{L}^{-1}$. (c) Adição de SWy-1, concentração final de $0,02 \mathrm{~g} \cdot \mathrm{L}^{-1}$. (d) Adição de SWy-1, concentração final de $0,08 \mathrm{~g} \cdot \mathrm{L}^{-1}$. (e) Adição de $\mathrm{SWy}-1$, concentração final de $0,09 \mathrm{~g} \cdot \mathrm{L}^{-1}$.Os tempos t estão expressos em minutos e d em dias.

Figura 23: Espectro-diferença. (a) Espectro da Figura 22(b) menos 22(a). (b) Espectro da Figura 22 (c) menos 22(a). (c) Espectro da Figura 22(d) menos 22(a). (d) Espectro da Figura 22(e) menos 22(a).

Figura 24: Variação da absorbância nos comprimentos de onda característicos em função do tempo para: (a) agregados (580nm), (b) monômeros $(670 \mathrm{~nm})$ e (c) monômeros protonados $(768 \mathrm{~nm})$, para as diferentes amostras.

Figura 25: Esquema proposto para representar o processo que representa as alterações espectrais observadas como resultado da adição de argila às suspensões corante-argila.

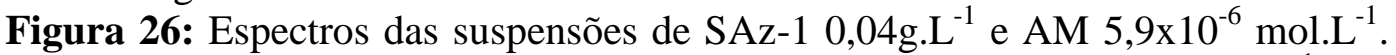
(a) Adição de água. (b) Adição de SAz-,1, concentração final de $0,01 \mathrm{~g} \cdot \mathrm{L}^{-1}$. (c) Adição de SAz-1, concentração final de $0,02 \mathrm{~g} \cdot \mathrm{L}^{-1}$. (d) Adição de SAz-1, concentração final de $0,08 \mathrm{~g} \cdot \mathrm{L}^{-1}$. (e) Adição de SAz-1, concentração final de $0,09 \mathrm{~g} \cdot \mathrm{L}^{-1}$. Os tempos t estão expressos em minutos e d em dias.

Figura 27: Espectro-diferença. (a) Espectro da Figura 26(b) menos 26(a). (b) Espectro da Figura 26(c) menos 26(a). (c) Espectro da Figura 26(d) menos 26(a ). (d) Espectro da Figura 26(e) menos 26(a). As linhas pontilhadas indicam floculação da suspensão

Figura 28: Esquema representado o processo de interação partícula - partícula

Figura 29: Espectros das suspensões de Laponita - B $0,04 \mathrm{~g} \cdot \mathrm{L}^{-1}$ e $\mathrm{AM} 5,9 \times 10^{-6}$ mol. $L^{-1}$. (a) Adição de água. (b) Adição de Laponita - B, concentração final de $0,01 \mathrm{~g} \cdot \mathrm{L}^{-1}$. (c) Adição de Laponita - B, concentração final de $0,02 \mathrm{~g} \cdot \mathrm{L}^{-1}$. (d) Adição de Laponita - B, concentração final de $0,09 \mathrm{~g} \cdot \mathrm{L}^{-1}$. Os tempos t estão expressos em minutos e $\mathrm{d}$ em dias.

Figura 30: Espectro-diferença. (a) Espectro da Figura 29(b) menos 29(a). (b) Espectro da Figura 29(c) menos 29(a). (c) Espectro da Figura 29(d) menos 29(a)

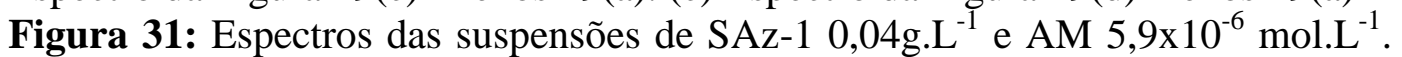
(a) Adição de água. (b) Adição de SWy-1, concentração final de $0,01 \mathrm{~g} \cdot \mathrm{L}^{-1}$. (c) Adição de SWy-1, concentração final de $0,02 \mathrm{~g} \cdot \mathrm{L}^{-1}$. (d) Adição de SWy-1, concentração final de $0,08 \mathrm{~g} \cdot \mathrm{L}^{-1}$. (e) Adição de $\mathrm{SWy}-1$, concentração final de 0,09g. $\mathrm{L}^{-1}$. Os tempos t estão expressos em minutos e d em dias.

Figura 32: Espectro-diferença. (a) Espectro da Figura 31(b) menos 31(a). (b) Espectro da Figura 31(c) menos 31(a). (c) Espectro da Figura 31(d) menos 31(a ). (d) Espectro da Figura 31(e) menos 31(a).

Figura 33: Variação da intensidade de absorbância em função do tempo dos (a) agregados $(575 \mathrm{~nm})$, (b) monômeros $(670 \mathrm{~nm})$ e (c) monômeros protonados (769nm), ), para os sistemas analisados após a adição de SWy-1 em diferentes concentrações. 


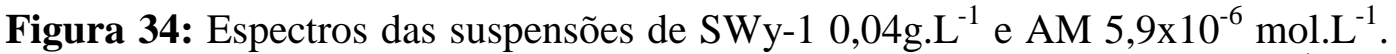
(a) Adição de água. (b) Adição de SAz-1, concentração final de 0,01g. $\mathrm{L}^{-1}$. (c) Adição de SAz-1, concentração final de 0,02g. $\mathrm{L}^{-1}$. (d) Adição de SAz-1, concentração final de $0,08 \mathrm{~g} \cdot \mathrm{L}^{-1}$. (e) Adição de SAz-1, concentração final de 0,09g. $\mathrm{L}^{-1}$. O tempo está expresso em minutos (t) e em dias (d).

Figura 35: Espectro-diferença. (a) Espectro da Figura 34(b) menos 34(a). (b) Espectro da Figura 34(c) menos 34(a). (c) Espectro da Figura 34(d) menos 34(a). (d) Espectro da Figura 34(e) menos 34(a).

Figura 36: Variação da intensidade de absorbância em função do tempo dos (a) agregados $(580 \mathrm{~nm})$, (b) monômeros $(671 \mathrm{~nm})$ e (c) monômeros protonados (769nm), para os sistemas analisados após a adição de SAz-1 em diferentes concentrações.

Figura 37: Espectros - diferença. (a) Espectro -diferença Figura 32(a). (b) Espectro -diferença Figura 35(a). (c) Espectro -diferença Figura 32(d). (d) Espectro -diferença Figura 35(d). Plotados em escalas semelhantes para comparação.

Figura 38: Espectros das suspensões de Laponita - B 0,04g. $\mathrm{L}^{-1}$ e AM 8x10 mol. $\mathrm{L}^{-1}$. (a) Adição de água. (b) Adição de $S W y-1$, concentração final de $0,01 \mathrm{~g} . \mathrm{L}^{-}$ 1. (c) Adição de SWy-1, concentração final de $0,02 \mathrm{~g} \cdot \mathrm{L}^{-1}$. (d) Adição de SWy-1, concentração final de $0,08 \mathrm{~g} \cdot \mathrm{L}^{-1}$. (e) Adição de $\mathrm{SWy}-1$, concentração final de $0,09 \mathrm{~g} \cdot \mathrm{L}^{-1}$. Os tempos t estão expressos em minutos e d em dias.

Figura 39: Espectro-diferença. (a) Espectro da Figura 38(b) menos 38(a). (b) Espectro da Figura 38(c) menos 38(a). (c) Espectro da Figura 38(d) menos 38(a ). (d) Espectro da Figura 38(e) menos 38(a).

Figura 40: Variação da intensidade de absorbância em função do tempo dos (a) agregados (580nm), (b) monômeros $(670 \mathrm{~nm})$ e (c) monômeros protonados (760nm), para os sistemas analisados após a adição de SWy-1 em diferentes concentrações.

Figura 41: Esquema representado os processos que ocorrem no sistema laponita B/AM com adição de SWy-1.

Figura 42: Espectros das suspensões de SWy-1 0,04g. $\mathrm{L}^{-1}$ e AM 8x10 $10^{-6}$ mol.L $\mathrm{L}^{-1}$. (a) Adição de água. (b) Adição de Laponita $-\mathrm{B}$, concentração final de $0,01 \mathrm{~g} \cdot \mathrm{L}^{-1}$. (c) Adição de Laponita - B, concentração final de $0,02 \mathrm{~g} \cdot \mathrm{L}^{-1}$. (d) Adição de Laponita - B , concentração final de $0,08 \mathrm{~g} \cdot \mathrm{L}^{-1}$. (e) Adição de Laponita - B, concentração final de $0,09 \mathrm{~g} \cdot \mathrm{L}^{-1}$.Os tempos t estão expresso em minutos e d em dias.

Figura 43: Espectro-diferença. (a) Espectro da Figura 42(b) menos 42(a). (b) Espectro da Figura 42(c) menos 42(a). (c) Espectro da Figura 42(d) menos 42(a). (d) Espectro da Figura 42(e) menos 42(a).

Figura 44: Variação da intensidade de absorbância em função do tempo dos (a) agregados $(580 \mathrm{~nm})$, (b) monômeros $(671 \mathrm{~nm})$ e (c) monômeros protonados (770nm), para os sistemas analisados após a adição de Laponita B em diferentes concentrações.

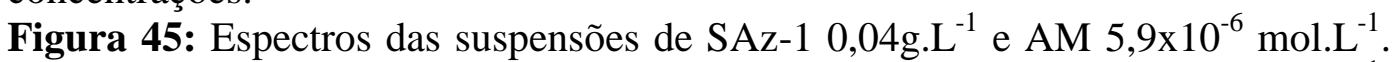
(a) Adição de água. (b) Adição de Laponita - B, concentração final de 0,01g. $\mathrm{L}^{-1}$. (c) Adição de Laponita - B, concentração final de $0,02 \mathrm{~g} \cdot \mathrm{L}^{-1}$. (d) Adição de Laponita - B, concentração final de $0,08 \mathrm{~g} \cdot \mathrm{L}^{-1}$. (e) Adição de Laponita - B, concentração final de $0,09 \mathrm{~g} \cdot \mathrm{L}^{-1}$. O tempo está expresso em minutos $(\mathrm{t})$ e em dias (d). 
Figura 46: Espectro-diferença. (a) Espectro da Figura 45(b) menos 45(a). (b) Espectro da Figura 45(c) menos 45(a). (c) Espectro da Figura 45(d) menos 45(a ). (d) Espectro da Figura 45(e) menos 45(a).

Figura 47: Esquema representado os processos que ocorrem no sistema SAz1/AM com adição de Laponita - B.

Figura 48: Possíveis mecanismos para a migração da molécula de AM entre partículas de argila. (a) Migração indireta (Passagem das moléculas de AM para a solução e posterior adsorção). (b) Migração direta (Passagem das moléculas de AM de uma partícula para outra partícula). ○ Representa as espécies (monômeros, agregados, dímeros) de AM. ::::::: Representa interações entre as partículas.

Figura 49: Representação do sistema utilizado nos experimentos com membrana.O béquer contem solução de corante e a membrana contem suspensão de argila.

Figura 50: Espectros das suspensões de argila com adição de corante através da membrana de diálise. (a) Suspensão de SAz-1 0,11g.L - $^{-1}$ (b) Suspensão de SWy-1 $0,11 \mathrm{~g} \cdot \mathrm{L}^{-1}$. A concentração de $\mathrm{AM}$ na solução $1 \times 10^{-5} \mathrm{~mol} \cdot \mathrm{L}^{-1}$. O tempo t está expresso em minutos e $\mathrm{d}$ em dias.

Figura 51: Espectros das suspensões separadas pela membrana de diálise. (a)

Espectro da suspensão de SWy-1 $\left(0,11 \mathrm{~g} \cdot \mathrm{L}^{-1}\right)$. (b) Espectro da suspensão de SAz$1\left(0,11 \mathrm{~g} . \mathrm{L}^{-1}\right) \mathrm{com}$ AM $\left(1 \times 10^{-5} \mathrm{~mol} \cdot \mathrm{L}^{-1}\right)$.

Figura 52: Esquema sumarizando os processos que ocorrem na suspensão de SWy-1/AM após adição de suspensão de argila.

Figura 53: Esquema sumarizando os processos que ocorrem na suspensão de SAz-1/AM após adição de suspensão de argila.

Figura 54: Esquema sumarizando os processos que ocorrem na suspensão de LapB/AM após adição de suspensão de argila.

Figura 55: Esquema representando o mecanismo de interação entre o corante catiônico azul de metileno e partículas de argila em suspensão aquosa. 
Lista de Tabelas

Tabela I: Propriedades e composição dos argilominerais utilizados 38

Tabela II: Sistemas estudados. 


\section{RESUMO}

Neste trabalho foi realizado um estudo das interações entre o corante catiônico azul de metileno com partículas de argilas em suspensão aquosa, visando detectar processos de migração de moléculas de corante entre partículas de argila.

Até o momento as interações entre moléculas de corante e partículas de argila vem sendo descritas tendo-se em conta dois processos, um deles devido a adsorção de moléculas de corante nas superfícies externas e migração do corante para a região interlamelar, e outro devido as interações partícula-partícula, onde as interações entre as partículas de argila levam a formação de aglomerados de partículas, com o corante aprisionado nas regiões internas formadas.

Há fortes indícios da ocorrência da migração de moléculas de corante entre partículas de argila, porém não houve detecção direta deste processo. No presente trabalho, foi idealizada uma metodologia que permitiu detectar variações espectrais, as quais podem ser atribuídas ao processo de migração de corante entre partículas de argila. A metodologia empregada consistiu na adição de suspensão de partículas de argila à suspensão argilacorante. Foram realizadas medidas espectrofotométricas na região do visível, em função do tempo, a partir do instante em que as suspensões foram misturadas. Os espectros determinados para as amostras foram comparadas com os espectros determinados para a amostra de referência, a qual foi preparada pela adição de água a suspensão corante argila. Os resultados mostraram que as amostras e a referência apresentam comportamento espectral distinto, e este comportamento pode ser atribuídos a migração de moléculas de corante entre partículas de argila.

De forma geral, verificou-se que a migração do corante entre partículas ocorre preferencialmente para as partículas da argila SWy-1, pois esta argila apresenta a região interlamelar disponível para a adsorção das moléculas de $\mathrm{AM}$, onde ocorre a protonação da molécula do corante, tornado-a mais estável.

Os experimentos utilizando membrana de diálise mostraram que quando as suspensões estão isoladas pela membrana a migração das moléculas de corante entre partículas de argila não ocorre, sendo necessário uma interação ou contato entre as partículas para que a migração ocorra. 


\section{ABSTRACT}

In the present work, studies on the interaction between the cationic dye methylene blue and clay particles in aqueous suspension are presented, aiming to detect migration processes of dyes molecules between clay particles.

Up to now, the interaction between dye molecules and clay particles is described considering mainly two processes, one due to the adsorption of the dye molecules onto the outer surfaces of the clay particles, and subsequent migration toward the inner surfaces of the clay tactoids. The other process involves particle-particle interaction; the interaction between clay particles promotes particle agglomeration, with dye molecules being trapped in the internal sites formed between particles.

There are strong evidences that dye molecules can exchange between dye coated particles, and in the present study a methodology was idealized to detect spectral changes, which could be attributed to migration of dye molecules between clay particles. According to the methodology used, clay particles were added to a dye-clay suspension and spectrophotometric measurements in the visible region was taken after different time intervals.

The results were compared with reference spectra, determined for samples prepared adding water to the clay-dye suspension. The results showed that the spectral behavior of the samples and the reference were different, and this behavior can be attributed to the migration of adsorbed dye molecules between clay particles.

It was observed that migration occurs preferentially in a direction towards the SWy-1 clay particles. The clay SWy-1 has interlamellar surfaces available to the dye adsorption. In the interlamellar region there are acids sites, where the dyes molecules are protonated. The protonation of dye molecules stabilize the adsorbed molecules.

The experiments using dialysis membrane showed that when the particles are isolated by a membrane, the migration between clay particles do not occur, indicating that a close contact or interaction between the clay particles is necessary to the migration occur. 


\section{Argilas}

\subsection{Argilas}

O termo argila apresenta vários sentidos, havendo uma variação considerável na terminologia das argilas nos diversos setores científicos e tecnológicos que se utilizam deste material. Por exemplo, para o ceraminista, o termo argila representa um material natural que quando misturado com água se converte em uma pasta plástica, para um sedimentologista, representa um termo granulométrico que abrange todos os sedimentos em que predominam partículas com diâmetro esférico equivalente ou menor que dois $2 \mu \mathrm{m}$, para o petrologista é uma rocha, para o mineralogista, as argilas são rochas, nas quais os argilominerais são os componentes característicos ${ }^{1,2}$.

A definição clássica designa argila como um material natural, terroso, que apresenta granulação fina, que quando umedecido com água apresenta plasticidade ${ }^{1,2}$.

Quimicamente, as argilas são formadas por alumino-silicatos, podendo conter também ferro e magnésio. Esses minerais apresentam estrutura cristalina perfeita ou quase prefeita, e como regra geral o tamanho do grão é muito pequeno. Suas partículas possuem tamanhos menores ou iguais a $2 \mu \mathrm{m}$ (eds, " eqivalent spherical diameter", diâmetro esférico equivalente), o que lhes confere uma grande área superficial disponível para interagirem com substâncias orgânicas, atuando com catalisadores em diversos processos naturais, como nas reações de formação do petróleo, transformações químicas nos solos, entre outros.

As argilas representam materiais de grande interesse tecnológico, com aplicação em diversas áreas, tais como, agricultura, indústrias de petróleo, metalurgia, tintas, cosméticos, papel, cerâmica e muitas outras. Dentre suas aplicações industriais podemos citar o uso como catalisadores, peneiras moleculares, trocadores iônicos e absorventes no tratamento de águas residuais ${ }^{3}$. O grande interesse tecnológico que este material desperta se deve a suas propriedades peculiares, aliadas a sua composição química. Uma importante característica das argilas consiste no fato de serem constituídas por um arranjo bidimensional de camadas ou lamelas, as quais, por sua vez são formadas por subcamadas, também designadas folhas, devido a esta característica, as argilas, 
pertencem à família dos minerais conhecidos como filosilicatos, esta palavra deriva do grego phylon, que significa folha.

\subsubsection{Estrutura e classificação dos argilominerais ${ }^{1,2,4}$}

Os argilominerais apresentam estrutura organizada em folhas ou lamelas, as quais são constituídas por tetraedros de silício e oxigênio e por octaedros de alumínio, ou magnésio, hidroxila e oxigênio. Essas folhas são combinadas em diferentes arranjos para formar as camadas que constituem o argilomineral.

Os tetraedros de silício são constituídos de átomos oxigênio presentes nos vértices e um átomo de silício central, conforme ilustrado na Figura 1(a). Tetraedros adjacentes são ligados pelos três átomos de oxigênio basais para formar as folhas tetraédricas (Figura 1(b)).

Os octaedros são formados por seis grupos hidroxilicos $(-\mathrm{OH})$ nos vértices e um átomo de alumínio, magnésio ou ferro no centro, conforme mostrado na Figura 2(a). Os octaedros adjacentes são coordenados pela face formando a folha octaédrica, Figura 2(b).

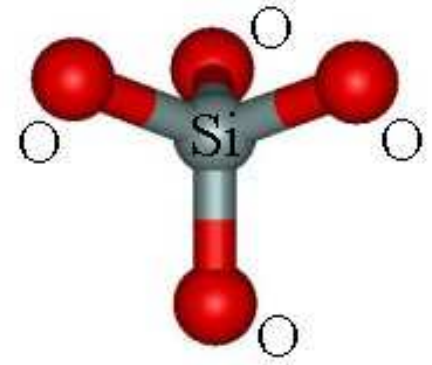

(a)

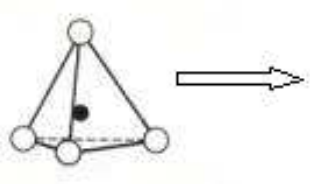

Átomos de Silício

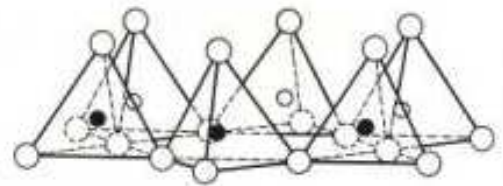

Átomos de oxigênio

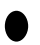

0

(b)

Figura 1: (a) Representação de um tetraedro constituído de um átomo de silício central e quatro átomos de oxigênio nos vértices ${ }^{5}$. (b) Representação da folha tetraédrica vista de lado ${ }^{6}$. 


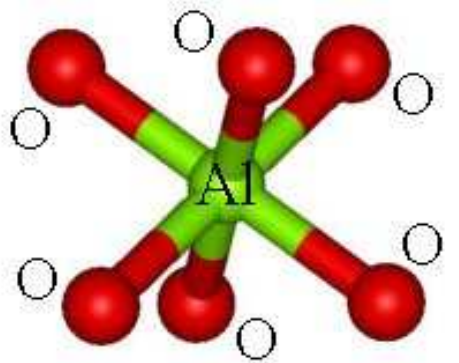

(a)

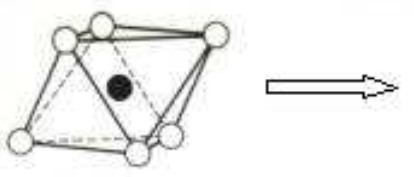

Átomos de Alumínio, Átomos de Hidroxila

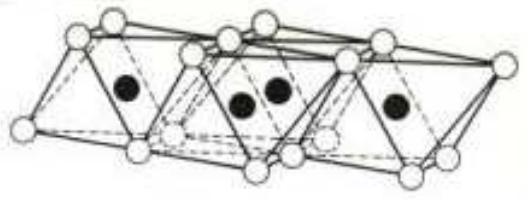

Magnésio ou Ferro

(b)

Figura 2: (a) Representação de um octaedro constituído de um átomo de alumínio, que pode ser substituído por ferro ou magnésio central e seis hidroxilas nos vértices ${ }^{5}$. (b) Representação da folha octaédrica vista de 1 lado $^{6}$.

Essas folhas podem se combinar umas com as outras de diferentes formas, dando origem às camadas, que podem ser classificadas de acordo com a razão de folhas tetraédricas para as folhas octaedricas. Por exemplo, quando uma folha octaédrica se combina com duas folhas tetraédricas tem se um material do tipo 2:1, como exemplo, podem ser citadas as montmorilonitas, já quando ocorre a combinação de uma folha tetraédrica com uma folha octaédrica, forma-se então um argilomineral do tipo $1: 1$, as caulinitas podem ser citadas como exemplo deste tipo de material.

As camadas ficam arranjadas umas sobre as outras no argilomineral e a distância entre um certo plano de uma camada e o plano correspondente da outra camada é denominado de distância interlamelar.

A Figura 3 representa a organização das folhas tetraédrica e octaédricas, na formação de uma argila do tipo 2:1. 


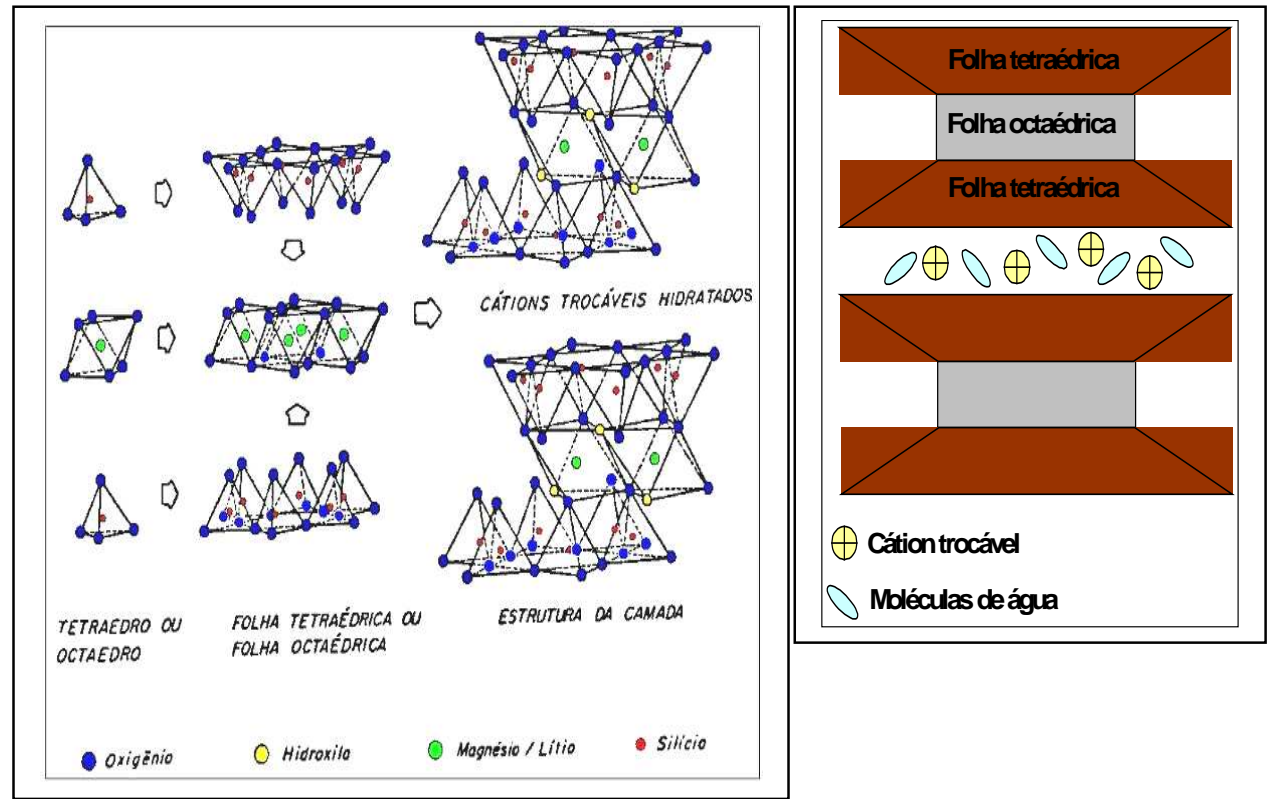

Figura 3: Representação da estrutura de uma partícula de argila do tipo 2:1. (a) forma tridimensional (b) forma esquemática ${ }^{1}$.

Basicamente, uma argila qualquer pode ser classificada de acordo com três características principais:

1. Estrutura lamelar;

2. Ocupação da camada octaédrica;

3. Natureza dos espaços interlamelares.

A primeira classificação, como já descrito anteriormente, depende da forma como as folhas que compõem as argilas se organizam formando as lamelas ou camadas, se $1: 1$ ou $2: 1$.

A outra classificação das argilas se refere ao grau de substituição na camada octaédrica. Quando as camadas octaédricas são formadas por octaedros contendo átomos de alumínio trivalente $\left(\mathrm{Al}^{3+}\right)$, na posição central, somente dois terços das posições centrais do octaedro podem estar preenchidas para manter a neutralidade elétrica da camada. Por esta razão, os minerais do tipo montmorilonitas, que contém principalmente alumínio trivalente são designados dioctaédricos. Por outro lado, minerais que contém magnésio divalente $\left(\mathrm{Mg}^{2+}\right)$ na folha octaédrica apresentam todas as posições preenchidas para manter a neutralidade elétrica da camada. Estes são designados trioctaédricos, como é o caso das hectoritas. 
Quando se substitui o $\mathrm{Si}^{4+}$ da camada tetraédrica por $\mathrm{Al}^{3+}$, ou o $\mathrm{Al}^{3+}$ é substituído por $\mathrm{Mg}^{2+}$ na camada octaédrica, gera-se uma deficiência de cargas positivas, resultando em uma camada carregada negativamente, sendo que a existência dessas cargas negativas nas lamelas é uma propriedade importante dos argilominerais. Este tipo de substituição é denominada isomórfica, pois os átomos que estão sendo trocados têm tamanhos semelhantes, não provocando distorção da estrutura lamelar.

A carga negativa da lamela é balanceada por cátions adsorvidos ou intercalados, normalmente cátions de metais alcalinos e alcalinos terrosos. Esses cátions são trocáveis, isto é, podem ser substituídos por outras moléculas.

A terceira forma de caracterização das argilas é através de seus espaços interlamelares, elas podem ser classificadas em expansíveis e não expansíveis. Em algumas argilas a distância interlamelar não é fixa, quando dispersas em água, elas tendem a expandir ou inchar. Essa expansão é causada pela adsorção total ou parcial de moléculas de água, as quais penetram entre as camadas da partícula de argila provocando o afastamento destas e conseqüentemente o aumento da distância interlamelar.

\subsubsection{Propriedades ${ }^{1,7}$}

A aplicação das argilas é dependente das propriedades destes materiais, como capacidade de troca de cátions, grau de dispersão, acidez interlamelar, área superficial, estabilidade da suspensão, dentre outras. Na seqüência serão descritas as principais propriedades dos argilominerais.

\subsubsection{Capacidade de troca de cátions}

Uma das propriedades importantes das argilas é a presença de cargas negativas que surgem como conseqüência das substituições isomórficas. Para compensar essas cargas negativas, existem cátions como $\mathrm{Na}^{+} \mathrm{e} \mathrm{Ca}^{2+}$ no espaço interlamelar, esses cátions são denominados trocáveis, pois, podem ser substituídos por outros eventualmente presentes no meio. A capacidade da argila em trocar esses cátions é medida pela CTC (capacidade de troca de cátions). A CTC representa a quantidade máxima de cátions 
necessários para neutralizar as cargas negativas que surgem em virtude da substituição isomórfica. A CTC é geralmente expressa em milequivalentes de carga por $100 \mathrm{~g}$ de argila.

Algumas das propriedades principais das argilas, como por exemplo, a expansibilidade advém da existência das cargas negativas na superfície das lamelas.

\subsubsection{Inchamento (Swelling)}

Outra propriedade característica das argilas é o inchamento (swelling), que se deve a adsorção de água nos espaços interlamelares, solvatando os cátions trocáveis que estão localizados entre as camadas. Após a solvatação os cátions deixam de balancear as cargas negativas geradas pelas substituições isomórficas. Assim as camadas da argila ficam carregadas negativamente, gerando repulsão mútua entre as lamelas, fazendo com que a argila se disperse no meio aquoso.

O grau de inchamento depende de várias condições, tais como, a carga das partículas da argila, natureza do contra-íon, energias de hidratação envolvidas, força iônica do meio e a água total contida ${ }^{4}$.

Além disso, o grau de inchamento está relacionado à densidade de carga da argila. A capacidade de inchamento diminui conforme a CTC da argila aumenta, dentro de certos limites (100-65meq/100g de argila $)^{8}$, pois a energia de coesão, ou seja, a energia que mantém as lamelas unidas, é diretamente proporcional a densidade de carga superficial. Uma estimativa da energia de coesão é dada pela equação de Stul e Uytterhoeven ${ }^{9}$, segundo a qual o inchamento dos espaços interlamelares diminui com o aumento da densidade de carga.

$$
E_{i}=\frac{\sigma_{i} e v}{16 \pi \varepsilon}\left(\frac{1}{D_{1}}-\frac{1}{D_{2}}\right)
$$

Equação 1

Sendo, $E_{1}$, a energia de coesão por $\mathrm{m}^{2}$ de área interlamelar, $\sigma_{\mathrm{i}}$, a densidade do cátion $\mathrm{i}, e$ é a carga elementar, $\varepsilon$ é a permissividade do meio, $\mathrm{D}_{1}$ e $\mathrm{D}_{2}$ referem-se às distâncias que separam os centros da carga positiva e das cargas negativas das lamelas, respectivamente.

De acordo com a equação 1, quanto maior a densidade de carga superficial, maior será a energia de coesão entre as lamelas. Isso faz com que em suspensão, a dispersão da argila seja menor, predominando partículas de tamanhos maiores, pois a capacidade de inchamento da argila fica diminuída. 
$\mathrm{Na}$ maioria das vezes, a dispersão não é completa e permanecem em suspensão partículas formadas por determinado número de lamelas associadas, denominadas tactóides, o qual está representado na Figura 4. Esses tactóides permanecem em suspensão, formando uma suspensão coloidal em água.

O tamanho do tactóide depende da natureza da argila, do cátion presente entre as lamelas, da concentração da suspensão, da energia de hidratação dos cátions e da energia de coesão entre as lamelas. Normalmente, o tamanho do tactóide aumenta com o aumento do raio iônico do cátion trocável ${ }^{10,11,12}$.
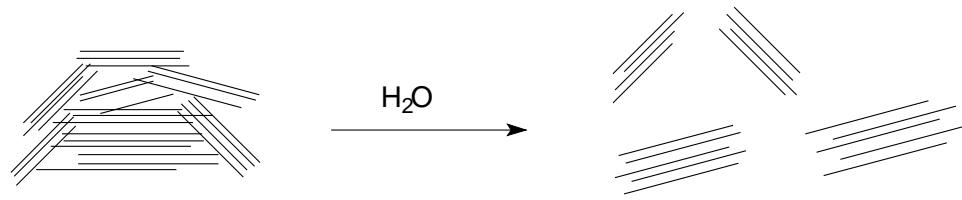

(a)

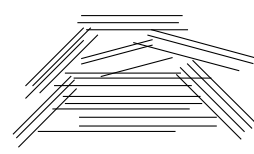

(b)

argila seca

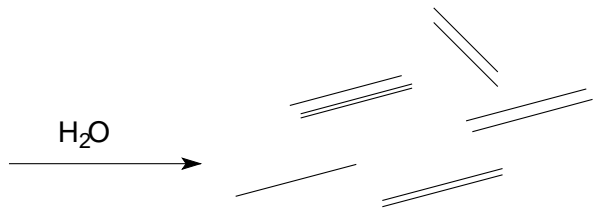

argila dispersa

Figura 4: Dispersão da argila e formação de tactóides suspensão aquosa.(a) argila com alta densidade de carga, (b) argila com baixa densidade de carga.

As cargas presentes nas lamelas representam um dos fatores mais importantes, que influenciam no tamanho do tactóide. Se a argila for expansível uma densidade de cargas mais alta faria com que a energia de coesão fosse maior, dificultando a separação das lamelas. Conseqüentemente haveria uma maior resistência a dispersão, um maior número de lamelas tenderia a permanecer associadas, e o tamanho da partícula na suspensão seria maior.

Da mesma forma, a intercalação de espécies químicas no espaço interlamelar de uma argila expansível, que é de fundamental importância em muitos processos químicos envolvendo argilas, deveria tornar-se mais difícil conforme a carga nas lamelas aumenta, devido a maior coesão entre as lamelas, dificultando a separação dessas para criar um espaço suficiente para acomodar as espécies que estão sendo intercaladas. Em argilas como vermiculitas e micas, as quais possuem densidade de carga superficial 
superiores que a das montmorilonitas, a intercalação é significativamente mais difícil quando comparadas a estas últimas. A intercalação de moléculas como glicol e etilenoglicol $^{13} \mathrm{em}$ argilas é utilizada para diferenciar as montmorilonitas (esmectitas) das micas e vermiculitas.

\subsubsection{Colóides Liofóbicos e Liofilicos ${ }^{4,14}$}

Os colóides podem ser classificados em liofilicos e liofóbicos. Colóides liofilicos apresentam afinidade pelo meio dispersante, são muito estáveis, adsorvem o meio dispersante e possuem viscosidade elevada. Colóides liofóbicos repelem o meio dispersante, são instáveis, não adsorvem o meio dispersante e possuem viscosidade reduzida. Há colóides que apresentam tanto propriedades liofilicas como liofóbicas. Quando o meio dispersante é a água os colóides podem ser classificados como hidrofílicos e hidrofóbicos.

Com relação às argilas, essas geralmente se comportam como colóides liofóbicos, mas algumas como por exemplo, as montmorilonitas, possuem certas propriedades dos colóides liofilicos.

A dispersão da argila em água é governada por um equilíbrio de ionização, estabelecido entre cátions adsorvidos (cátions trocáveis) e as superfícies das partículas de $\operatorname{argila}^{1}$.

$$
\text { M-argila } \rightleftharpoons \mathrm{M}^{+}+\operatorname{argila}^{-}
$$

Se a argila sofre uma forte ionização, maior será a carga negativa de suas partículas em suspensão, conseqüentemente a repulsão entre as partículas será maior, o que evita a aproximação entre elas, isto é, evitando a floculação (formação de um precipitado com partículas de argila). A floculação ocorre quando as forças repulsivas são fracas e causa a diminuição da energia livre do sistema.

As partículas também estão sujeitas às forças de natureza atrativa, como forças de van de Walls, ligações de hidrogênio e outras forças eletrostáticas. Quanto menor a distância entre as partículas, maior será a intensidade dessas forças, como ocorre no caso de suspensões muito concentrada. 
Quando a argila encontra-se defloculada, as forças de repulsão entre as partículas são elevadas, entretanto quando ela se encontra floculada, as forças repulsivas são baixas e não superam o efeito das forças atrativas.

$\mathrm{Na}$ Figura 5, são apresentadas as curvas de energia repulsiva (r), energia atrativa (a) e a curva resultante das duas (R), em função da distância entre as partículas.

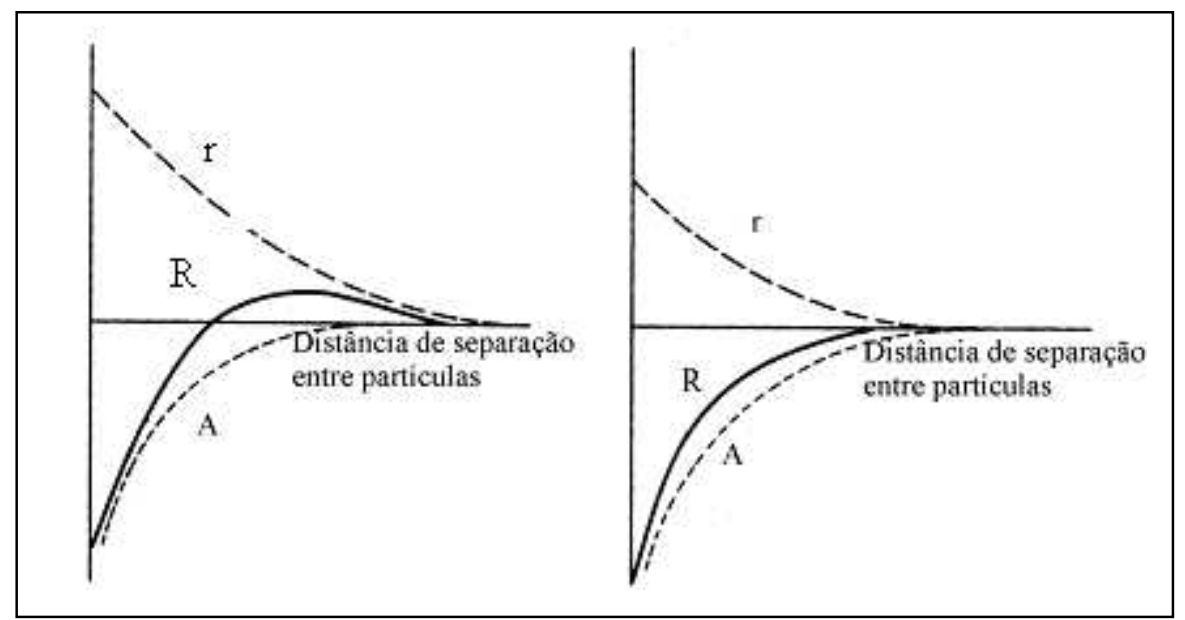

Figura 5: Curvas de energia repulsiva (r), atrativa (a) e resultante (R) em função da distância entre as partículas.

Em 1879, surgiu a primeira teoria para explicar a situação dos cátions trocáveis após a ionização em água e os estados de floculação das partículas de argila carregadas. Esta teoria, proposta por Helmholtz, dizia que os cátions estariam situados a uma distância fixa em relação à superfície da partícula, criando uma monocamada ao redor da superfície das partículas. As cargas negativas nas superfícies dessas partículas atraem e orientam as moléculas de água próximas a elas, sendo que o grau de orientação das moléculas de água diminui a medida que distância em relação a superfície aumenta. A Figura 6(a) representa esta teoria.

Em 1910, Chapman propôs uma teoria que veio aperfeiçoar a teoria da dupla camada de Helmholtz, considerando os efeitos da agitação térmica e de forças eletrostáticas de repulsão e atração. Segundo esta nova teoria, os cátions não se situam a uma distância fixa em relação às partículas de argila, eles estão mais próximos da superfície e sua concentração diminui à medida que a distância em relação a superfície aumenta, desta maneira é formada uma camada difusa ao redor da superfície da partícula.

A linha pontilhada na Figura 6(b) representa o limite da água que está rigidamente presa à partícula. 


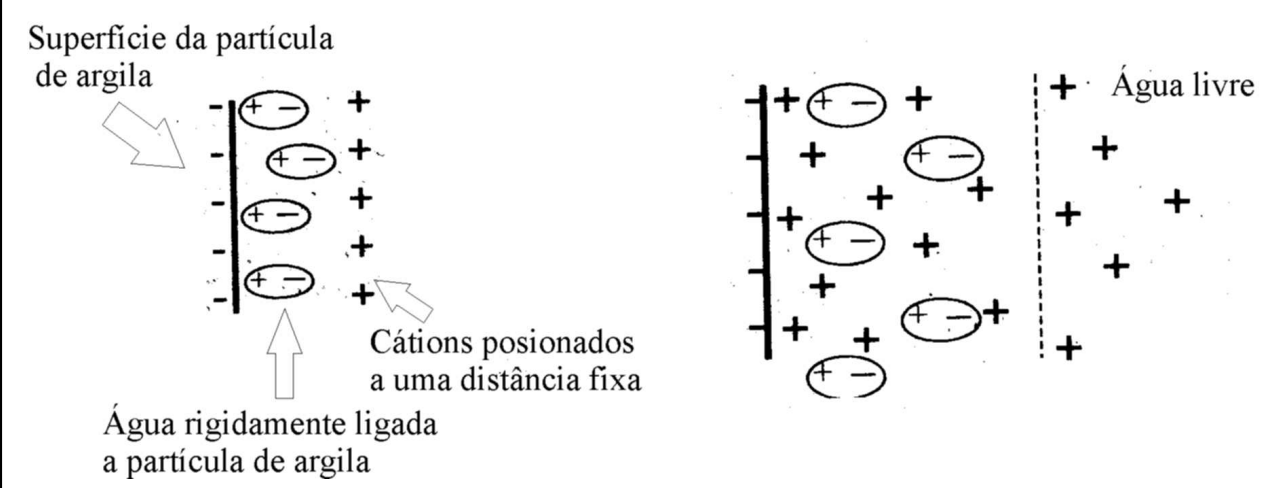

Figura 6: Distribuição dos cátions trocáveis em volta das partículas de argila. (a) modelo descrito por Helmholtz e (b) modelo proposto por Gouy e Chapman.

A variação do potencial elétrico com o aumento da distância das partículas está representada na Figura 7. A letra $d$ representa os limites da água rigidamente presa à superfície da partícula.

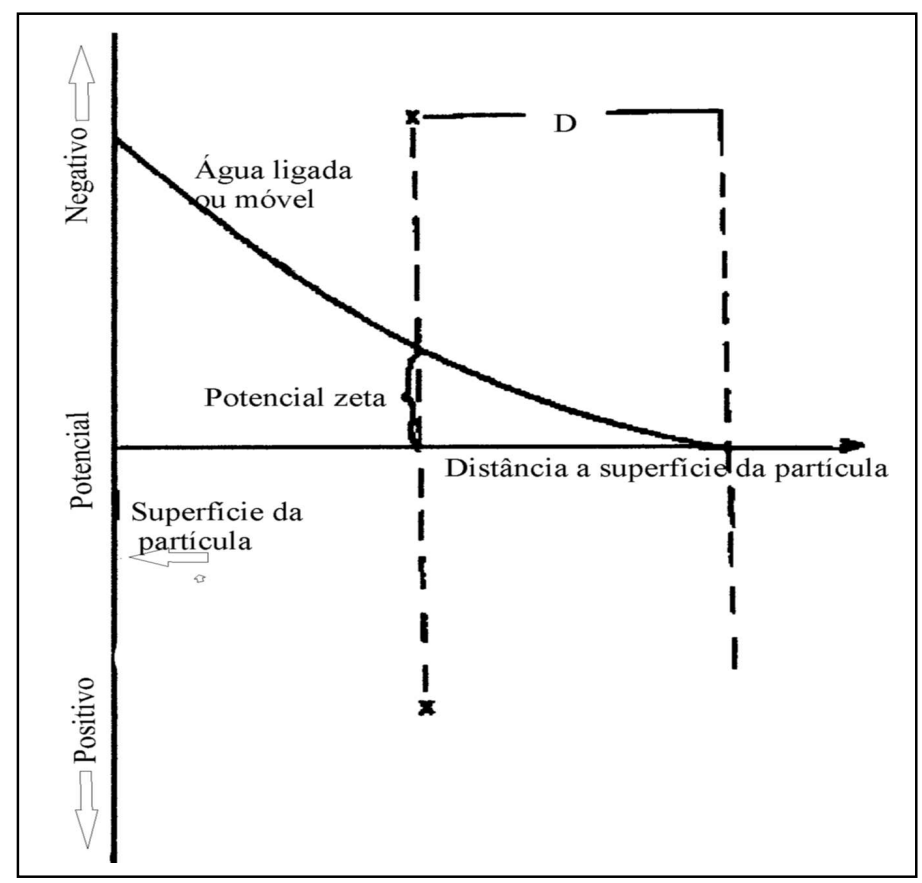

Figura 7: Variação do potencial elétrico em função do aumento da distância da superfície da partícula.

Numa suspensão aquosa de argila a menor distancia entre as partículas sem que ocorra floculação, é o limite de água rigidamente ligado às partículas. O potencial 
neste limite, é denominado Potencial Zeta $(\zeta)$. Ele é determinante no balanço de forças de atração e repulsão entre as partículas.

Stern, em 1924, propôs uma teoria que veio corrigir a teoria da dupla camada de Gouy-Chapman. Este nova teoria ainda é aceita atualmente e propõe que uma camada de cátions trocáveis rigidamente ligados à superfície da partícula de argila é formada seguida de uma camada difusa dos mesmos cátions. A primeira camada é denominada camada de Stern, e o potencial elétrico entre as duas camadas é conhecido como Potencial de Stern $\left(\psi_{\mathrm{D}}\right)$ e o potencial na superfície da partícula é denominado Potencial de Nernst $\left(\psi_{\mathrm{O}}\right)$. A espessura $\delta$ da dupla camada corresponde à espessura da camada de solvatação, isto é, a espessura da camada de água fixamente ligada à partícula, e no seu limite está o Potencial Zeta (Figura 7).

Para que uma suspensão seja estável, ou seja, para que o tempo em que ela permaneça defloculada seja infinitamente longo, é necessário que o Potencial Zeta seja superior a um valor mínimo. Valores menores que este valor mínimo, permitem a aproximação entre as partículas, suficiente para que haja a floculação.

O cátion presente nas superfícies das partículas pode provocar mudanças nos valores de potencial zeta e conseqüentemente na estabilidade das suspensões.

A adição de um sal inerte a uma suspensão de argila favorece a associação entre as partículas, pois ocasiona a compressão da dupla camada e diminuição do potencial zeta.

\subsection{Corantes catiônicos}

As características espectrofotométricas de corantes catiônicos em solução aquosa variam significativamente com a concentração ${ }^{15}$. Essas modificações foram observadas por desvios da Lei de Beer e se devem as diferentes formas nas quais as moléculas de corante podem se apresentar ${ }^{16}$ :

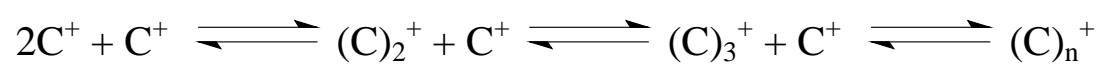

$\mathrm{Na}$ equação: $\mathrm{C}^{+}$, representa a molécula de corante na forma monomérica, $(\mathrm{C})_{2}{ }^{+}$e $(\mathrm{C})_{3}{ }^{+}$, representam, respectivamente, dímeros e trimeros e $(\mathrm{C})_{\mathrm{n}}{ }^{+}$representa os agregados maiores. Esses agregados são termodinamicamente estáveis. Esse equilíbrio apresenta constante da ordem de $10^{4}$ e $\Delta \mathrm{G}^{0}$ entre $3-5 \mathrm{Kcal} / \mathrm{mol}^{15}$, desta forma, mesmo em concentrações baixas $\left(10^{-4} \mathrm{M}\right)$, o equilíbrio favorece a formação de agregado. 
A forma monomérica difere do agregado quanto aos espectros eletrônicos de absorção. As modificações que ocorrem nos estados fundamentais e excitado das moléculas que constituem os agregados podem ser observadas no espectro de absorção através do aparecimento de novas bandas em diferentes comprimentos de onda, com referência à banda correspondente ao monômero. Devido a essa característica das moléculas de corante, as técnicas espectrofotométricas, como o uv-visível tornam se muito importantes no estudo desses sistemas.

A Figura 8 representa os espectros de absorção do corante azul de metileno em três concentrações diferentes em solução aquosa homogênea.

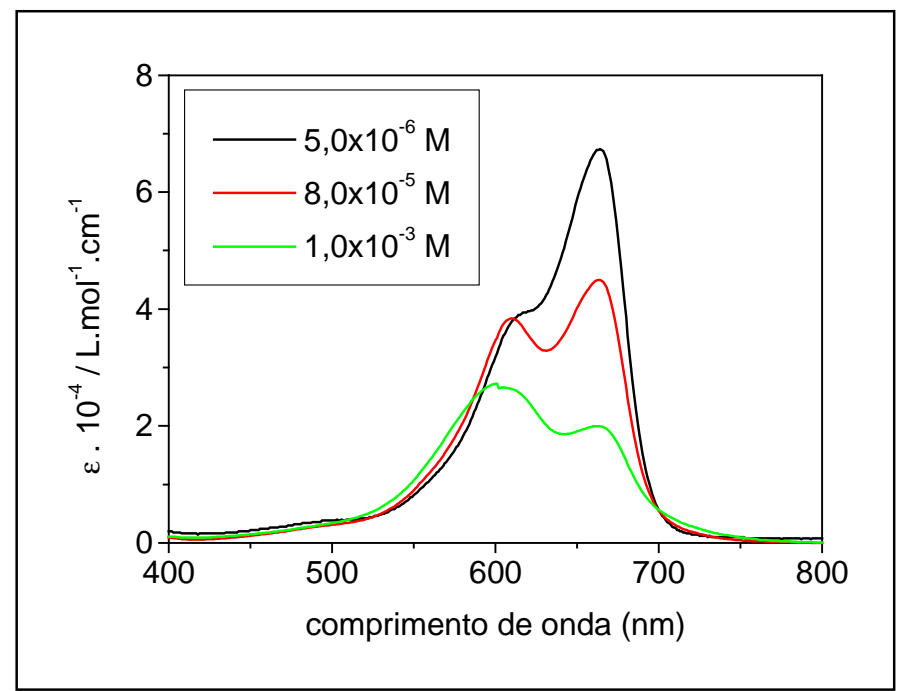

Figura 8: Espectros de azul de metileno para três concentrações diferentes em solução aquosa homogênea, $5,0 \times 10^{-6} \mathrm{~mol} / \mathrm{L}, 8,0 \times 10^{-5} \mathrm{~mol} / \mathrm{L}$ e $1,0 \times 10^{-3} \mathrm{~mol} / \mathrm{L}$.

Observando-se o espectro da Figura 8, pode-se verificar que para as soluções com menor concentração de corante $\left(5 \times 10^{-6}\right.$ mol. $\left.\mathrm{L}^{-1}\right)$ há apenas uma banda com máximo de absorção em torno de $665 \mathrm{~nm}$, correspondente à forma monomérica do corante. Há um pequeno ombro em aproximadamente 610nm, o qual representa uma banda vibrônica típica de monômero de azul de metileno. Com o aumento da concentração do corante, observa-se a redução da intensidade da banda em 665nm e o surgimento de uma nova banda em $605 \mathrm{~nm}$, correspondente aos dímeros de corante, que sobrepõem a banda vibrônica do monômero.

Já em concentrações ainda mais elevadas, observa-se o surgimento de uma banda por volta de $570 \mathrm{~nm}$, a qual corresponde à trímeros e agregados maiores. Em solução, as espécies agregadas estão em equilibrio sendo que esse pode ser deslocado, variando-se aconcentração do corante, o solvente, a temperatura e a força iôncia do meio. 
A tendência que os corantes iônicos têm de se agregar em solução é devida a vários tipos de forças, entre elas podemos citar, forças do tipo Van der Waals ${ }^{15}$, ligações de hidrogênio intermolecular ${ }^{17}$, interações de elétrons $\pi^{15,18}$ e a hodrofobicidade do corante $^{15,19}$. Assim, a agregação de corantes iônicos não pode ser atribuída a uma força específica, sendo difícil a determinação da contribuição individual dessas forças.

Quando o corante azul de metileno se encontra em meios suficientemente ácidos (acima de $3 \mathrm{~N}$ ) ocorre a protonação das moléculas do corante, havendo a formação da espécie $\mathrm{AMH}^{2+}$, a qual exibe uma banda na região de 750nm, outra com menor intensidade por volta de $680 \mathrm{~nm}$ e um ombro em aproximadamente $615 \mathrm{~nm}$, sendo que as intensidades relativas são 1:0,52:0,17, respectivamente, o que indica que o corante está totalmente protonado. $\mathrm{O}$ espectro de azul de metileno em solução aquosa de $\mathrm{HCl}$ está representado na Figura 9.

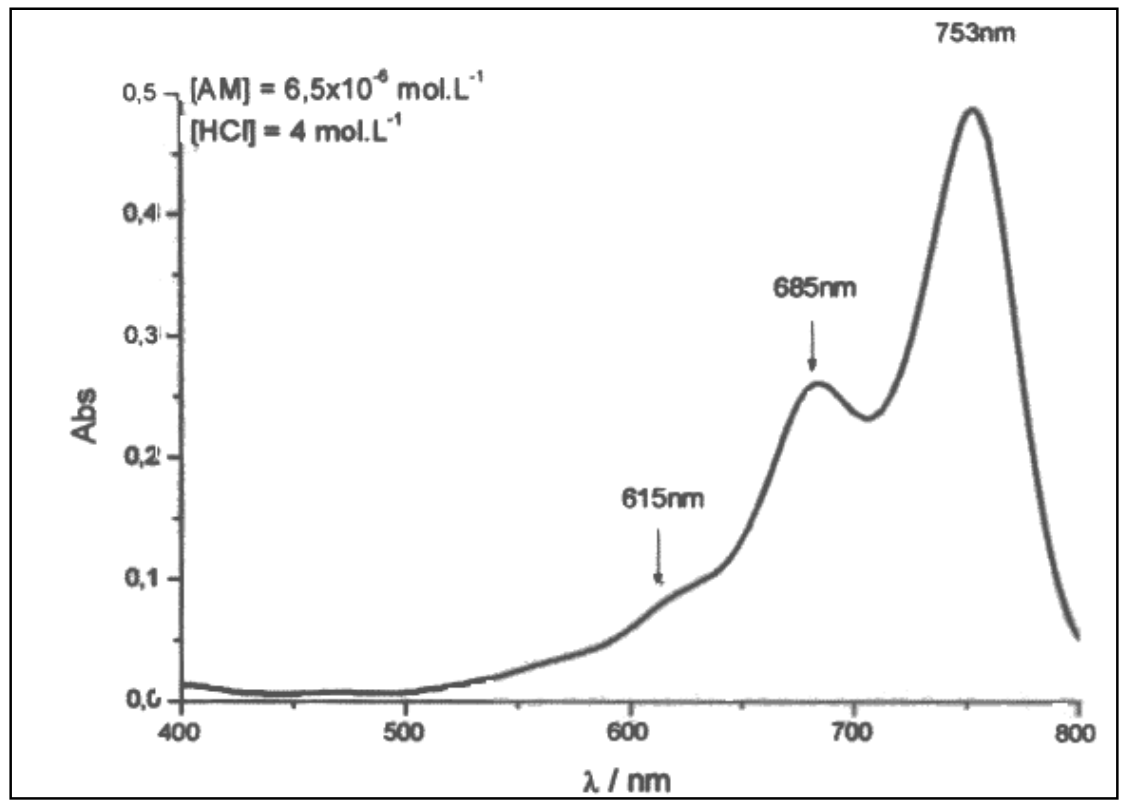

Figura 9: Espectro do azul de metileno em solução de $\mathrm{HCl}$ 4mol.L ${ }^{-1}$.

\subsubsection{Estudo de corantes em argila em suspensão aquosa.}

A interação entre moléculas de corante com outras espécies químicas (substratos) é de grande interesse em áreas bastante diversas, tais como, indústrias (tingimento de fibras têxteis, artefatos de couro, coloração de papéis), biológicas e médicas (estudos histológicos e carcinogênicos). 
A partir da primeira metade do século XX, começaram a ser publicados os primeiros trabalhos tratando dos sistemas argila-corante, verificando-se que os corantes têm grande afinidade pelos sítios ácidos das argilas ${ }^{20}$.

Os corantes catiônicos são utilizados como sondas nas superfícies das argilas, permitindo uma avaliação do ambiente em que se encontram. De acordo com estudos já realizados ${ }^{21,22}$, os corantes apresentam grande afinidade pelos sítios das argilas, sendo rapidamente adsorvidos e após esta adsorção há formação de diferentes espécies, as quais são detectadas por espectrofotometria de uv-visível e por medidas de emissão de fluorescência. Assim, pode-se determinar interações que ocorrem no sistema em estudo, e caracterizar os diferentes micro ambientes presentes em cada tipo de argila.

Gessner e col. ${ }^{23}$ e Neumann e col. ${ }^{24}$ realizaram estudos dos sistemas argilacorante, através de medidas espectrofotométricas e tomando o tempo como uma variável. A introdução desta variável permitiu detectar vários processos antes não observados, e formular mecanismos, levando a um melhor entendimento dos processos que acontecem nesses sistemas.

De forma geral, quando moléculas de corante são adicionadas a uma suspensão de argila, ocorre inicialmente uma rápida adsorção dessas moléculas nas superfícies externas dos tactóides de argila, ocorre o aumento da concentração local, induzindo a formação de dímeros, trimeros e agregados maiores. É estabelecido um "equilíbrio" entre agregados e monômeros. Posteriormente podem ocorrer dois processos, em um deles, ocorre uma reorganização que consiste na migração das moléculas de corante para a região interlamelar, onde ocorre a protonação do corante devido a existência de sítios ácidos nesta região (Figura 10). Uma conseqüência desse processo é a contínua desagregação das moléculas de corante, ocasionando o aumentando as bandas de absorção devido aos monômeros na superfície externa e surgimento da banda de absorção na região de $765 \mathrm{~nm}$, referente as moléculas de azul de metileno protonadas $\left(\mathrm{AMH}^{2+}\right)$. Estes processos ocorrem tipicamente na escala de tempo de minutos e horas.

Um outro processo envolve a interação partícula-partícula com moléculas de corante adsorvidas, causando o aprisionamento de moléculas do corante, resultando em alterações significativas no espectro de absorção da suspensão.

Esses processos fazem parte de um mecanismo proposto pelo grupo de fotoquímica do IQS/USP ${ }^{25}$, representado na Figura 11. 


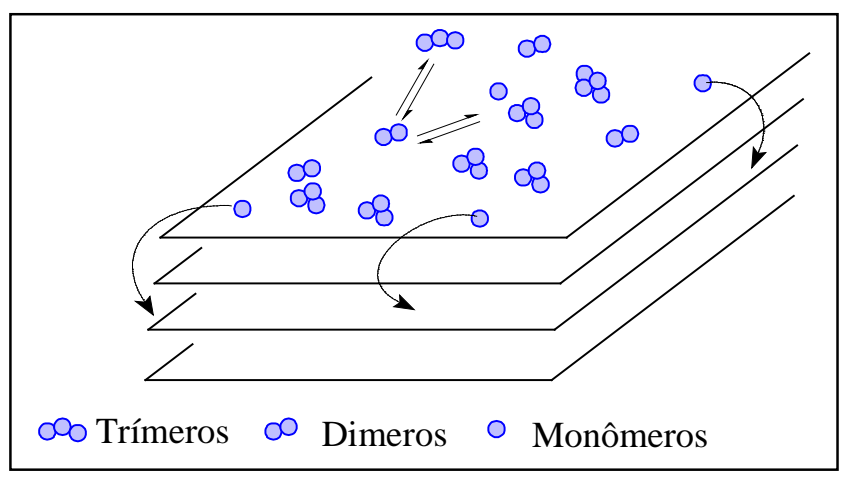

Figura 10: Esquema do rearranjo das moléculas de corante na superfície de uma partícula de argila em suspensão.

As variações espectrais são dependentes do argilomineral considerado. O acesso do corante à região interlamelar está relacionado a capacidade de expansibilidade da argila. Na Figura 12(a) são observados os espectros de azul de metileno adsorvido em partículas de SWy-1, uma argila expansível. Nesta suspensão ocorre o processo em que o corante é adsorvido rapidamente nas superfícies externas dos tactóides e passados alguns minutos tem inicio o processo de migração para a região interlamelar. Na Figura 12(b), tem-se os espectros para a suspensão de Laponita - B e azul de metileno. Esses espectros foram determinados nas mesmas condições que os da Figura 12(a). Na suspensão de Laponita - B e azul de metileno predomina o processo em que após a adição do corante ocorre uma rápida adsorção destas nas superfícies externas dos tactóides, porém, na sequiência predomina o processo de interação partícula-partícula. 


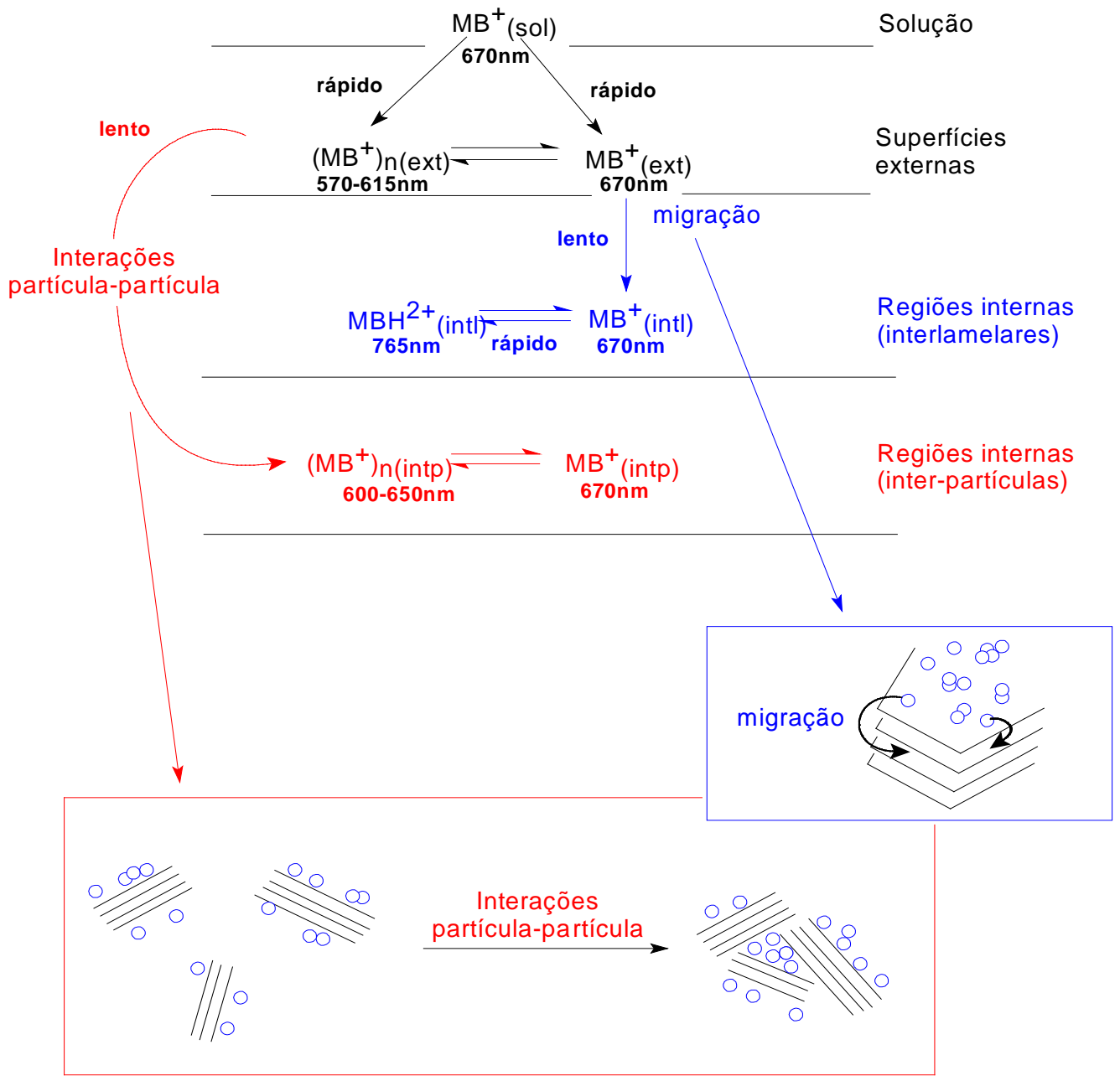

Figura 11: Esquema proposto para descrever as interações entre moléculas de corante e partículas de $\operatorname{argila}^{25}$. 


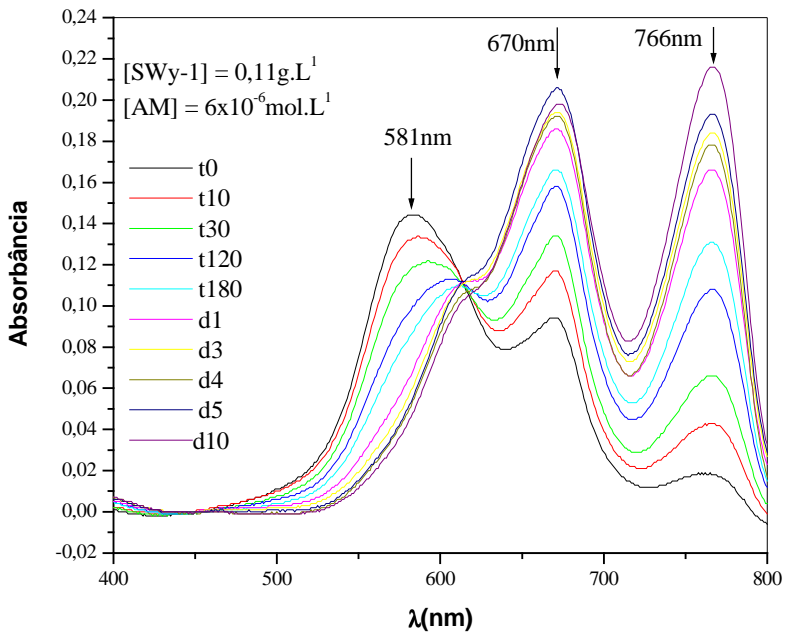

(a)

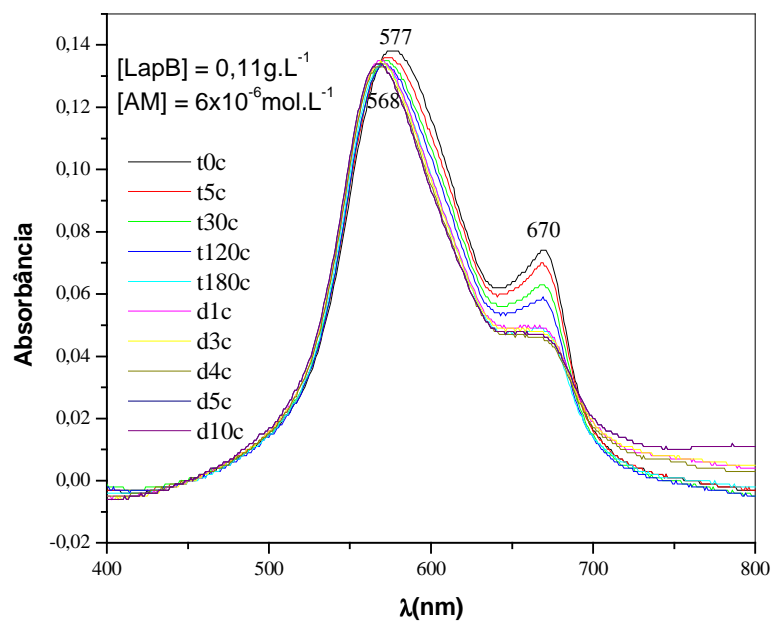

(b)

Figura 12 : Espectros da suspensão de (a) $\mathrm{SWy}-1$ 0,11g.L $\mathrm{L}^{-1}$ e $[\mathrm{AM}]=6 \times 10^{-6}$ mol. $\mathrm{L}^{-1}$ e (b) Laponita - B 0,11g. $\mathrm{L}^{-1}$ e $[\mathrm{AM}]=6 \times 10^{-6} \mathrm{~mol} . \mathrm{L}^{-1}$

O presente trabalho será uma continuação destes estudos, com objetivo de obter informações que poderão complementar o mecanismo até então proposto. Investigando as variações espectrais que ocorrem nas suspensões de argila e corante após adição de suspensão de argila livre de moléculas de corante. 


\section{Revisão da Literatura}

$\mathrm{Na}$ literatura especializada existe um grande número de trabalhos reportados que tratam das interações corante - argila. Selecionamos os que achamos mais relevantes, e a análise dos mesmos será importante para uma melhor discussão dos resultados.

Geiseking e Jenny ${ }^{20}$ em 1936, realizaram a primeira investigação a respeito da adsorção de azul de metileno em partículas de argila. Os autores concluíram que o processo de adsorção se dava através da troca entre as moléculas de corante e os cátions inorgânicos presentes nas regiões interlamelares de certas argilas. Na década seguinte, Faust $^{26}$ determinou que as argilas apresentam maior capacidade de adsorver corantes básicos quando comparadas com outros minerais como sílica e quatzo, os quais absorviam quantidades insignificantes do corante.

Segundo Plesh e Robertson ${ }^{27}$ a adsorção de AM em argilas é governada por dois mecanismos, sendo um deles a troca iônica e o outro a adsorção física. Adicionando o corante a uma suspensão de argila, primeiro ocorre uma troca irreversível do corante pelos cátions originalmente presentes na argila, até que a CTC da argila seja atingida. O excesso de corante seria então adsorvido fisicamente na argila já saturada em relação a sua CTC. O resultado líquido seria a adsorção irreversível do corante na superfície da argila por um processo de troca iônica.

Até a década de 60, os estudos envolvendo argila eram qualitativos, baseados na determinação da quantidade de corante que era adsorvida, obtendo assim as isotermas de absorção. Com o desenvolvimento e a popularização de técnicas como a espectrofotometria de absorção no uv - visível, tornou-se possível elucidar as variações espectrais do corante quando adsorvido em soluções contendo argila, sendo possível avaliar os processos que governam as interações corante - argila. Também existem estudos que procuram determinar propriedades especificas das argilas, tais como, a capacidade de troca catiônica (CTC) e a área superficial das argilas.

Bergamann e $\mathrm{O}^{\prime} \mathrm{Konski}^{21}$ foram os pioneiros no estudo do comportamento espectral do azul de metileno na presença de argila e verificaram a existência de quatro bandas distintas, as quais foram atribuídas à trimeros e agregados maiores $(575 \mathrm{~nm})$, a dímeros $(610 \mathrm{~nm})$, a monômeros $(670 \mathrm{~nm})$ e a banda $\mathrm{J}$ do dímero $(760 \mathrm{~nm})$. Observaram uma variação espectral grande quando se variou a concentração relativa corante/argila. Esses e outros pesquisadores ${ }^{34,35}$ observaram o mesmo comportamento mesmo em concentrações baixas. 
Yariv e Lurie ${ }^{28,29}$ analisaram o mesmo tipo de sistema que Bergamann e O’Konski, obtendo resultados semelhantes, entretanto concluíram que a variação espectral que ocorre quando a banda atribuída aos monômeros se desloca para comprimentos de onda menores, como sendo devida a interação do sistema $\pi$ do corante, com o par de elétrons livres dos átomos de oxigênio, que estão sobre a superfície externa da partícula de argila. O deslocamento para comprimentos de onda maiores foi atribuído à forma protonada ou semireduzida do corante.

Cenens e Schoonheydt ${ }^{30}$, também estudaram o comportamento espectral do azul de metileno adsorvido em três tipos de argila, hectorita, Laponita - B (hectorita sintética) e barasyn (montmorilonita sintética). Os autores atribuíram as bandas a diferentes espécies formadas pelas moléculas de corante através de comparação com o espectro de azul de metileno em solução aquosa em diferentes concentração e condição de pH. Desta forma, as bandas em menores comprimentos de onda correspondiam a dímeros e trimeros. Através de cálculos demonstraram que a banda $\mathbf{J}$ do dímero deveria ser em $720 \mathrm{~nm}$, já a banda 760nm foi atribuída a forma protonada da molécula de corante, a qual era realmente observada em meio ácido, contrariando o trabalho de Bergamann e O’Konski ${ }^{21}$ que atribuíram a banda em $760 \mathrm{~nm}$ aos dímeros $\mathrm{J}$.

Em um outro estudo Cenens e Schoonheydt ${ }^{31}$, realizaram um tratamento quantitativo para os processos de dimerização e trimerização da proflavina e o azul de metileno sobre barasyn, laponita e hectorita saturadas com $\mathrm{Na}^{+} \mathrm{e} \mathrm{Ca}^{2+}$ em suspensão aquosa. Consideraram as superfícies externas e internas disponíveis para a difusão e agregação das moléculas de corante e também que as interações entre o corante e a superfície das partículas de argila não seriam suficientemente fortes para provocar desvios do comportamento observado para os equilíbrios em solução homogênea. Segundo os autores os desvios deste comportamento ocorreriam, se o inchamento fosse incompleto, pois a distância interlamelar não seria suficiente para acomodar o dímero.

Em 1994, Schoonheydt ${ }^{32}$ voltou a discutir a adsorção de corantes catiônicos sobre a superfície das argilas, reforçando a idéia de que a reorganização das moléculas de corante, favorece sua agregação sobre a superfície bidimensional da argila e que as propriedades espectroscópicas dos corantes adsorvidos refletem a natureza heterogênea das superfícies das partículas de argila.

Muitos pesquisadores vêm se dedicando aos estudos de sistemas contendo corante e argila, como um exemplo, pode ser citado Arbeloa ${ }^{33,34}$ que tem dado uma 
contribuição significativa a estes estudos. Segundo Arbeloa, as moléculas de corante carregadas negativamente interagem com as partículas de argila, sendo protonadas. Este processo de protonação é muito importante, pois estabiliza as moléculas de corante. A hidrofobicidade das moléculas de corante também apresenta significante influência nas interações corante - argila ${ }^{35-37}$.

A influência da densidade de carga superficial nas interações corante-argila é considerada o principal determinante no comportamento desses sistemas, de acordo com uma série de estudos publicados por Bujdák ${ }^{38,39}$ e Bujdák e Komadel ${ }^{40}$. Nesses estudos eram utilizadas argilas com diferentes densidades de carga e verificou-se que a formação de monômeros, dímeros, trimeros e agregados maiores era determinada pela densidade de carga. Argilas que apresentam valores de densidade de carga altos, possuem pequenas distâncias entre as cargas na superfície, induzindo a adsorção de moléculas de corante em sítios vizinhos, próximo uns aos outros, favorecendo a formação de agregados. Para as argilas com menores valores para a densidade de cargas, a distância entre as cargas aumenta, ocasionando uma menor agregação das moléculas de corante adsorvidas.

Bujdák e $\operatorname{col}^{41}$ investigaram a agregação de azul de metileno em montmorilonitas com diferentes densidades de carga, consideraram que a agregação do corante ocorre na dupla camada das partículas carregadas. A força iônica relativamente alta nesta região induz a formação dos agregados $\mathrm{H}$ que estão adsorvidos na superfície da argila. Os autores enfatizam que as moléculas de corante se adsorvem de acordo com as cargas na superfície das partículas de argila.

O grupo de fotoquímica do IQSC/USP, vem realizando, de forma sistemática estudos de sistemas contendo partículas de argilas em suspensão utilizando corantes catiônicos como sondas ${ }^{42-46}$. A metodologia desenvolvida se baseia em medidas espectrofotométricas e espectrofluorimétricas para o estudo destes sistemas. Em um dos trabalhos, Gessner e col. ${ }^{28}$ e Neumann e $\operatorname{col}^{29}$, realizaram estudos dos sistemas argilacorante através de medidas espectrofotométricas tomando o tempo como uma variável. A introdução desta variável permitiu detectar vários processos antes não observados, e formular mecanismos, levando a um melhor entendimento dos processos que acontecem nesses sistemas.

De forma geral, quando o corante é adicionado a suspensão, suas moléculas são rapidamente adsorvidas nas superfícies externas das partículas da argila, aumentando a concentração local e induzindo a agregação das moléculas de corante, sendo possível a 
detecção dos dímeros, trimeros e agregados maiores adsorvidos nas partículas de argila. Com o passar do tempo são detectadas alterações espectrais significativas, que foram interpretadas como sendo devidas à reorganização do corante na partícula de argila, com a migração dos monômeros para a região interlamelar, onde ocorre a protonação dessas moléculas devido a presença de sítios ácidos nesta região. Conseqüentemente, ocorre a diminuição da concentração das espécies nas superfícies externas e os agregados maiores tendem a se transformar em agregados menores e monômeros. Esses processos ocorrem na escala de tempo de minutos e horas. Para tempos maiores predominam os processos de interação partícula-partícula, criando regiões nas quais as moléculas de corante ficam aprisionadas, resultando em mudanças características no espectro de absorção.

Cione e $\operatorname{col}^{47}$ estudaram a adsorção competitiva de azul de metileno e laranja de acridina em SWy-1 e laponita usando o método espectrofotométrico, considerando o tempo como variável. Neste trabalho novas bandas de absorção correspondentes à mistura dos corantes foram identificadas imediatamente após a mistura, com propriedades espectroscópicas similares àquelas dos dímeros formados em solução aquosa $^{48}$. Para tempos longos, a banda dos dímeros deslocou, sugerindo uma nova localização para esses dímeros. Concluiu-se que a primeira absorção corresponde aos dímeros na superfície externa, enquanto que a absorção posterior era devida aos dímeros internos aprisionados durante o processo de agregação - desagregação da argila.

Num outro estudo foi desenvolvida uma metodologia baseada em medidas de emissão de fluorescência para a determinação do ponto de saturação de argilas, utilizando corantes catiônicos ${ }^{43}$. A importância deste estudo se deve a determinação de CTCs de argilas e de áreas superficiais. De acordo com os resultados verificou-se que o uso de corantes nem sempre é o mais indicado para estas determinações. Esses resultados podem ser aplicados para outras superfícies como sílica, alumina, carvão ativado, etc.

Realizou-se um estudo geral das interações de surfactantes catiônicos com partículas de argilas em suspensão ${ }^{44}$ utilizando corantes catiônicos como sonda. O estudo permitiu concluir que as moléculas de surfactantes interagem primeiramente com as superfícies externas das partículas de argila, formando agregados, e depois migram para os espaços interlamelares. Foram propostos mecanismos para descrever as interações surfactante-argila-corante e identificar os fatores que exercem influência nesses sistemas, como por exemplo o tamanho da cadeia alquilica do surfactante. 
Cione e $\operatorname{col}^{49}$, realizaram estudos acerca das propriedades coloidais das argilas em suspensão aquosa, mostrando que a adição de eletrólitos como $\mathrm{NaCl}$, por exemplo, provoca a diminuição da repulsão eletrostática entre as cargas residuais presentes nas folhas, devido o efeito de força iônica. Como resultado tem-se a compressão das camadas, resultando em partículas com menor capacidade de inchamento e com maior numero de folhas associadas, fazendo com que o tamanho das partículas aumente. Adicionando-se uma quantidade adequada de eletrólitos $\left(0,5-1,0 \mathrm{~mol} \cdot \mathrm{L}^{-1}\right)$ às suspensões de argila, nota-se que os processos de associação partícula-partícula são acelerados, observando-se os efeitos similares aos detectados nas argilas em tempos longos na ausência de sal. Para o caso da laponita, verificou-se que o aumento dos monômeros internos com absorção em torno de $658 \mathrm{~nm}$, é mais rápido na presença de sal. Isso significa que as moléculas de corante originalmente nas superfícies externas das partículas de argila são aprisionadas durante o processo de rearranjo das lamelas induzidos pelo efeito do sal.

Realizou-se também um estudo de interações entre partículas de argila e compostos orgânicos aromáticos. Neste estudo foram utilizadas amostras em fase sólida, realizadas medidas de fluorescência e medidas de fotólise de pulso por laser para caracterizar os transientes formados a partir das moléculas orgânicas nas superfícies das partículas $^{45,50}$.

Há também um estudo a respeito da influência da densidade de carga nas interações entre os corantes catiônicos e as partículas de argila em suspensão ${ }^{51}$ Concluiu-se que à medida que a densidade de carga aumenta, o tamanho da partícula em suspensão aumenta e os espaços interlamelares estão menos disponíveis para a intercalação de moléculas orgânicas. Esses resultados são importantes para a compreensão do comportamento das partículas de argila em suspensão, e das interações dessas partículas com compostos orgânicos como pesticidas, herbicidas e outros.

Em suspensões de montmorilonitas altamente carregadas, como SAz-1 e SCa-3, verifica-se uma intensa agregação das moléculas do corante adsorvido. A desagregação não é observada para tempos longos, em contraste com a suspensão de argilas com densidade de cargas superficial baixa, como a SWy-1. As cargas na superfície das partículas de argila influenciam a distribuição das moléculas de corante sobre a superfície. Com o aumento da densidade de carga superficial, a distância entre os sítios de adsorção carregados diminui, assim as moléculas se adsorvem próximas umas as outras. No entanto, o grau de dispersão das argilas com densidade de carga elevada é menor do 
que observado para argilas com baixa densidade de carga, como por exemplo, a SWy-1. Isso ocorre pois a energia de coesão que mantêm as camadas unidas aumenta com o aumento da carga superficial, resultando em partículas maiores em suspensão. $\mathrm{O}$ aumento do tamanho da partícula resulta em menor área superficial externa disponível para adsorção, induzindo uma maior agregação das moléculas de corante. Adicionalmente, as partículas de argila estarão mais próximas, dificultando a migração das moléculas de corante para a região interlamelar ${ }^{52}$.

As revisões publicadas recentemente ${ }^{53,54}$, mostram que muitos estudos da interação corante-argila foram realizados enfatizando aspectos diferentes: a habilidade que certas partículas têm de adsorver moléculas de corante e procedimentos para determinar as propriedades das argilas. Posteriormente, os corantes passaram a ser usados como sonda espectrofotométrica. Recentemente, os métodos espectrofotométricos dependentes do tempo, vêm sendo utilizados com sucesso para determinar os processos envolvidos na adsorção das moléculas de corantes. A compreensão dos mecanismos de interação entre partículas de argila e moléculas orgânicas é muito importante no estudo do poder catalítico desses minerais, e além disso, pode também ser utilizado como um modelo para a interação entre poluentes orgânicos e partículas de argilas, considerando a aplicação desses minerais na remoção de contaminantes ${ }^{55}$. A partir de 2000, um grande número de estudos visando a remoção de corantes de efluentes industriais, envolvendo a aplicação da adsorção de corantes por argilas, começaram a ser divulgados. Segundo Fadali ${ }^{56}$, a remoção de corantes básicos por montmorilonitas é mais econômica que o uso de carvão ativado (PAC). A eficiência da remoção do corante por argilas é de $40 \%$ em relação ao PAC, no entanto o seu custo é 40 vezes menor. Em alguns casos a associação da argila com outros compostos apresenta melhores resultados. A remoção de corantes básicos de efluentes industriais por argilas ativadas é praticamente instantânea e obedece a isoterma de Langmuir ${ }^{57}$.

Segundo os estudos já realizados, torna-se claro que as interações coranteargila envolvem não apenas a troca catiônica, mas muitos outros processos. Progressos vêm sendo realizados para o entendimento desses sistemas. Muitos aspectos, tais como, a não uniformidade das partículas de argila, a distribuição destas partículas que conferem propriedades diferentes aos sistemas, e a migração de moléculas de corante entre partículas de argila, devem ser investigados para se obter um conhecimento mais amplo destes sistemas. Recentemente, Lu e $\mathrm{col}^{58}$, realizando medidas de transferência de energia entre 
moléculas adsorvidas em argilas, encontraram fortes indícios da possibilidade de migração de moléculas de corante entre partículas de argila. 


\section{Objetivos}

O presente trabalho apresenta como objetivo o estudo de sistemas coranteargila, procurando detectar processos de migração de moléculas de corante entre partículas de argila em suspensão aquosa, visando complementar os mecanismos propostos para descrever as interações corante-argila, os quais não fazem menção aos processos de migração entre partículas citados. 


\section{Parte Experimental}

\subsection{Reagentes}

O corante foi utilizado sem prévia purificação. A água utilizada no preparo das soluções foi destilada, deionizada e passada em sistema de purificação millipore.

\subsubsection{Corante}

Azul de metileno (AM) - CI52015: Procedência - Carlos Erba, PA

Fórmula molecular: $\mathrm{C}_{16} \mathrm{H}_{18} \mathrm{ClN}_{3} \mathrm{~S} .3 \mathrm{H}_{2} \mathrm{O}$

Fórmula estrutural:

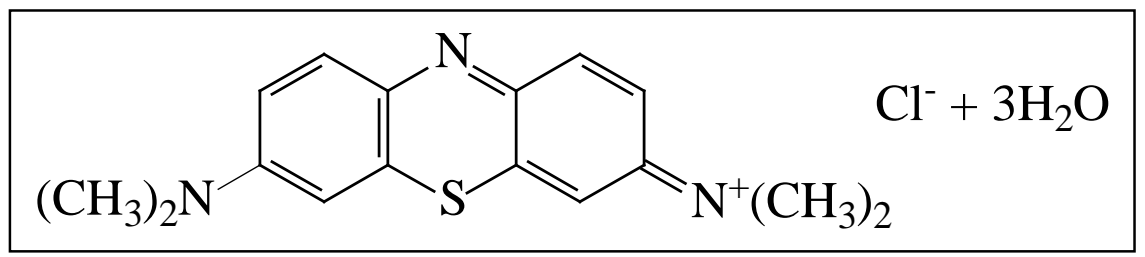

\subsubsection{Argilominerais}

As argilas SAz-1, SWy-1 utilizadas no trabalho foram adquiridas do Source Clays Minerals, University of Missouri (Columbia - USA) . A argila Laponita - B, também utilizada no trabalho foi obtida da Laporte Industries - UK.

As principais propriedades dos argilominerais utilizados neste trabalho estão apresentadas na Tabela I. 
Tabela I: Propriedades e composição dos argilominerais utilizados ${ }^{59}$.

\begin{tabular}{|c|c|c|c|}
\hline PROPRIEDADES & SWy-1 & SAz-1 & Laponita - B \\
\hline CTC(meq/100g) & 76,4 & 120,0 & 73,3 \\
\hline Área superficial & 31,82 & 97,42 & 360 \\
\hline$\left(\mathrm{m}^{2} / \mathrm{g}\right)$ & Montmorilonita & Montmorilonita & Hectorita \\
\hline Tipo & natural & natural & Sintética \\
\hline Origem & Wyoming, U.S & Arizon, U.S & Laporte Industries \\
\hline \multicolumn{4}{|c|}{ COMPOSIÇÃO } \\
\hline $\mathrm{SiO}_{2}$ & 62,9 & 60,4 & 55,0 \\
\hline $\mathrm{Al}_{2} \mathrm{O}_{3}$ & 19,6 & 17,6 & - \\
\hline $\mathrm{TiO}_{2}$ & 0,09 & 0,24 & - \\
\hline $\mathrm{Fe}_{2} \mathrm{O}_{3}$ & 3,35 & 1,42 & - \\
\hline $\mathrm{FeO}$ & 0,32 & 0,08 & - \\
\hline MnO & 0,006 & 0,099 & - \\
\hline MgO & 3,05 & 6,46 & 27,0 \\
\hline $\mathrm{CaO}$ & 1,68 & 2,82 & - \\
\hline $\mathrm{Na}_{2} \mathrm{O}$ & 1,53 & 0,063 & 3,8 \\
\hline $\mathbf{K}_{2} \mathbf{O}$ & - & 0,19 & - \\
\hline $\mathbf{L i}_{2} \mathbf{O}$ & 0,049 & 0,02 & 1,4 \\
\hline $\mathbf{P}_{2} \mathbf{O}_{5}$ & 0,05 & - & - \\
\hline $\mathbf{S}$ & 0,111 & 0,287 & - \\
\hline $\mathbf{F}$ & & - & 5,6 \\
\hline
\end{tabular}




\subsection{Equipamentos Utilizados}

Espectrofotômetro Hitachi U-2000, de feixe duplo, conectado a um microcomputador compatível com IBM-PC,

Liofilizador,

Centrifuga Hitachi, Himac CR 20B2

Phmetro Micronal B374

\subsection{Procedimentos experimentais}

\subsubsection{Purificação das argilas}

Em 1,5L de água destilada e deionizada, foram dispersos $30 \mathrm{~g}$ de argila e, sob agitação constante foi adicionado $\mathrm{HCl} 2 \mathrm{~mol}^{-1} \mathrm{~L}^{-1}$ até $\mathrm{pH} 3,5$. Após 20 minutos a suspensão resultante foi centrifugada e este procedimento foi repetido por de mais duas vezes. Esta etapa teve como objetivo a remoção dos sais solúveis, como os carbonatos, por exemplo.

O sedimento foi novamente centrifugado e ressuspendido em 1,5L de água destilada e deionizada, adicionando-se $\mathrm{NaOH} 2 \mathrm{~mol}^{-\mathrm{L}^{-1}}$ até se obter $\mathrm{pH}$ 8. A suspensão foi deixada por 12 horas em repouso para separar as partículas por gravitação, e após este período o sobrenadante foi sifonado e guardado em um béquer. $\mathrm{O}$ sedimento depositado foi novamente suspendido à $\mathrm{pH} 8$. Após 12 horas o sobrenadante foi sifonado e colocado junto com o material resultante da sifonação anterior. Esta operação foi repetida até que o sobrenadante ficasse claro, sem material em suspensão.

$\mathrm{O}$ sobrenadante foi acidificado até $\mathrm{pH}$ 3,5 sendo então adicionada uma solução saturada de $\mathrm{NaCl}$, para colocar a argila na forma homoiônica (argila-Na). A suspensão ficou em repouso por um período de 12 horas, para flocular. Após a floculação submeteu-se o sistema à sifonação para a retirada da água do sistema bifásico. A argila ainda hidratada fica depositada no fundo do becker.

A argila floculada foi Submetida à centrifugação, utilizando os seguintes parâmetros:

- $\quad$ Rotor 29

- Velocidade: 10000rpm 
- Temperatura: $25^{\circ} \mathrm{C}$

- Tempo: $30 \mathrm{~min}$.

Após este procedimento seguiu-se com a diálise: a argila foi transferida para as membranas em forma de tubos, sendo estes amarrados em suas extremidades com barbante e mergulhados em água destilada e deionizada em um becker de 4L. O sistema ficou em repouso por algumas horas, sendo feito em seguida o teste de presença de íons cloreto $\left(\mathrm{Cl}^{-}\right)$utilizando $\mathrm{AgNO}_{3}$ em amostra de água do sistema. O cloreto pode ser observado em função da reação que ocorre:

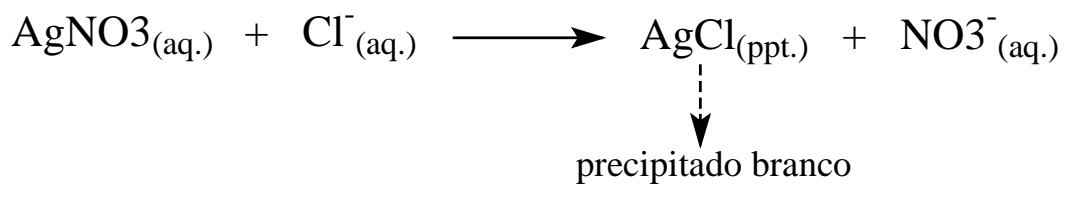

Esse teste é ainda efetuado por alguns dias, enquanto for detectada a presença desses íons na água, havendo contínuas trocas da água do becker. O processo de

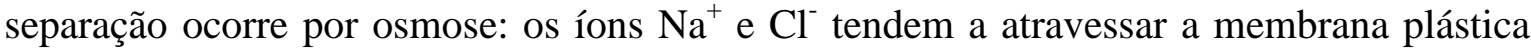
que retém a argila pré-purificada passando para a água e estabelecer o equilíbrio do sistema.

A argila purificada foi seca por liofilização, obtendo-se no final um produto de cor clara, quase branca, com uma consistência parecida com algodão.

\subsubsection{Preparação das suspensões e soluções}

As amostras foram preparadas a partir das suspensões estoque de argilas e soluções estoque de corante.

Preparou-se solução estoque de corante na concentração de $4 \times 10^{-4}$ mol. $\mathrm{L}^{-1}$. As demais concentrações de corante foram obtidas a partir da diluição desta solução.

As suspensões foram preparadas pesando-se aproximadamente $0,067 \mathrm{~g}$ de argila. Esta massa foi dispersa em água, deixada sob agitação por no mínimo 12 horas. $\mathrm{O}$ volume foi completado para $25 \mathrm{~mL}$. Desta suspensão foi retirada uma alíquota de $0,90 \mathrm{~mL}$, a qual foi novamente dispersa em água e submetida a 90 minutos de agitação. $\mathrm{O}$ volume desta suspensão foi ajustado para $25 \mathrm{~mL}$, adicionando-se $21 \mathrm{~mL}$ de água e por último $3 \mathrm{~mL}$ de AM na concentração de $1,2 \times 10^{-4} \mathrm{~mol} \cdot \mathrm{L}^{-1}$. As concentrações finais obtidas foram de $0,1 \mathrm{~g} . \mathrm{L}^{-1}$ e $1,5 \times 10^{-5} \mathrm{~mol} . \mathrm{L}^{-1}$ de argila e corante, respectivamente. 
Esta suspensão foi dividida em 5 amostras, adicionando-se $1,2 \mathrm{~mL}$ da suspensão descrita previamente (concentração final de argila e corante foi de $0,04 \mathrm{~g}$. $\mathrm{L}^{-1} \mathrm{e}$ de $5,9 \times 10^{-6} \mathrm{~mol}$. $\mathrm{L}^{-1}$, respectivamente) e $1,8 \mathrm{~mL}$ de água ou de suspensão argila em diferentes concentrações, de forma que as concentrações de argila adicionada foram de 0,00g. $\mathrm{L}^{-1}$ (adição de água), 0,01g.L (adição de argila 0,016g.L $\mathrm{L}^{-1}$ ), 0,02 (adição de argila 0,034g. $\left.\mathrm{L}^{-1}\right), 0,08$ (adição de argila $0,13 \mathrm{~g} \cdot \mathrm{L}^{-1}$ ) e 0,09 ((adição de $\operatorname{argila~} 0,15 \mathrm{~g} \cdot \mathrm{L}^{-1}$ ). As suspensões de argila em diferentes concentrações foram preparadas a partir da solução estoque, a cada diluição a suspensão era submetida a 90 minutos de agitação.

O preparo das amostras deve proceder da seguinte forma: inicialmente adiciona-se a suspensão de argila/corante e na seqüência adiciona-se a água ou a suspenão de argila sem moléuclas de corante adsorvidas.

Este procedimento foi utilizado para os sistemas apresentados na Tabela II.

Tabela II: Sistemas estudados.

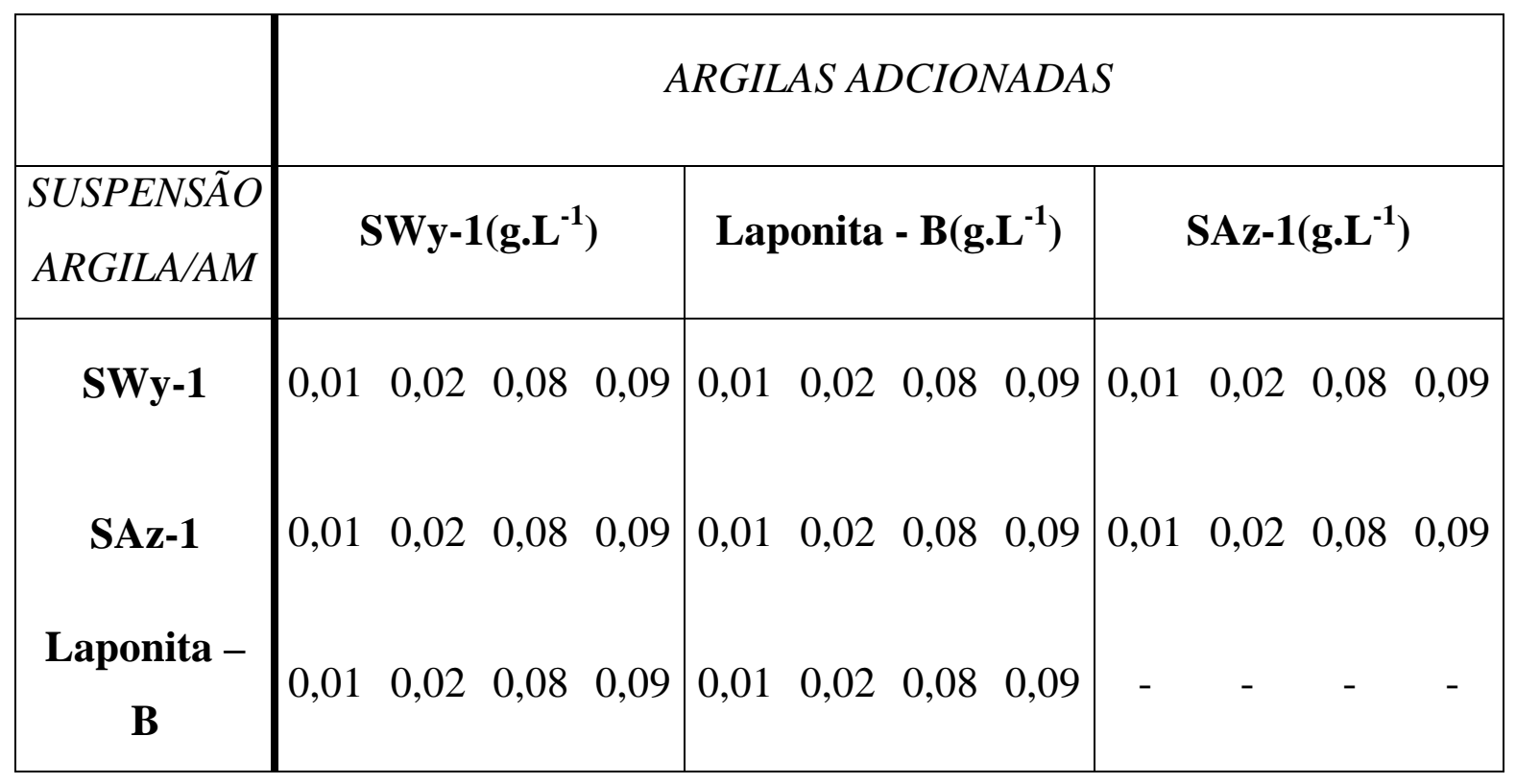

\subsubsection{Experimentos com membrana de diálise.}

Foram realizados experimentos com membrana de diálise (sacos de diálise Inlab, 33x $21 \mathrm{~mm}$, porosidade de 25 angstrons, produzidos a partir de celulose). Estudou-se o comportamento espectral das argilas SWy-1 e SAz-1 quando o corante é adicionado indiretamente, ou seja a adição lenta de AM através da membrana de diálise. 
Preparou-se suspensões das argilas na concentração de $0,11 \mathrm{~g} \cdot \mathrm{L}^{-1}$, essas suspensões foram colocadas em um béquer e isoladas da solução de AM através de uma membrana de diálise. A concentração de AM na solução foi de $1 \times 10^{-5}$ mol. $\mathrm{L}^{-1}$.

\subsection{Espectros dos corantes em suspensões de argila}

As cubetas utilizadas foram de acrílico da marca Sigma, com caminho ótico de $10 \mathrm{~mm}$.

Os espectros de absorção foram registrados utilizando-se como referência uma amostra preparada em condições idênticas a da amostra a ser analisada, mas sem a presença do corante.

\subsection{Espectros diferença}

Para uma melhor comparação entre amostra e referência foram determinados os espectros-diferença. Esse espectro consiste na subtração entre os espectros determinados para a referência e os espectros determinados para a amostra. 


\section{Resultados e Discussões}

Inicialmente foram realizados experimentos envolvendo os sistemas contendo as argilas SWy-1, SAz-1 e Laponita B, utilizando o corante catiônico azul de metileno como sonda. Embora esses sistemas já tenham sido estudados anteriormente, é importante que sejam repetidos, pois fornecem subsídios para a interpretação e discussão dos resultados obtidos.

\subsection{Estudo do sistema SWy-1/AM.}

A argila SWy-1 é uma montmorilonita natural, dioctaédrica, 2:1 e possui algumas propriedades peculiares, como por exemplo, quando dispersa em água, forma tactóides, cujos espaços interlamelares ficam disponíveis para a intercalação de moléculas orgânicas, sendo portanto expansível. O valor da CTC da SWy-1 é de 76,4meq/100g. ${ }^{53}$.A argila SWy-1 foi estudada com diferentes corantes de forma sistemática pelo grupo de fotoquímica do IQSC/USP. Foram identificados vários processos que ocorrem nestes sistemas, sendo propostos mecanismos para explicar as interações entre as partículas da argila e o corante ${ }^{25}$.

O AM se mostrou um dos corantes mais adequados para o presente estudo, pois apresenta propriedades metacromáticas tanto em meio homogêneo quanto em meio heterogêneo, as quais são bem conhecidas, e além disso as diferentes espécies apresentam bandas de absorção em comprimentos de onda bem definidos e bem separadas umas das outras, facilitando a detecção das diferentes espécies.

A Figura 13 apresenta os espectros obtidos para as suspensões de SWy-1 com diferentes concentrações de AM em função do tempo. 


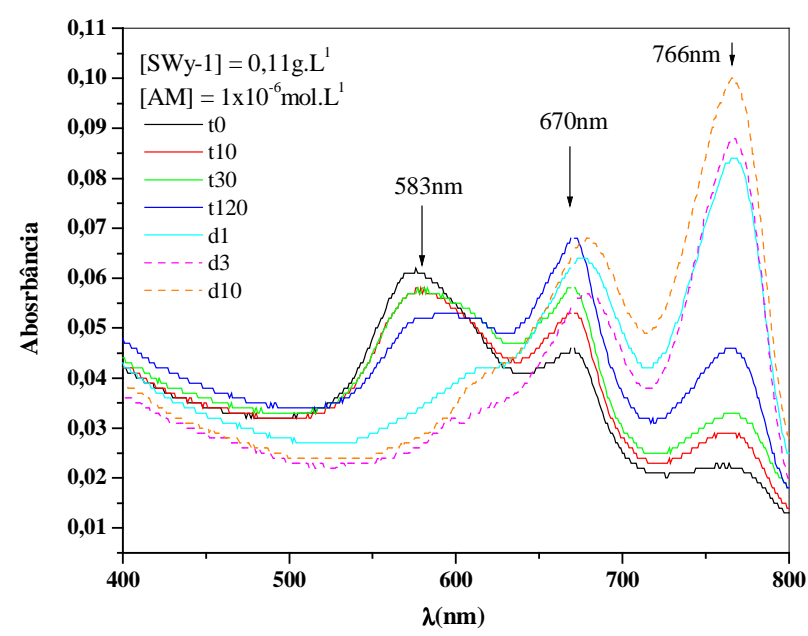

(a)

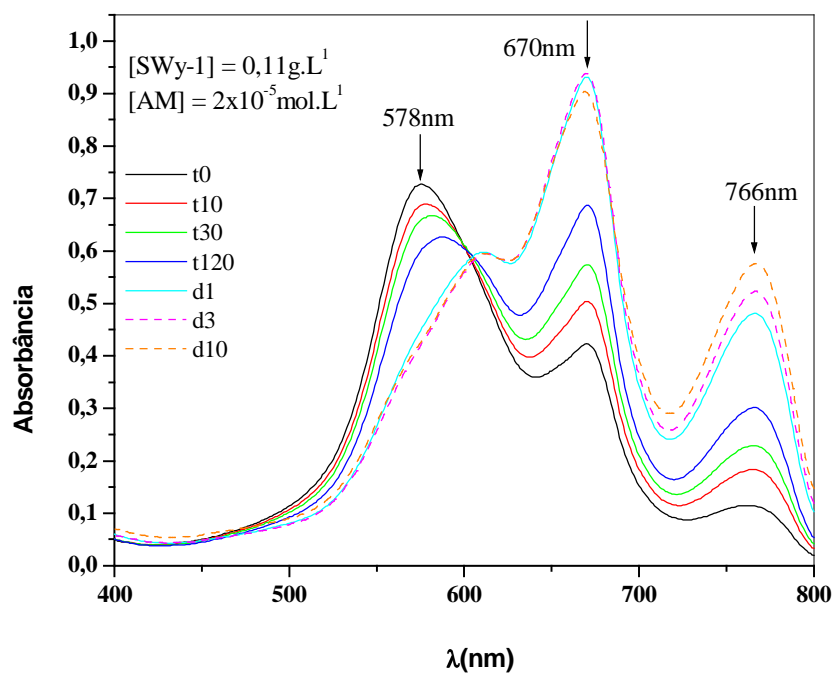

(c)

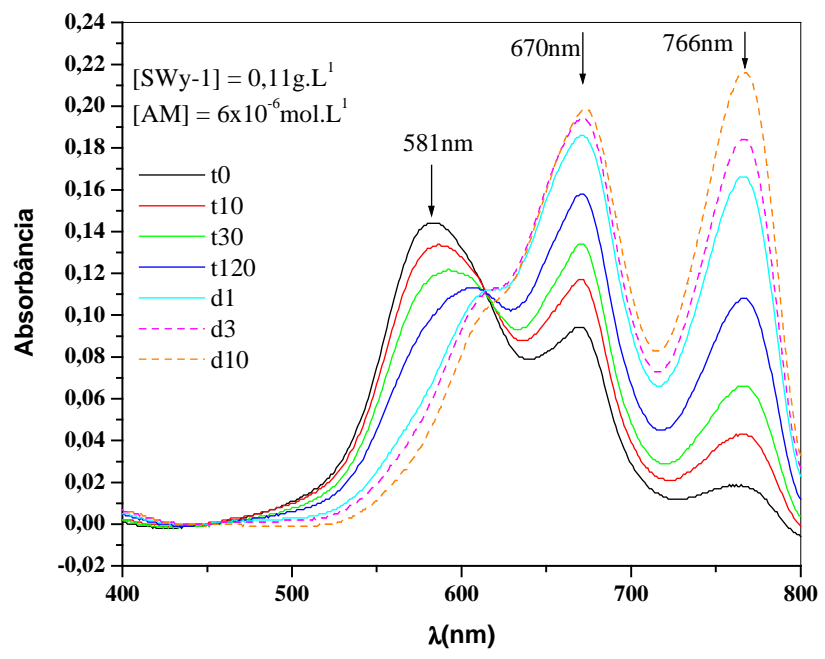

(b)

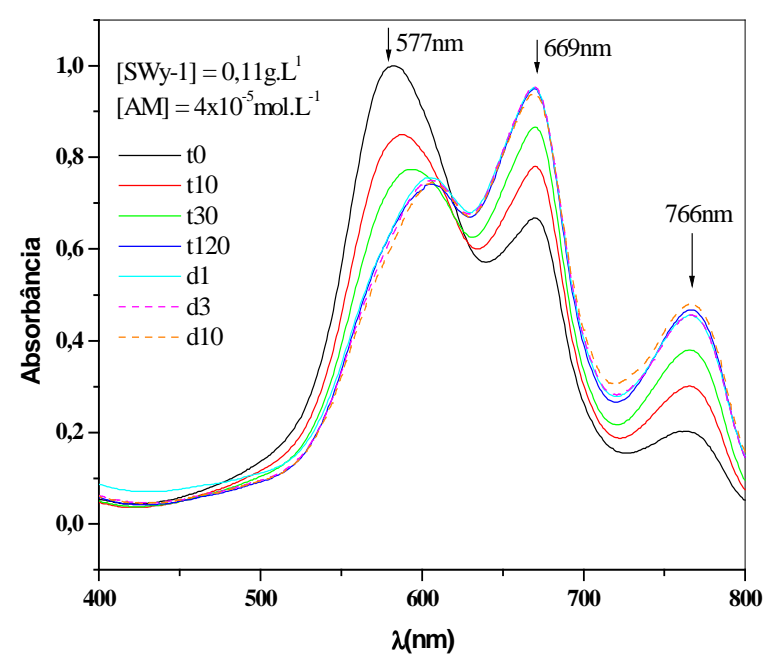

(d)

Figura 13: Espectros da suspensão de SWy-1 $0,11 \mathrm{~g} \cdot \mathrm{L}^{-1} 1$ (a) $[\mathrm{AM}]=1 \times 10^{-6} \mathrm{~mol} \cdot \mathrm{L}^{-1}$ (b) $[\mathrm{AM}]=6 \times 10^{-6} \mathrm{~mol} \cdot \mathrm{L}^{-1},(\mathrm{c})[\mathrm{AM}]=2 \times 10^{-5} \mathrm{~mol} \cdot \mathrm{L}^{-1}$, (d) $[\mathrm{AM}]=4 \times 10^{-5} \mathrm{~mol} \cdot \mathrm{L}^{-1}$. Os tempos t estão em minutos e d em dias.

Conforme podemos observar na Figura 13, ocorrem significativas alterações espectrais com o passar do tempo. Inicialmente verifica-se que a banda correspondente aos agregados de AM, na região de 578-580nm, é intensa. Com o passar do tempo, nota-se que a intensidade desta banda é reduzida ao mesmo tempo em ocorre o aumento da banda referente aos monômeros de AM, 670nm, e o surgimento da banda referente aos monômeros protonados de AM, em aproximadamente 760nm. 
Quando o corante é adicionado à suspensão de argila, as moléculas se adsorvem rapidamente nas superfícies externas das partículas da argila, ocorrendo um considerável aumento da concentração local de corante, induzindo, então, a formação de grande quantidade de dímeros, trimeros e agregados maiores. Os espaços interlamelares não estão imediatamente disponíveis para a adsorção do corante.

Conforme o tempo passa, a banda de absorção dos agregados diminui de intensidade, e ao mesmo tempo as bandas de absorção dos monômeros e monômeros protonados (670 e 770nm) vão surgindo e se intensificando. Esta observação é reflexo do processo de migração das moléculas de AM para as regiões interlamelares. Moléculas do corante penetram nas regiões interlamelares, e a quantidade de agregados diminui. À medida que as moléculas migram para a região interlamelar, a concentração na superfície externa diminui, ocasionando o consumo dos agregados maiores. $\mathrm{Na}$ região interlamelar existem sítios de protonação, onde as moléculas de corante adsorvidas são protonadas e podem ser monitoradas pela banda de absorção na região de 765nm.

É importante observar que o comportamento espectral das amostras também depende da concentração de corante utilizada. À medida que a concentração de corante aumenta, o máximo de absorção referente aos agregados é deslocado para comprimentos de onda menores, de 583nm para 577nm, conforme mostrado na Figura 14. Isso se deve a formação de agregados maiores que trímeros, conforme a concentração do corante aumenta. Para as concentrações de corante menores $\left(1,0 \times 10^{-6} \mathrm{~mol} \cdot \mathrm{L}^{-1}\right)$ verifica-se que após um dia a banda de absorção na região de 575nm devido aos agregados do corante, praticamente desaparece. Após esse tempo a maior parte das moléculas de corante inicialmente adsorvidas nas superfícies externas migrou para as regiões interlamelares onde foram protonadas.

Com o aumento da concentração do corante, como por exemplo $4 \times 10^{-}$ ${ }^{5}$ mol. $\mathrm{L}^{-1}$, verifica-se que após 120 minutos a banda referente aos monômeros e monômeros protonados de AM não apresenta variação, indicando que os espaços internos disponíveis para adsorção do corante não são mais suficientes para acomodar todas as moléculas de AM.

Na Figura 15 estão representados os gráficos da variação da absorção das principais espécies (agregados, monômeros e monômeros protonados) em função da concentração de corante. 
O mecanismo que representa os processos que ocorrem na suspensão de SWy-1 após adição de AM foi apresentado na Figura 11.

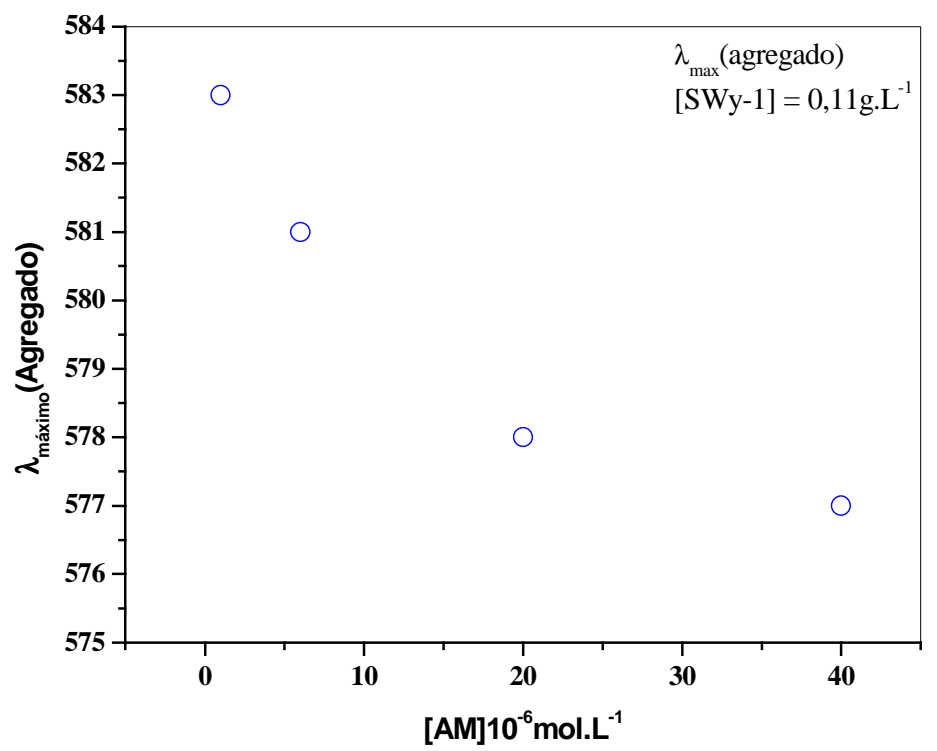

Figura 14: Variação do comprimento de onda correspondente ao máximo de absorção para os agregados de AM em função da concentração de corante adicionada, no tempo inicial.

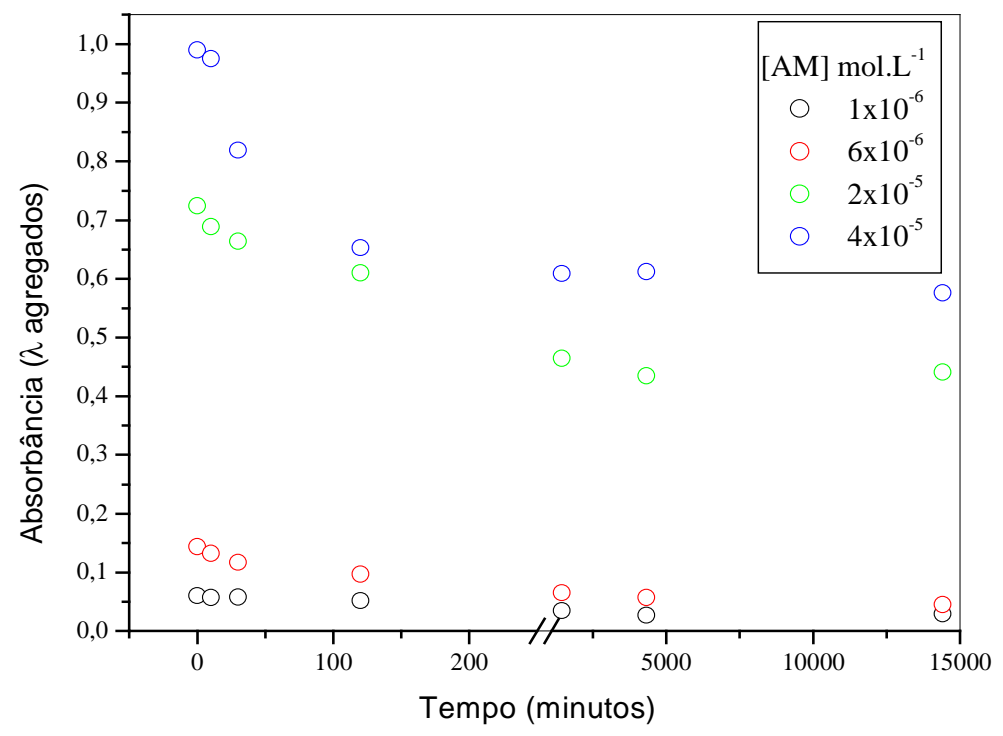

(a) 


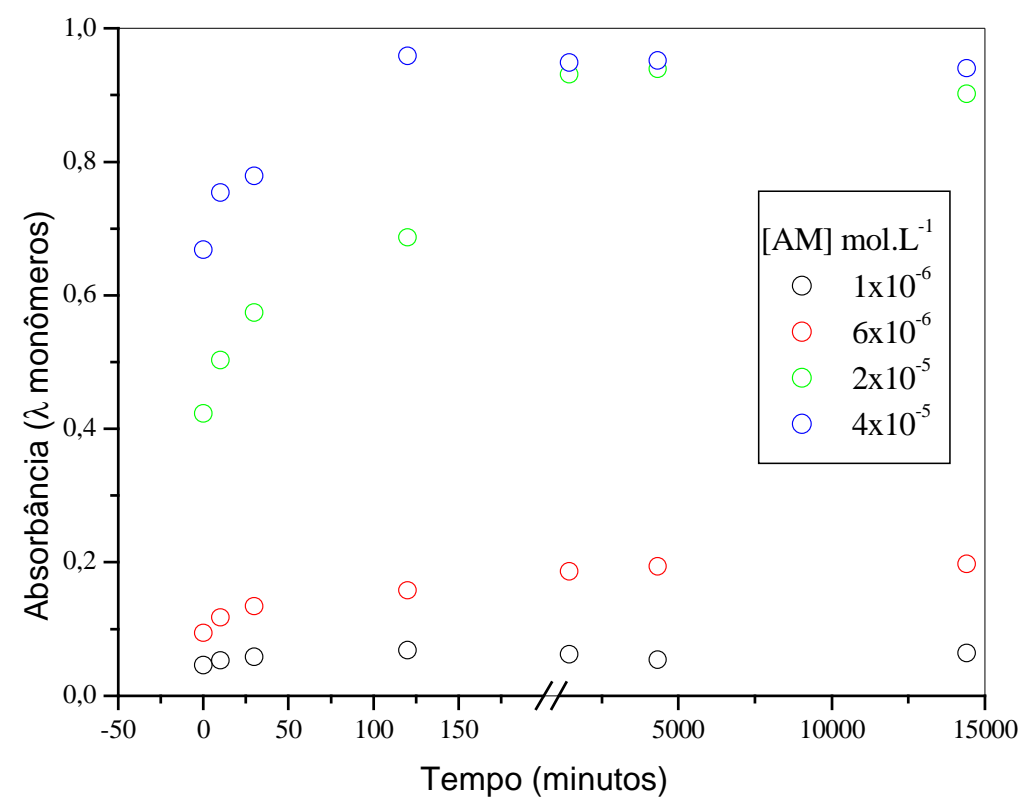

(b)

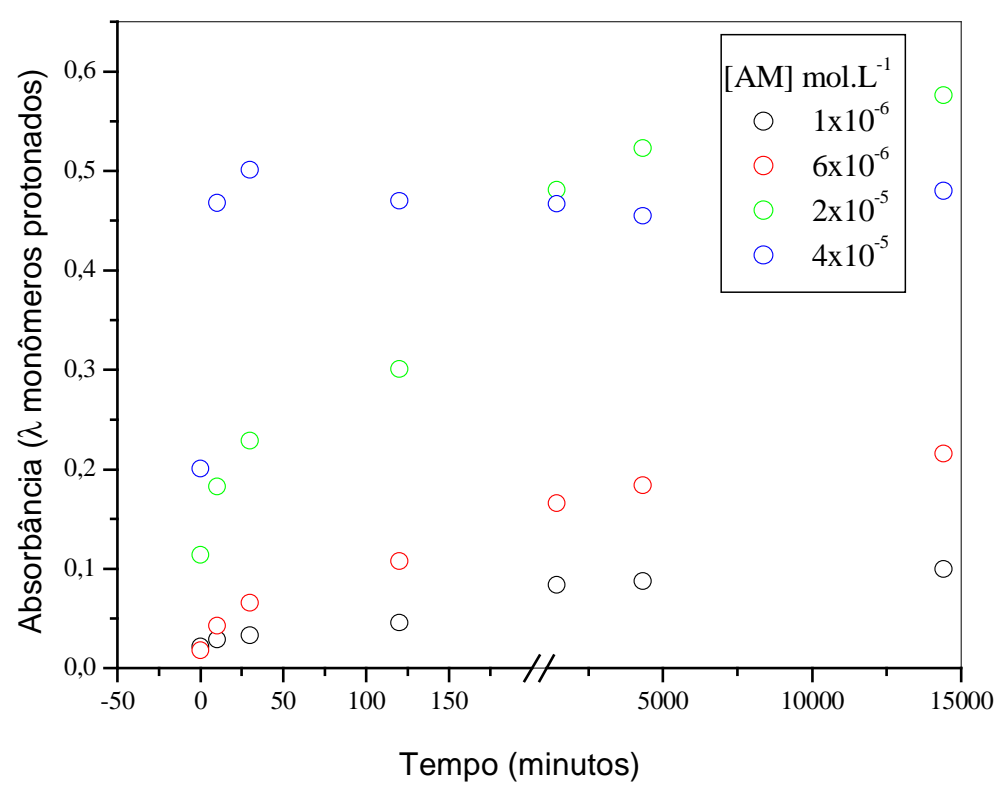

(c)

Figura 15: Variação da absorbância em função do tempo para as diferentes espécies de AM. (a) Agregados, (b) monômeros e (c) monômeros protonados

Na Figura 15, verifica-se que de forma geral a absorção das espécies agregadas de AM diminui progressivamente ao longo do tempo e as absorções das espécies devidas aos monômeros e monômeros protonados aumentam, conforme discutido anteriormente. Essas variações de absorbância estão em acordo com o mecanismo proposto, segundo o qual, inicialmente ocorre a adsorção das moléculas de AM nas 
superfícies externas dos tactóides de argila, e o aumento da concentração local induz a formação das espécies agregadas de AM. Com o processo de migração para as regiões interlamelares, a concentração nas superfícies externas diminui, provocando a desagregação das moléculas de AM (redução das absorções na região de 570-580nm). Na região interlamelar ocorre a protonação dos monômeros de AM. Nesta etapa do processo as bandas de absorção devidas aos monômeros e monômeros protonados ganham importância no espectro, exceto para os casos em que a concentração de corante é elevada $\left(4 \times 10^{-5} \mathrm{~mol} . \mathrm{L}^{-1}\right)$ pois ocorre a saturação dos espaços internos disponíveis para a adsorção dos monômeros, aumentando a quantidade das moléculas de corante que permanecem agregadas. Para a suspensão de argila contendo AM na concentração de $4 \times 10^{-5} \mathrm{~mol}^{-\mathrm{L}^{-1}}$, verifica-se que mesmo após dez dias a banda referente aos agregados continua dominando o espectro.

\subsection{Estudo do sistema Laponita B/AM}

A argila Laponita - B é uma smectita sintética. Sua estrutura e composição são parecidas com a argila natural hectorita. Quanto à classificação, esta argila é do tipo $2: 1$, trioctaédrica e expansível.

Preparou-se uma suspensão de Laponita B na concentração de 0,11 g. $\mathrm{L}^{-1}$ (concentração final na cubeta) à qual adicionou-se AM. Os espectros obtidos encontram-se na Figura 16.

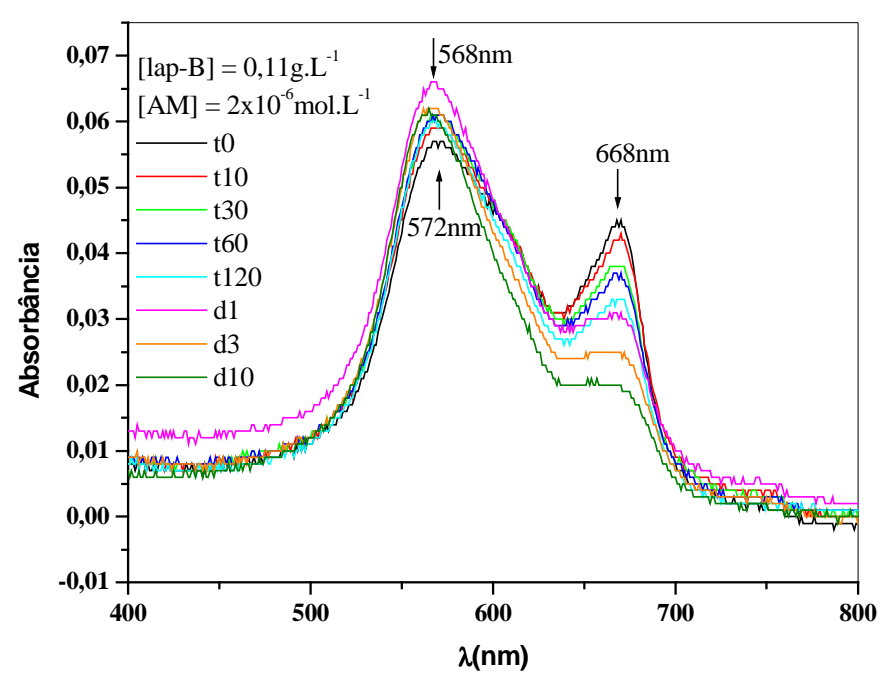

(a)

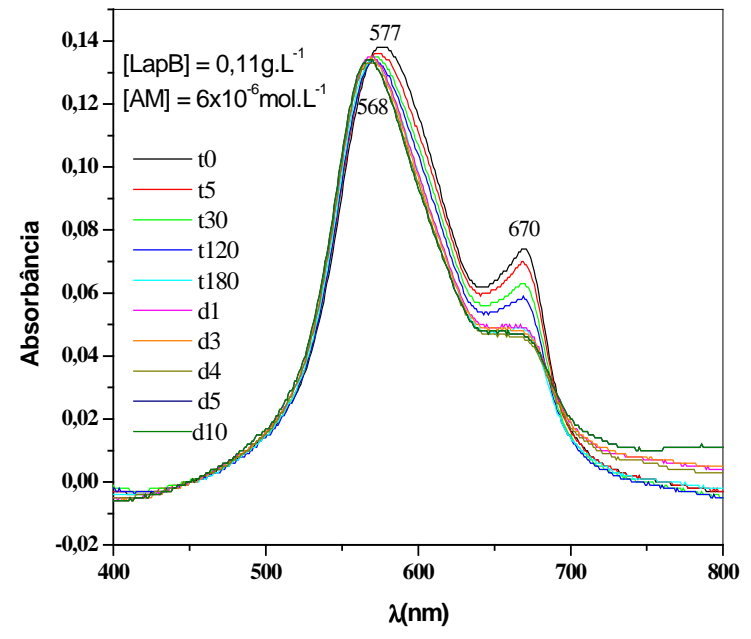

(b) 


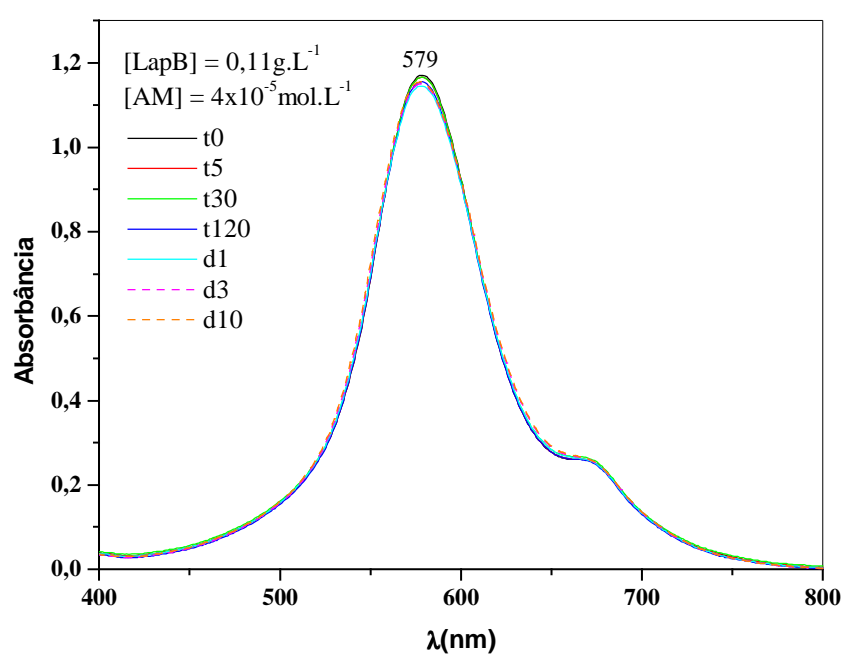

(c)

Figura 16: Espectros da suspensão de Laponita $B$ 0,11g.L $\mathrm{L}^{-1} 1$ (a) $[\mathrm{AM}]=2 \times 10^{-6} \mathrm{~mol} . \mathrm{L}^{-1}$, (b) $[\mathrm{AM}]=6 \times 10^{-6} \mathrm{~mol} \cdot \mathrm{L}^{-1}$, (c) $[\mathrm{AM}]=4 \times 10^{-5} \mathrm{~mol} \cdot \mathrm{L}^{-1}$. Os tempos t estão expressos em minutos e d em dias.

$\mathrm{Na}$ Figura 16, verifica-se que os espectros determinados para o sistema Laponita - B/AM, variando-se a concentração do corante, apresentam o mesmo padrão. As alterações espectrais com o tempo não são significativas, principalmente à medida que a concentração de AM aumenta. Observa-se uma banda de elevada intensidade por volta de $578 \mathrm{~nm}$ e uma banda de pequena intensidade na região de 670nm. Na Figura 16(a), observa-se que ocorrem pequenas alterações espectrais com o passar do tempo. A banda em $577 \mathrm{~nm}$ apresenta um deslocamento para $568 \mathrm{~nm}$, enquanto que a banda em $670 \mathrm{~nm}$ diminui de intensidade. $\mathrm{O}$ aumento da concentração de corante reduziu ainda mais a intensidade das variações espectrais.

A Figura 17 mostra a variação do comprimento de onda máximo de absorção dos agregados de AM adsorvidos em partículas de Laponita-B em função da concentração de corante. 


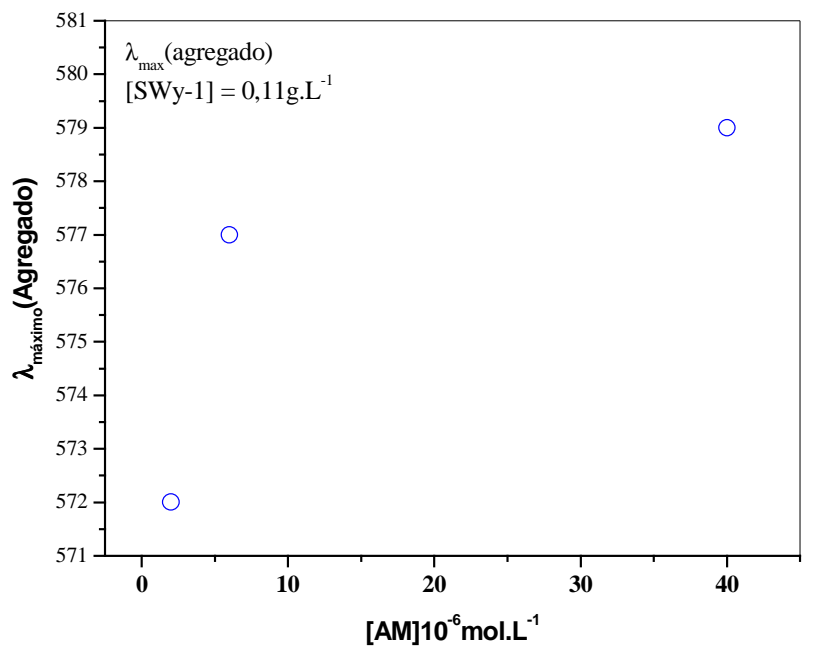

Figura 17: Variação do comprimento de onda correspondente ao máximo de absorção para os agregados de AM em função da concentração de corante adicionada, no tempo inicial.

Na Figura 17, verifica-se que à medida que a concentração de corante aumenta, os comprimentos de onda máximo para a absorção das espécies agregadas também aumenta. Esta tendência pode ser atribuída a estabilidade da suspensão. Em concentrações menores de AM, como por exemplo, $2 \times 10^{-6}$ mol. $\mathrm{L}^{-1}$, o recobrimento das superfícies é menor, de forma que o processo de interação partícula-partícula é favorecido, resultando na formação das espécies de AM aprisionadas nos aglomerados de partículas de argila. Essas espécies se caracterizam por absorverem em menores comprimentos de onda em relação aos agregados adsorvidos nas superfícies das partículas.

A Figura 18, apresenta os gráficos que mostram a variação da absorbância das principais espécies de corante, os agregados (570nm), os monômeros (670nm) e monômeros protonados (770nm).

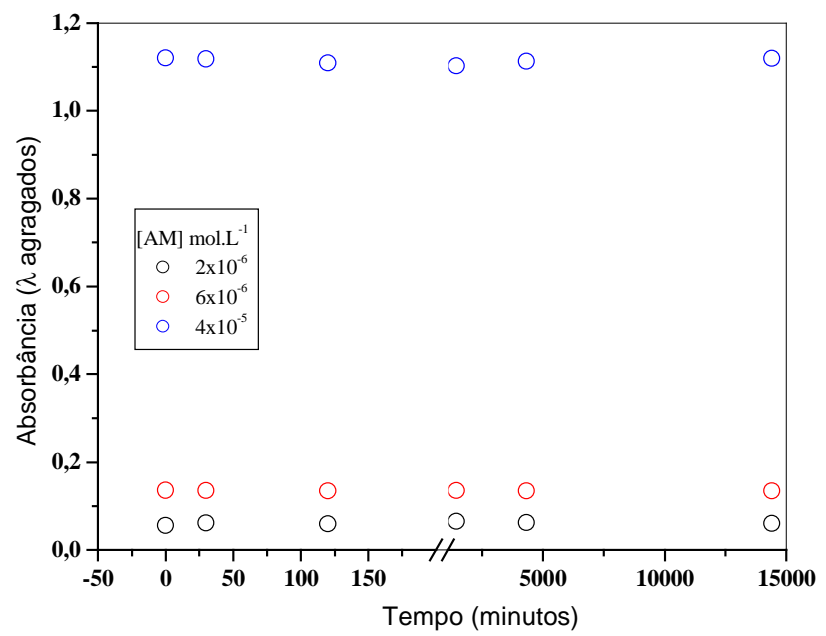

(a) 


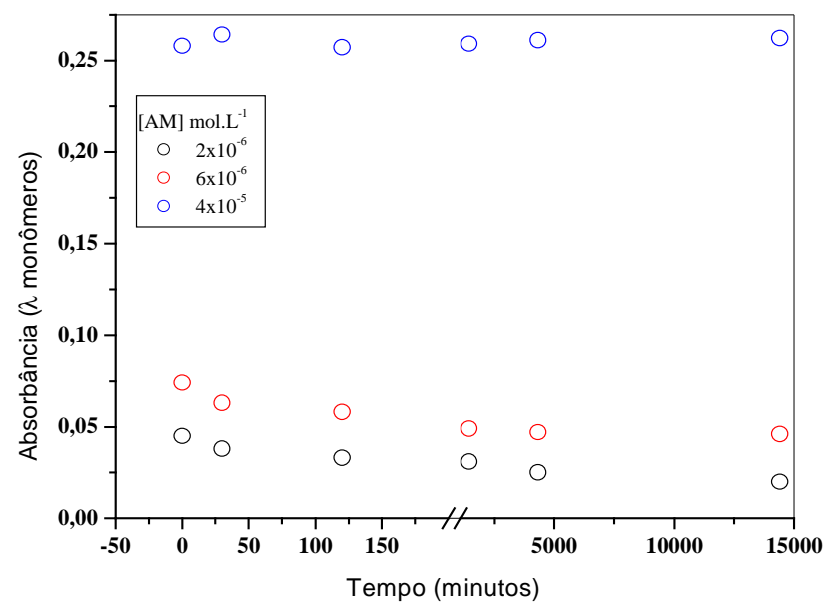

(b)

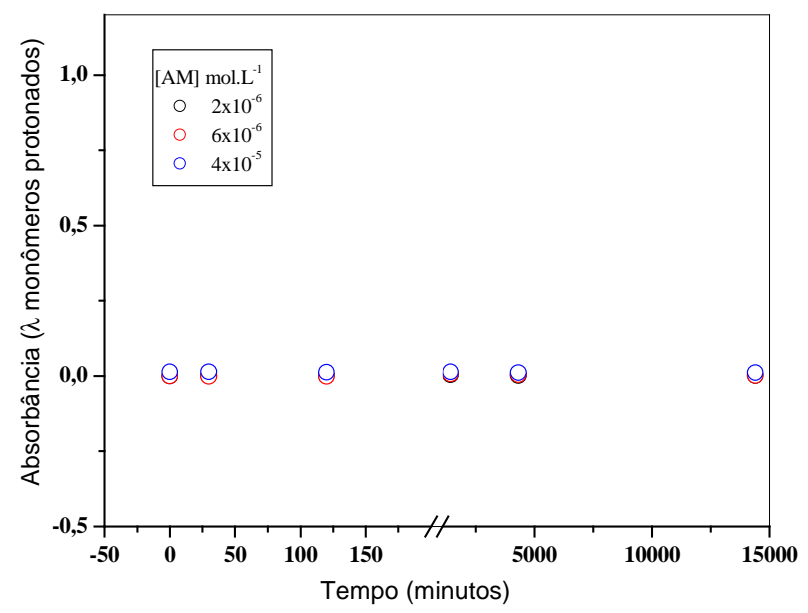

(c)

Figura 18: Variação da absorbância em função do tempo para as diferentes espécies de AM. (a) Agregados, (b) monômeros e (c) monômeros protonados

Na Figura 18, fica evidente que as variações espectrais com o tempo são mínimas. As absorbâncias dos agregados e monômeros não variam significativamente ao longo do tempo. Verifica-se também que quanto maior a concentração de corante, maior a absorção dessas espécies.

Na Figura 18(c), observa-se que absorção dos monômeros protonados de AM é nula, indicando que não há formação dessas espécies ao longo do tempo.

As observações da Figura 18, permitem a conclusão de que não ocorrem rearranjos nas superfícies das partículas de Laponita-B, predominando os processos de interação partícula-partícula. 


\subsection{Estudo do sistema SAz-1/AM}

A argila SAz-1, assim como a SWy-1, é uma montmorilonita natural, a dispersão não é completa, e conseqüentemente forma tactóides quando em suspensão aquosa. No entanto o valor da CTC desta argila é maior que o valor da SWy-1, cerca de $120 \mathrm{meq} / 100 \mathrm{~g}^{59}$. Essa diferença no valor da CTC causa modificações nas propriedades das partículas de argila em suspensão, como exemplo a energia de coesão entre as lamelas que formam as partículas de SAz-1 é relativamente alta. Como consequiência a dispersão desta argila em água resulta em partículas relativamente grandes, muito maiores do que as produzidas na suspensão de $S W y-1$, conseqüentemente a variação espectral observada para o sistema SAz-1/AM será diferente do observado no caso do sistema SWy-1/AM. Na Figura 19 estão apresentados os espectros de absorção do azul de metileno em suspensão de SAz-1, determinados em função do tempo.

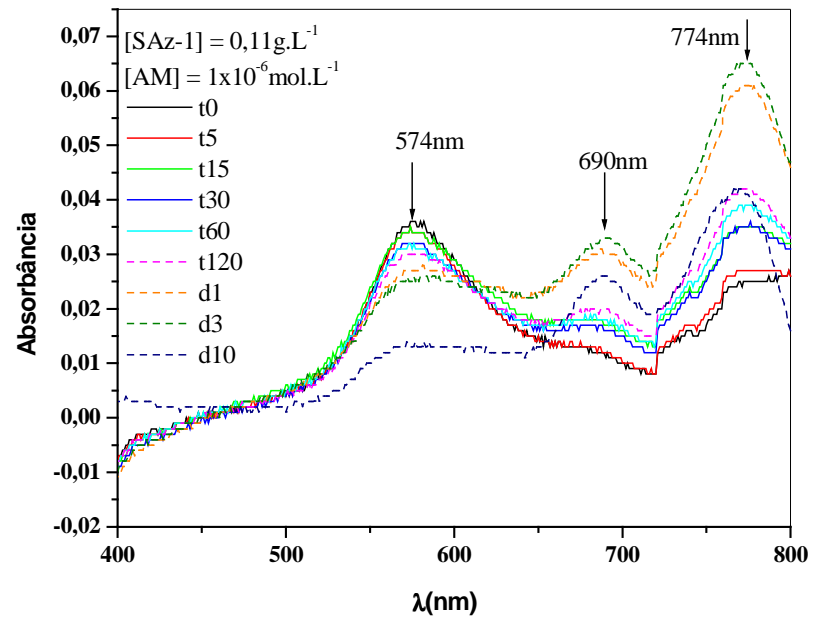

(a)

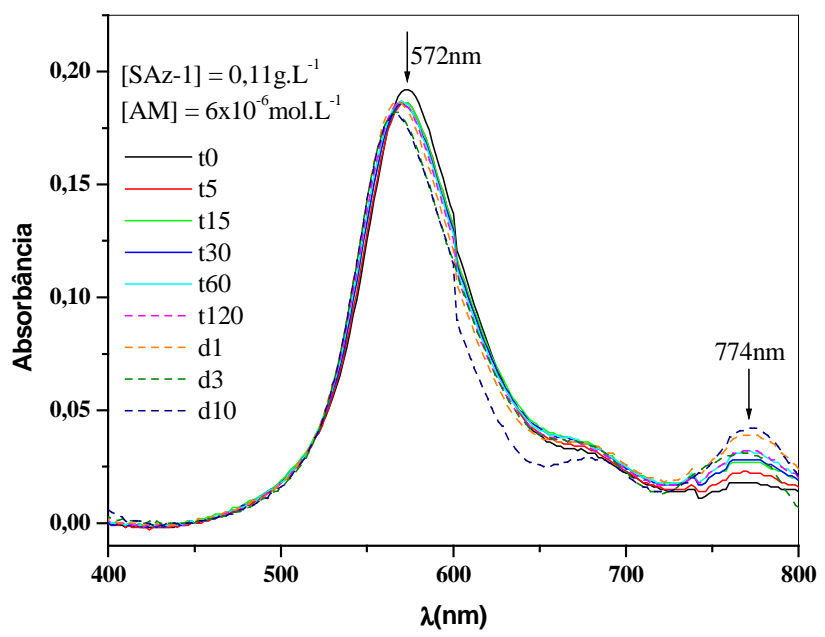

(b) 


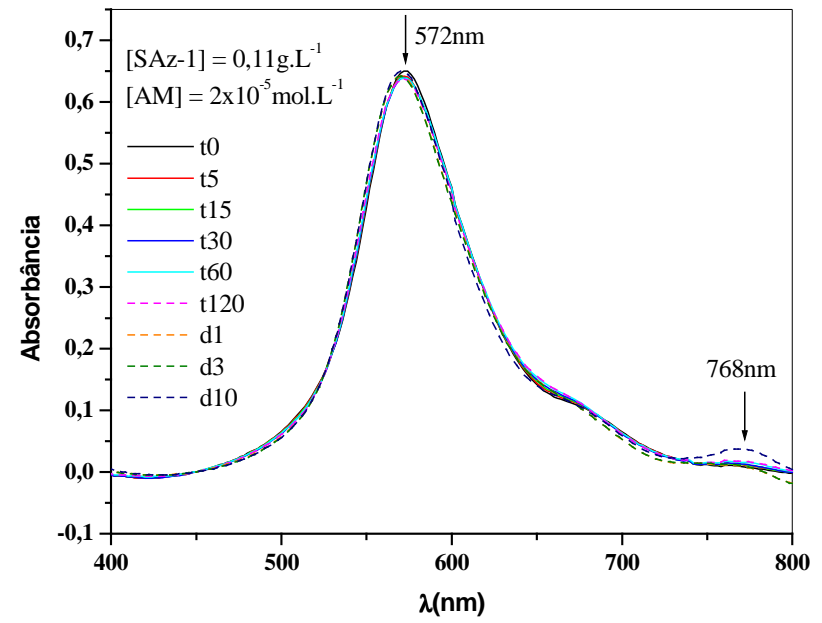

(c)

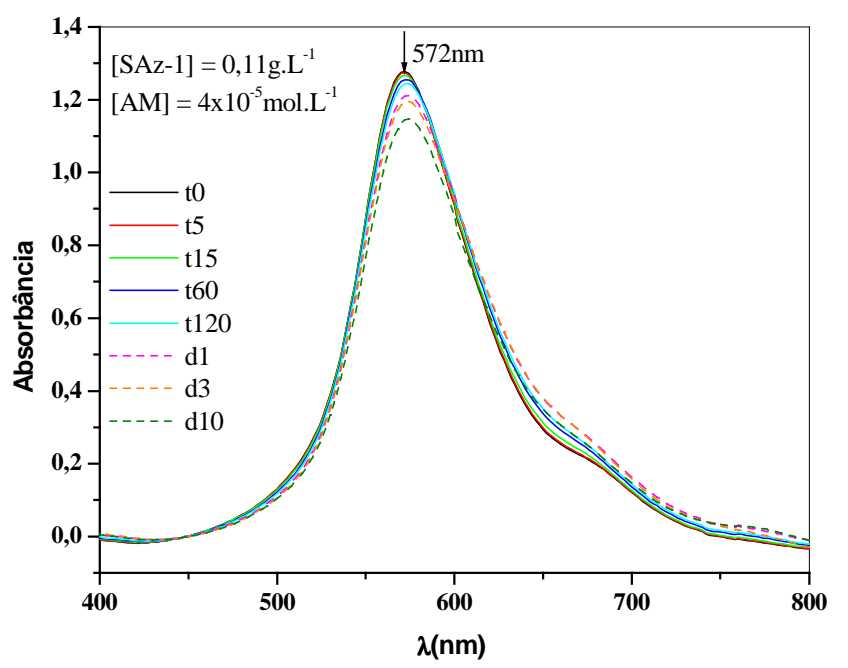

(d)

Figura 19 Espectros da suspensão de SAz-1 $0,11 \mathrm{~g} \cdot \mathrm{L}^{-1}$ 1(a) $[\mathrm{AM}]=1 \times 10^{-6} \mathrm{~mol} \cdot \mathrm{L}^{-1}$ (b) $[\mathrm{AM}]=6 \times 10^{-6} \mathrm{~mol} \cdot \mathrm{L}^{-1}$, (c) $[\mathrm{AM}]=2 \times 10^{-5} \mathrm{~mol} \cdot \mathrm{L}^{-1}$, (d) $[\mathrm{AM}]=4 \times 10^{-5} \mathrm{~mol} \cdot \mathrm{L}^{-1}$. Os tempos t estão expressos em minutos e d em dias.

Analisando os espectros mostrados na Figura 19 vê-se que praticamente não ocorrem mudanças nos espectros ao longo do tempo, a não ser para as concentrações de corante menores $\left(1,0 \times 10^{-6}\right.$ e $\left.6,0 \times 10^{-6} \mathrm{molL}^{-1}\right)$. Verifica-se também que o comportamento espectral do azul de metileno nessa suspensão é muito diferente do comportamento apresentado quando adsorvido nas partículas de SWy-1 (Figura 13). De modo geral a banda na região de 570nm é a predominante no tempo inicial assim como nos demais tempos. As bandas na região de 670 e $765 \mathrm{~nm}$ aparecem apenas como ombros, exceto na concentração de AM igual a $1 \times 10^{-6}$ mol. $\mathrm{L}^{-1}$, para a qual observa-se que a intensidade da banda referente aos monômeros protonados de AM aumenta consideravelmente quando comparada com as demais bandas. Outra observação muito interessante, é que nos espectros das suspensões de SAz-1/AM na concentração de AM de $1 \times 10^{-6} \mathrm{~mol}^{-L^{-1}}$, Figura 19(a), verifica-se a presença de uma banda de absorção em 690nm, a qual é devida a banda vibronica das espécies de AM protonadas, indicando que não há formação de monômeros de AM, embora ocorra a migração das moléculas de corante para a região interlamelar e conseqüente protonação, evidenciada pelo aparecimento da banda em 774nm.

As observações espectrais indicam que inicialmente ocorre a adsorção das moléculas de AM nas superfícies externas dos tactóides, ocasionando o aumento significativo da concentração local, induzindo a formação de dímeros, trimeros e agregados maiores, da mesma forma que ocorre nas suspensões de SWy-1. A elevada 
densidade de carga da argila SAz-1, ocasiona a diminuição da distância entre os sítios de adsorção carregados. Quando uma molécula de AM se adsorve as demais tendem a se adsorvem próximas umas as outras, pois além de interagiram com as cargas negativas da superfície estarão interagindo também com as moléculas de AM, sendo esta uma situação de maior estabilidade para as moléculas de AM. A migração das moléculas de corante para as regiões interlamelares é dificultada pela alta energia de coesão entre as lamelas. A elevada energia de coesão mantem as lamelas fortemente unidas, restringindo o acesso das moléculas de corante à região interlamelar.

Outra diferença entre este sistema e o sistema SWy-1/AM se refere a absorção na região dos agregados. Além das bandas de absorção dos agregados serem predominantes nos espectros da suspensão de SAz-1/AM, verifica-se também que não há variação do comprimento de onda de máximo de absorção dos agregados de AM, conforme mostrado na Figura 20.

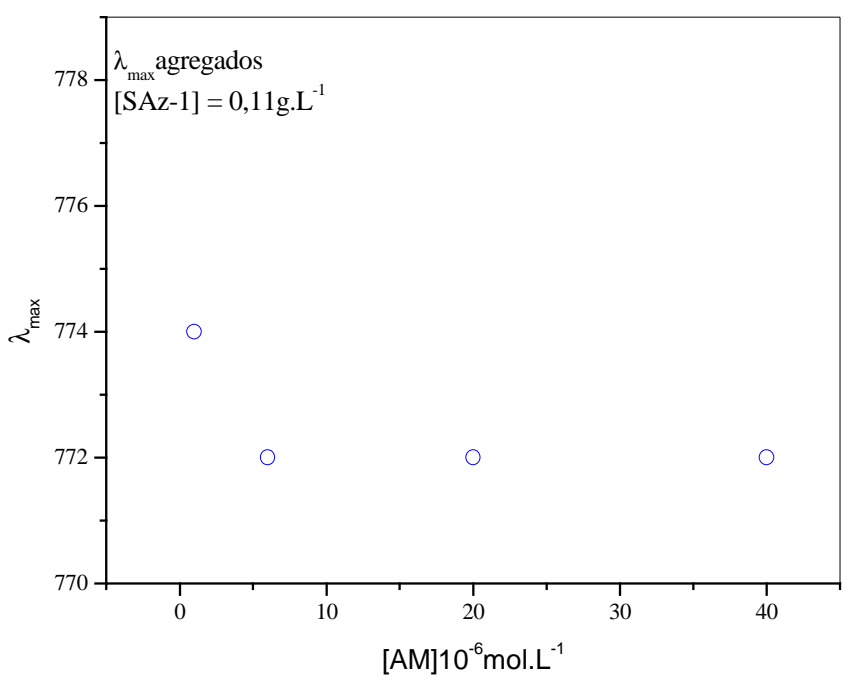

Figura 20: Variação do comprimento de onda correspondente ao máximo de absorção para os agregados de AM em função da concentração de corante adicionada, no tempo inicial.

Na Figura 21, estão mostradas as variações da absorbância das espécies de AM em função do tempo para as diferentes concentrações do corante. Na Figura 21(b), verifica-se que a absorção dos agregados praticamente não apresenta variação de intensidade com o passar do tempo. Quanto maior a concentração de corante, maior a quantidade de agregados formada.

É importante observar que a absorção dos agregados apresenta intensidade consideravelmente maior do que a absorção dos monômeros, indicando que a quantidade de agregados em relação aos monômeros é maior, conforme pode ser verificado na Figura 
21(a) e 21(c). Essa diferença poderia ser devida principalmente à densidade de carga superficial das partículas da argila SAz-1, conforme discutido anteriormente.

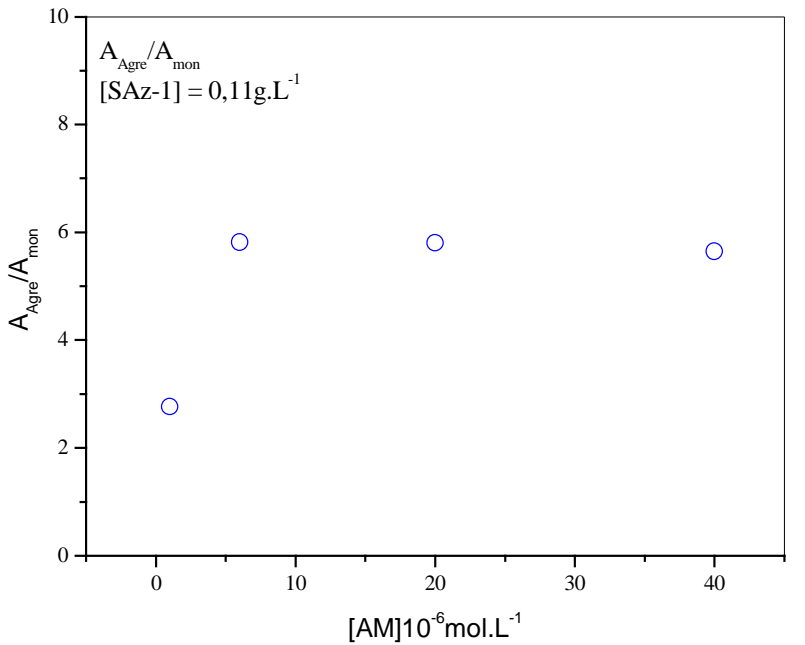

(a)

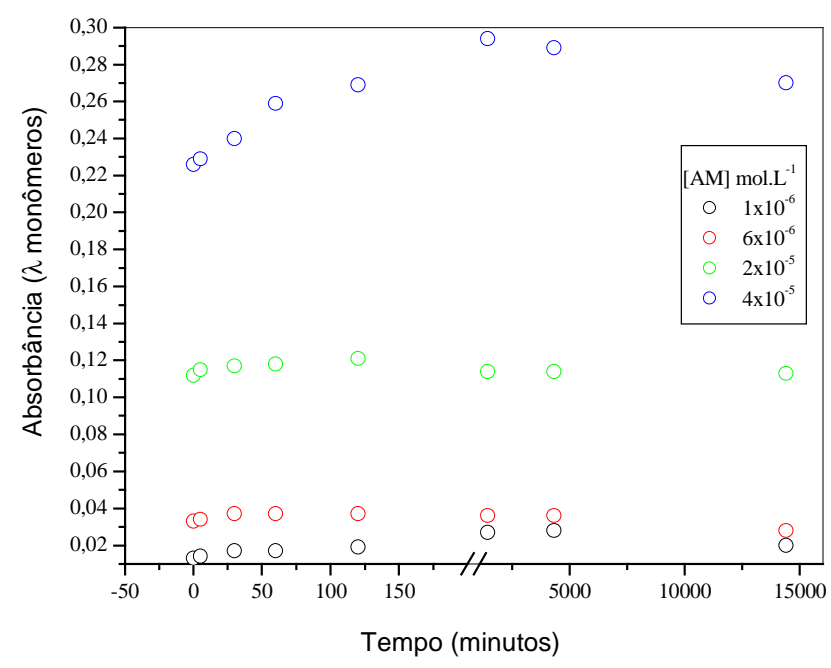

(c)

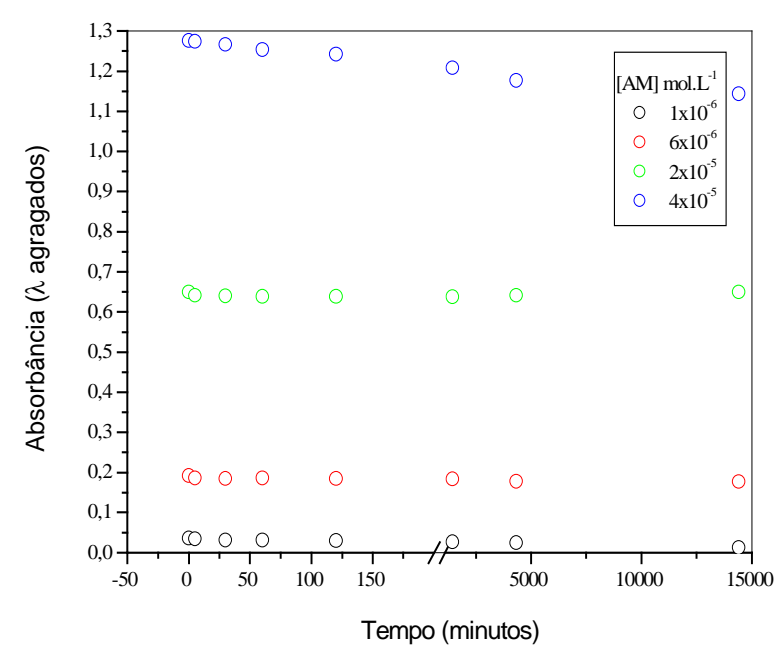

(b)

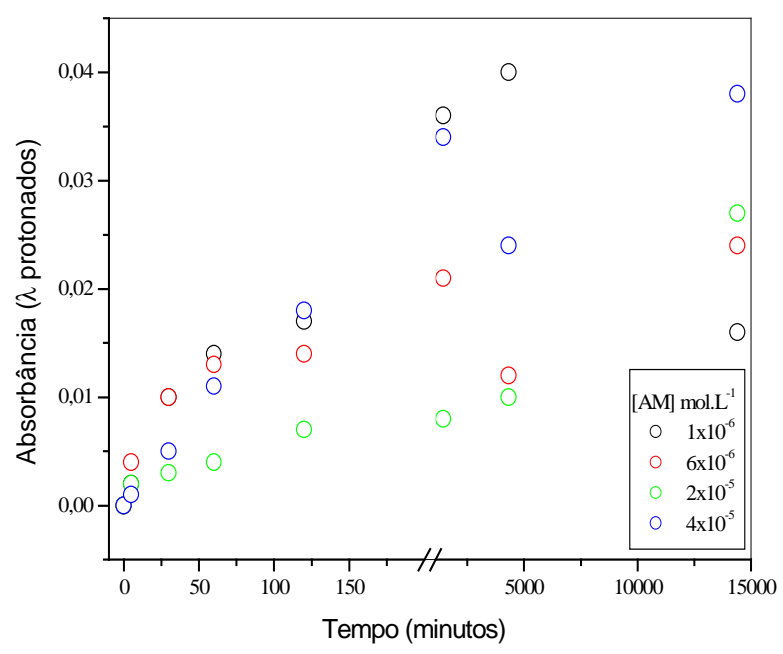

(d)

Figura 21: (a) Variação da razão $A_{\text {agre }} / A_{\text {mon }}$ em suspensões de $S A z-1$ e função da concentração de AM, no tempo inicial. Variação da absorbância em função do tempo para as diferentes espécies de AM. (b) Agregados, (c) monômeros e (d) monômeros protonados.

Na Figura 21(d), verifica-se que a quantidade de monômeros protonados formados com o passar do tempo não é significativa, permitindo concluir que o processo de migração para a região interlamelar não é significativa, predominando as interações partícula-partícula. 


\subsection{Estudo do sistema SWy-1/AM com adição de SWy-1.}

Com o objetivo de detectar a migração de moléculas de corante entre partículas de argila, idealizou-se uma metodologia baseada na mistura de uma suspensão de argila-corante com uma suspensão de argila. Foram determinados os espectros para as amostras resultantes da mistura das suspensões em função do tempo. Esses espectros foram comparados com os espectros determinados para a amostra referência, a qual foi obtida adicionando-se água à suspensão argila-corante. Caso amostra e referência apresentassem as mesmas variações espectrais, seria indicativo de que a migração de moléculas de corante entre partículas de argila não ocorre. No entanto, variações espectrais diferentes, poderiam ser atribuídas a este tipo de migração.

Como já descrito na parte experimental, preparou-se uma suspensão da argila SWy-1 0,1g.L $\mathrm{L}^{-1}$, na qual foi adicionada solução de azul de metileno, de modo que a concentração do corante ficasse igual a $1,7 \times 10^{-5} \mathrm{~mol} \mathrm{~L}^{-1}$. Essa suspensão argila corante foi dividida, colocando-se volumes iguais $(1,2 \mathrm{~mL})$ em diferentes frascos. Em cada um destes frascos adicionou-se um volume fixo $(1,8 \mathrm{~mL})$ de suspensão da argila $\mathrm{SWy}-1$ com diferentes concentrações, de modo que após a adição a concentração da argila adicionada nas amostras variou desde $0,0 \mathrm{gL}^{-1}$ (somente água) até $0,09 \mathrm{gL}^{-1}$. Os espectros determinados em função do tempo são mostrados na Figura 22. As concentrações finais encontram-se nas Figuras.

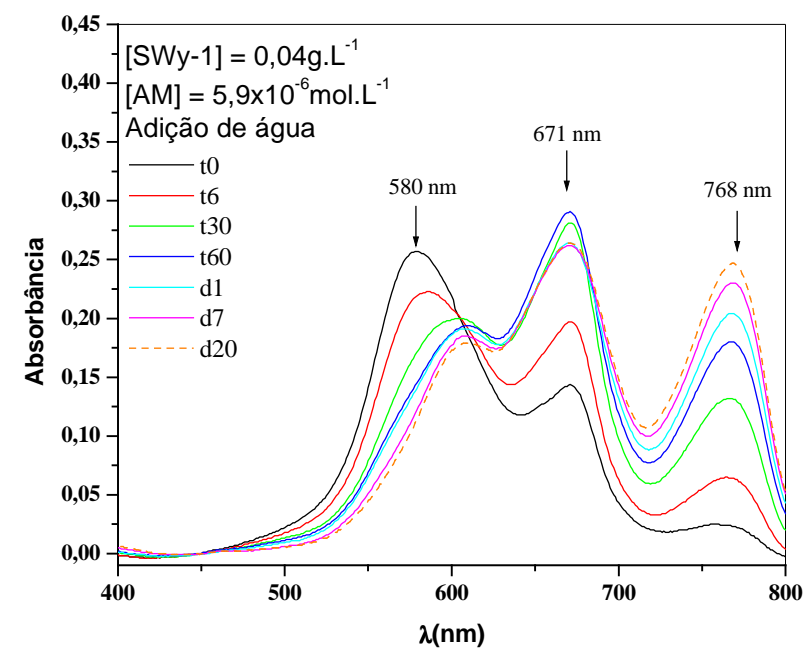

(a)

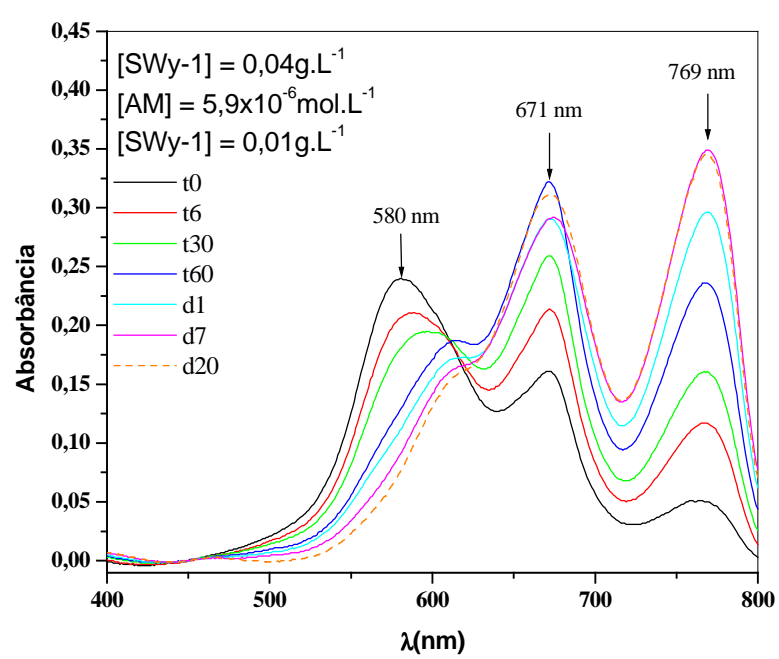

(b) 


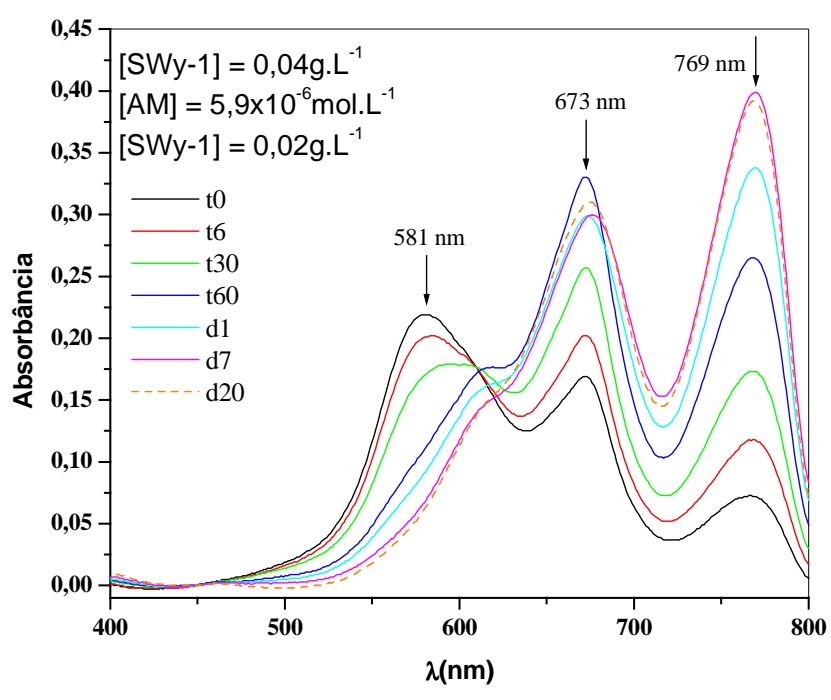

(c)

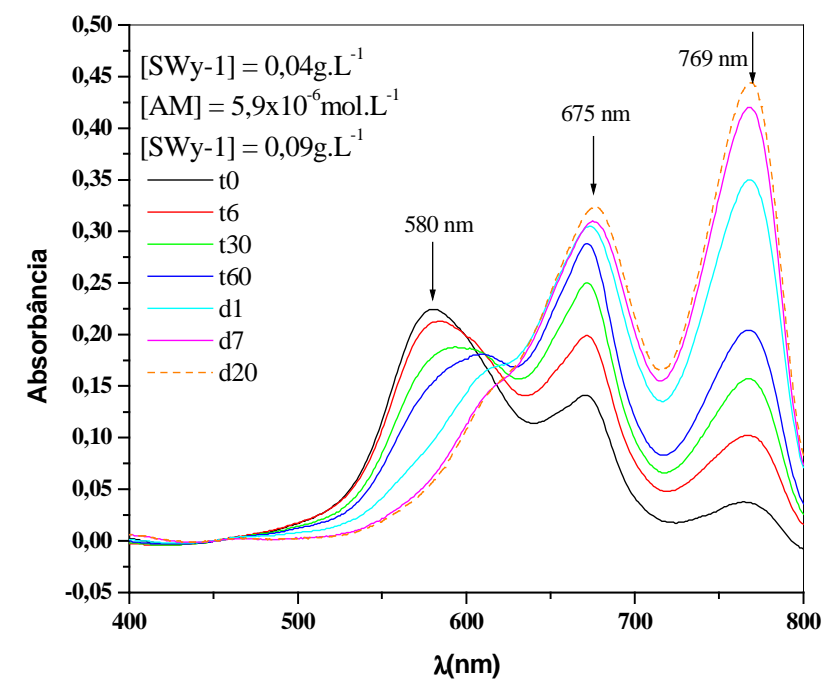

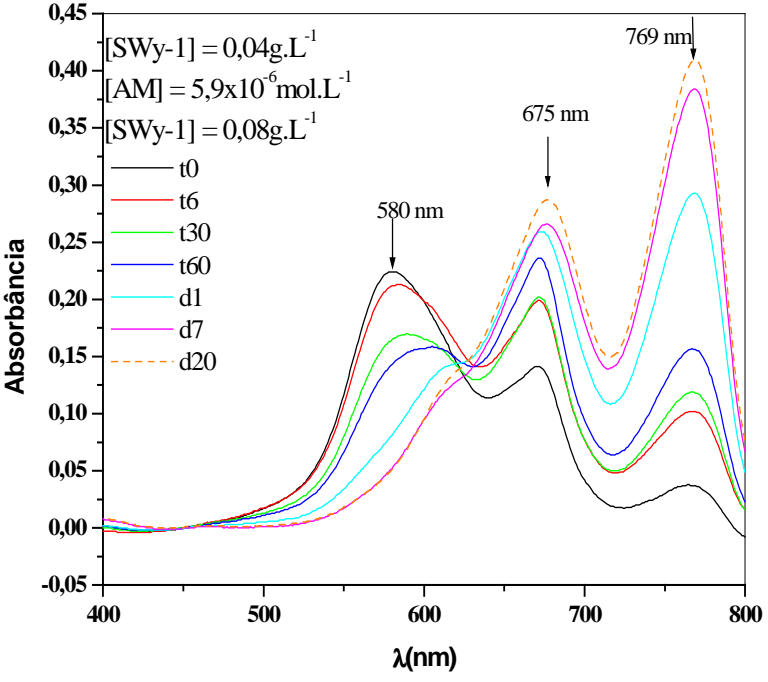

(d)

(e)

Figura 22: Espectros das suspensões de SWy-1 0,04g.L $\mathrm{L}^{-1}$ e $\mathrm{AM} 5,9 \times 10^{-6} \mathrm{~mol} \cdot \mathrm{L}^{-1}$. (a) Adição de água. (b) Adição de SWy-1, concentração final de $0,01 \mathrm{~g} \cdot \mathrm{L}^{-1}$. (c) Adição de SWy-1, concentração final de 0,02g. $\mathrm{L}^{-1}$. (d) Adição de SWy-1, concentração final de 0,08g. $\mathrm{L}^{-1}$. (e) Adição de SWy-1, concentração final de $0,09 \mathrm{~g} \cdot \mathrm{L}^{-1}$. Os tempos $\mathrm{t}$ estão expressos em minutos e $\mathrm{d}$ em dias.

Na Figura 22, observa-se variações espectrais típicas para o AM adsorvido em partículas de SWy-1. No entanto uma análise mais detalhada indica que as variações espectrais temporais, embora sigam o mesmo "padrão", as intensidades das variações dependem da quantidade de argila adicionada à suspensão que continha o AM adsorvido nas partículas de SWy-1. Esse padrão, como já observado anteriormente, mostra que à 
medida em que o tempo passa, a absorbância ao redor de 570-580nm (que corresponde aos agregados de AM) diminui de intensidade, ao passo que as absorbâncias ao redor de 670 e 760nm (devido aos monômeros e monômeros protonados) aumentam progressivamente de intensidade. Isto pode ser mais bem visualizado nos espectros-diferença. Os espectros diferença foram determinados tomando-se o espectro da amostra em questão, subtraindo-se o espectro da amostra de referência, sendo que a amostra na qual foi adicionado somente água foi tomada como referência. Esses espectros estão mostrados na Figura 23.

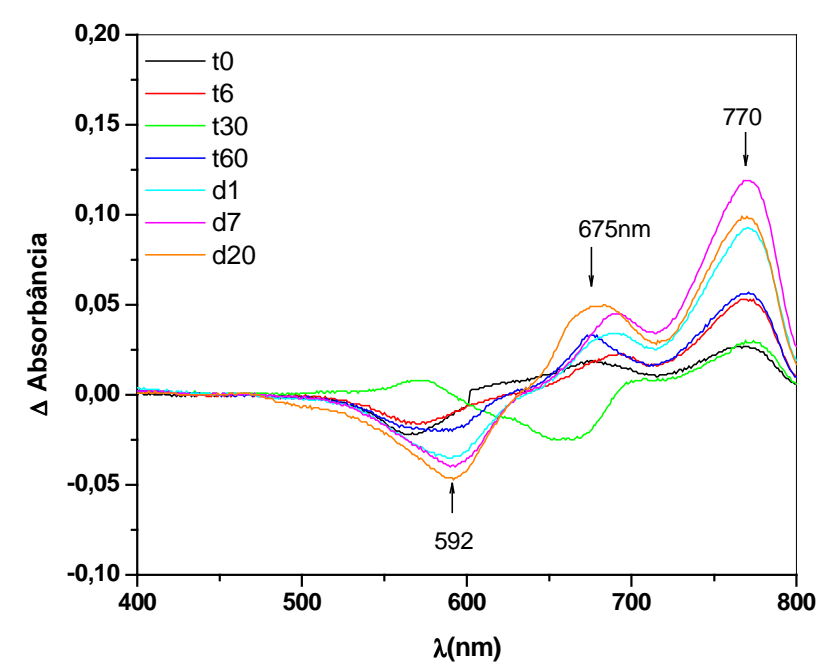

(a)

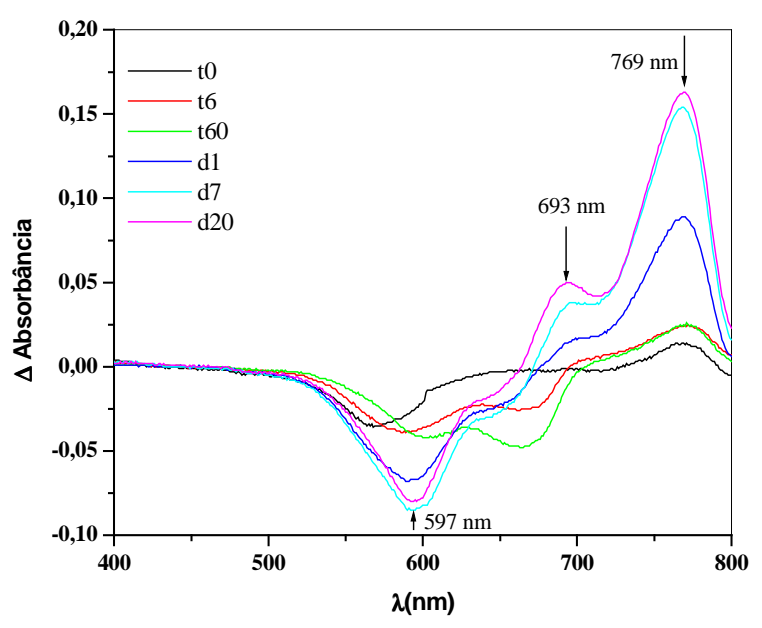

(c)

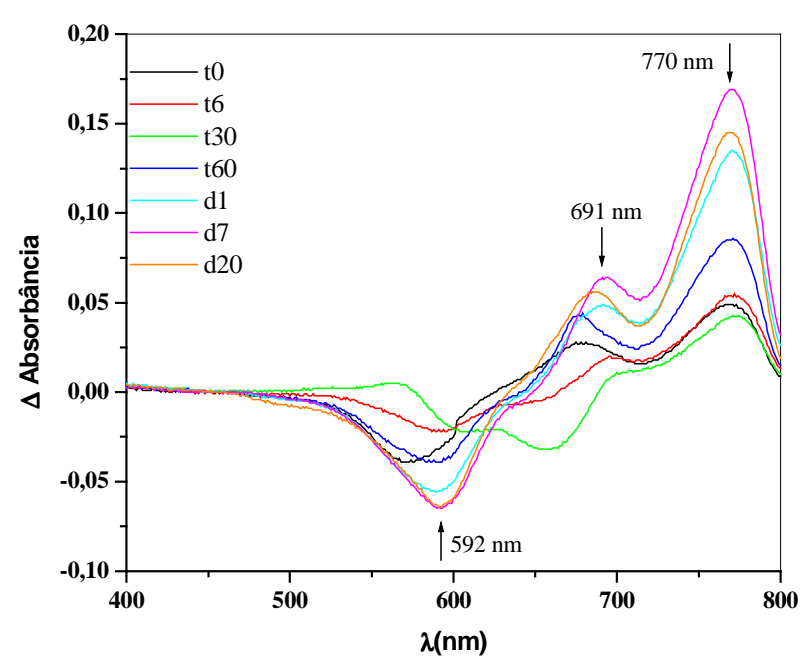

(b)

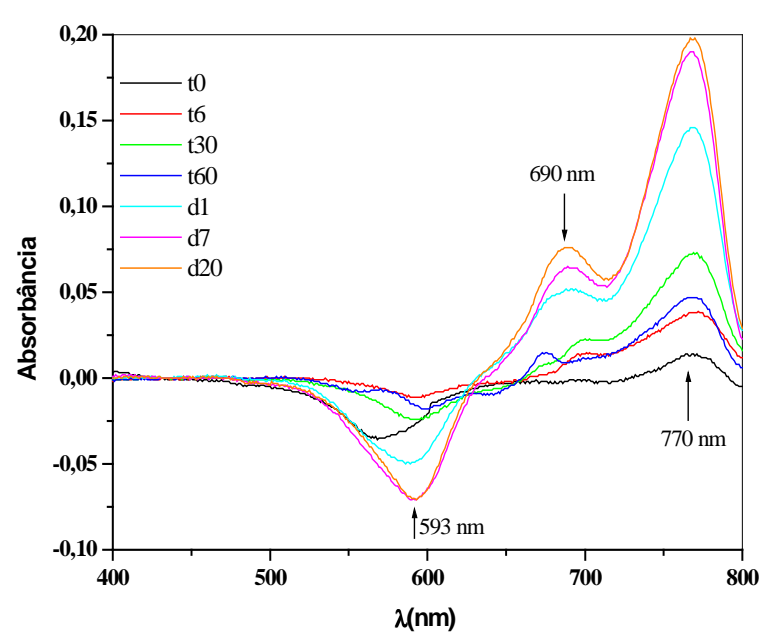

(d)

Figura 23: Espectro-diferença. (a) Espectro da Figura 22(b) menos 22(a). (b) Espectro da Figura 22 (c) menos 22(a). (c) Espectro da Figura 22(d) menos 22(a ). (d) Espectro da Figura 22(e) menos 22(a). 
Se não houvesse diferença entre os espectros das amostras e da referência, ter-se-ia somente uma linha reta paralela ao eixo x, e o $\Delta$ Absorbância seria igual a 0,00 . No entanto, o que se observa é que existem diferenças significativas entre os espectros das amostras e da referência, nos comprimentos de onda característicos das diferentes "espécies" (monômeros, monômeros protonados e agregados) do corante.

A variação negativa ao redor de 590nm indica que na referência existem mais agregados do que nas amostras, enquanto que as variações positivas ao redor de 670$690 \mathrm{~nm}$, e ao redor de 760nm indicam que nas amostras existem mais monômeros e monômeros protonados que na referência. Verifica-se que conforme a concentração de SWy-1 adicionada ao sistema aumenta e à medida em que o tempo passa, a banda na região de $675 \mathrm{~nm}$ desloca-se para 690nm. A absorção na região de 690nm representa a banda vibrônica dos monômeros protonados que absorvem em 770nm.

No tempo inicial as diferenças espectrais são pequenas, rigorosamente deveriam ser nulas, mas o intervalo de tempo entre a adição da argila e a medida já é suficiente para que ocorram as mudanças detectadas. Conforme o tempo passa as diferenças aumentam significativamente.

Na Figura 24 estão mostradas as variações de absorbância em função do tempo para as diferentes espécies do corante. Na Figura 24(a) pode ser visto que a absorbância em 580nm diminui conforme o tempo passa, indicando a desagregação do corante nas superfícies das partículas de argila. Essa desagregação aumenta conforme a quantidade de argila adicionada aumenta.

Na Figura 24 (b) pode ser visto que as absorbâncias em 670nm aumentam conforme o tempo passa, indicando um aumento na quantidade de monômeros do corante adsorvido na argila. A partir de 60 minutos (t60), nota-se que a absorção na região de 670nm começa a diminuir e após 1400 minutos (d1) ela se mantém constante, indicando que praticamente todo monômero de $\mathrm{AM}$ foi protonado. $\mathrm{O}$ máximo de absorção se desloca para a região de 690nm, sendo que esta absorção é atribuída a banda vibrônica dos monômeros protonados de AM cujo máximo está situado ao redor de 770nm. A quantidade de monômeros protonados também aumenta com o tempo como mostrado na Figura 24(c), indicando um aumento destas espécies conforme a quantidade de argila adicionada aumenta. 
Vale ressaltar que nas condições dos experimentos realizados o corante está sempre todo adsorvido nas partículas de argila. Como explicar então o fato de que as variações espectrais dependem da quantidade de argila adicionada? Se o corante estava adsorvido nas partículas de argila no momento da adição de mais argila à suspensão, e se não existisse outro processo acontecendo, as variações espectrais das amostras deveriam ser iguais às da referência, conforme mostra o esquema proposto para as variações espectrais nos sistemas corante-argila, mostrado na Figura 11.

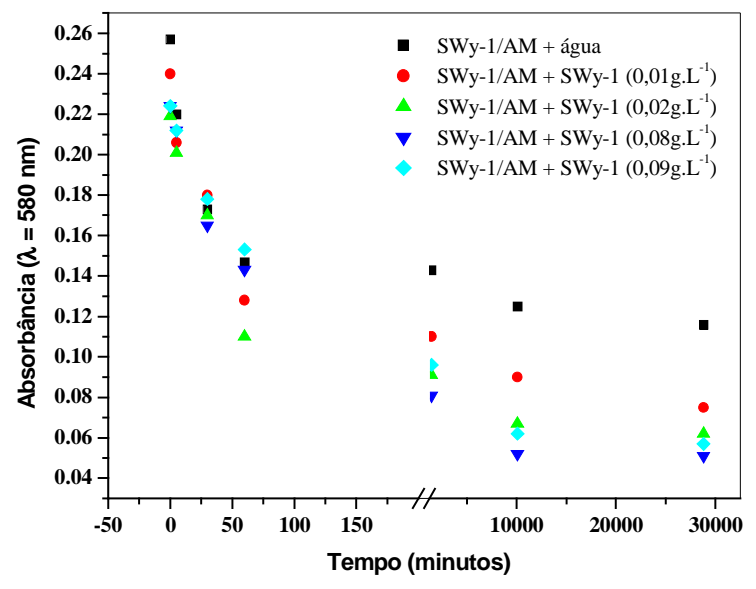

(a)

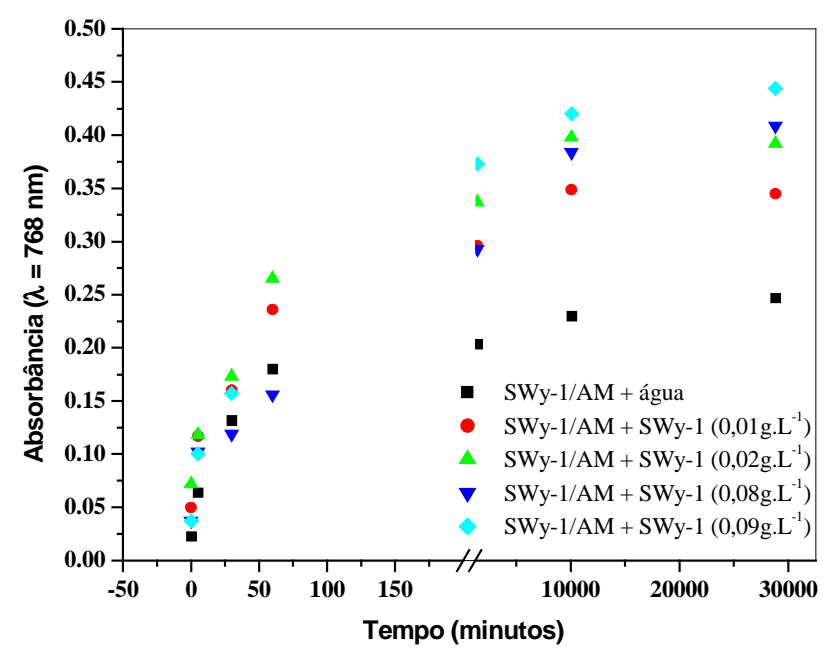

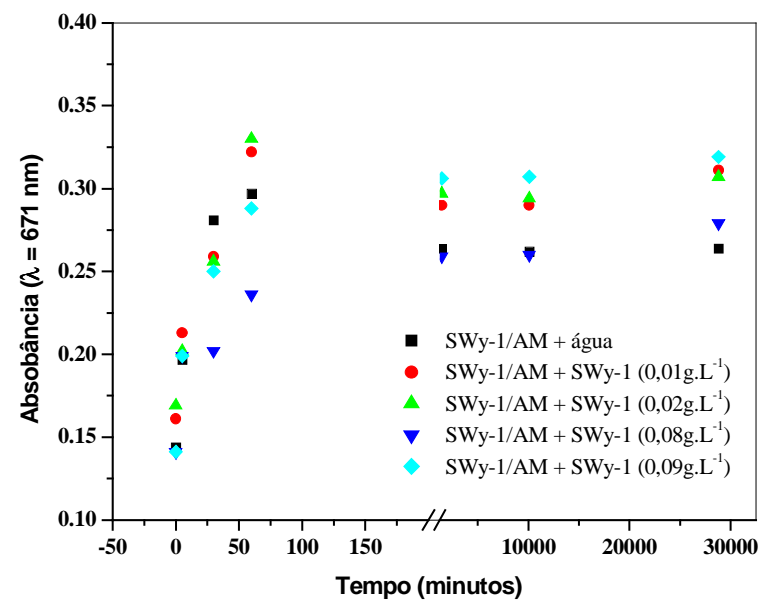

(b)

(c)

Figura 24: Variação da absorbância nos comprimentos de onda característicos em função do tempo para: (a) agregados $(580 \mathrm{~nm})$, (b) monômeros (670nm) e (c) monômeros protonados $(768 \mathrm{~nm})$, para as diferentes amostras.

Fica evidente então ser necessário complementar o referido esquema para que se possa entender como, ou por que as variações espectrais observadas devido a adição 
de partículas de argila à suspensão corante-argila acontecem. A Figura 25, representa um esquema de um processo que pode justificar os resultados obtidos.

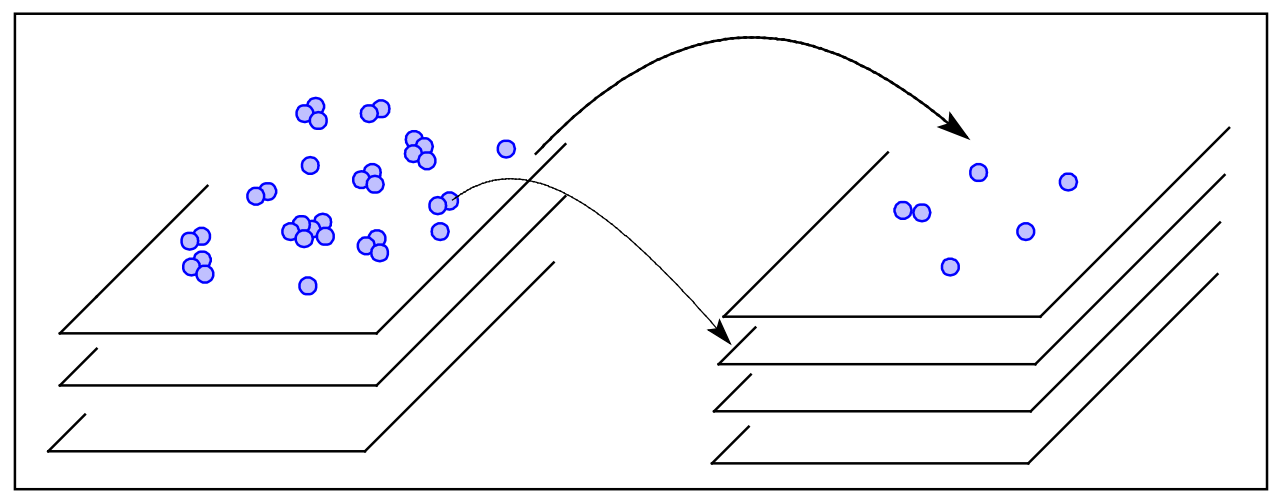

Figura 25: Esquema proposto para o processo que representa as alterações espectrais observadas como resultado da adição de argila às suspensões corante-argila.

A Figura 25 representa o processo de migração de moléculas de AM adsorvidas numa partícula de SWy-1 para outra partícula de SWy-1 adicionada posteriormente. Este processo justifica as alterações espectrais observadas. A desagregação das moléculas de AM estaria ocorrendo pois estas moléculas poderiam migrar para outras partículas, e conseqüentemente ocorreria aumento da quantidade de monômeros e monômeros protonados devido a presença de novas regiões interlamelares disponíveis para adsorção das moléculas de corante. 


\subsection{Estudo do sistema SAz-1/AM com adição de SAz-1.}

As amostras utilizadas no estudo deste sistema foram preparadas como descrito anteriormente. Neste sistema o corante está todo adsorvido nas partículas de SAz1, sendo adicionadas ao sistema partículas de SAz-1. Foram realizadas medidas espectrofotométricas das amostras em função de tempo, e os espectros obtidos são apresentados na Figura 26.

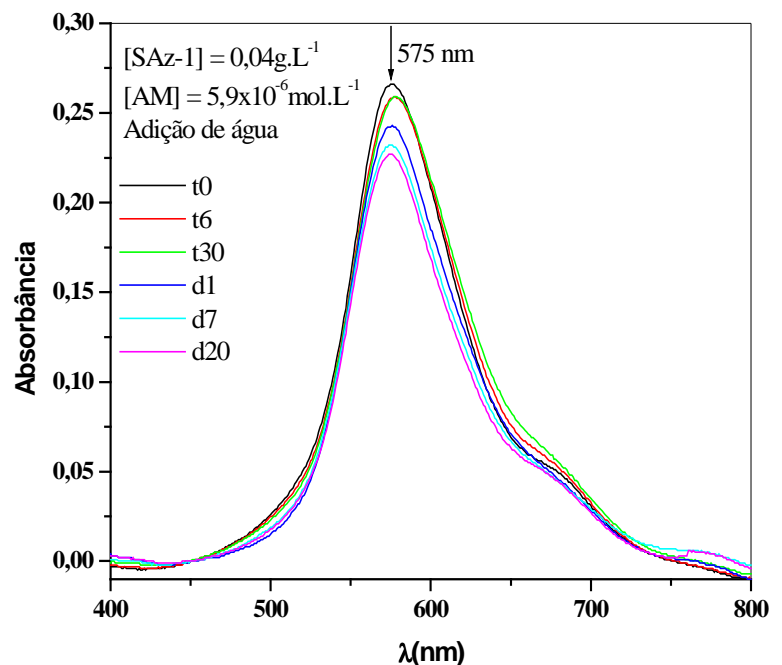

(a)

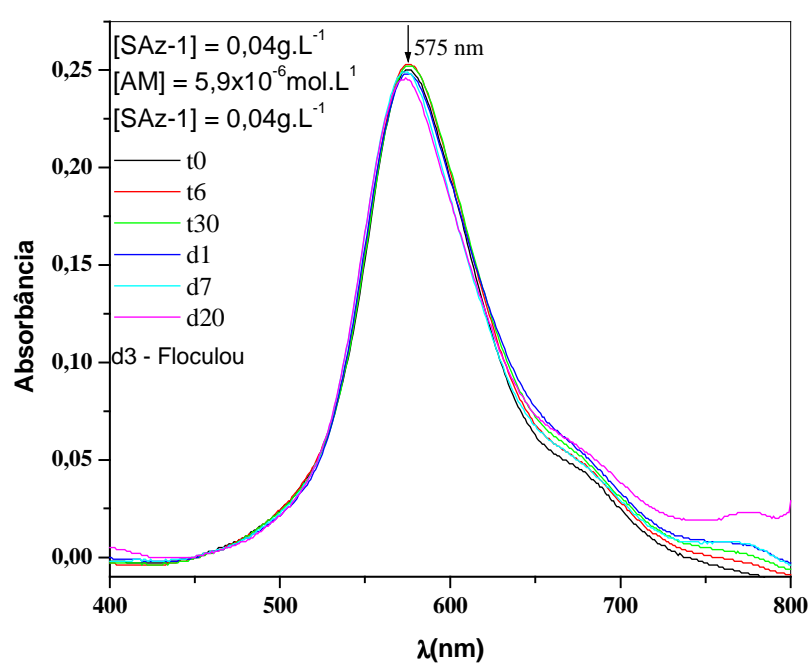

(c)

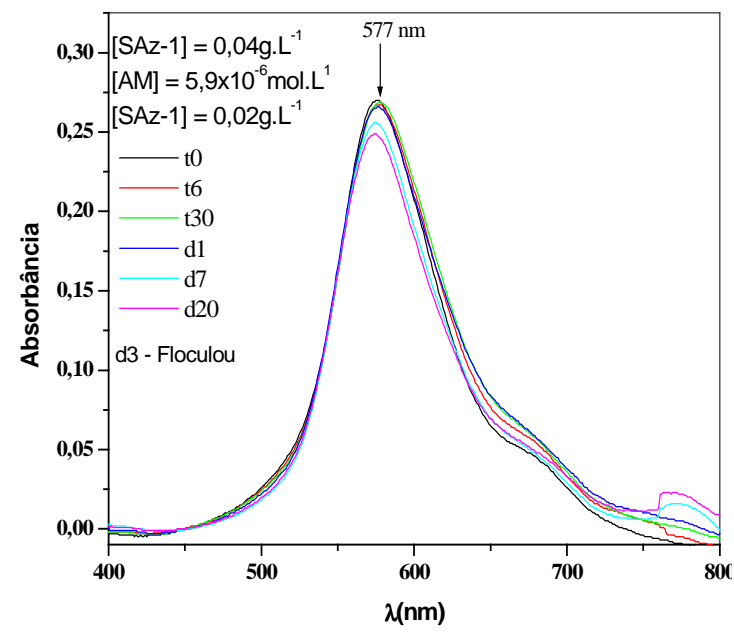

(b)

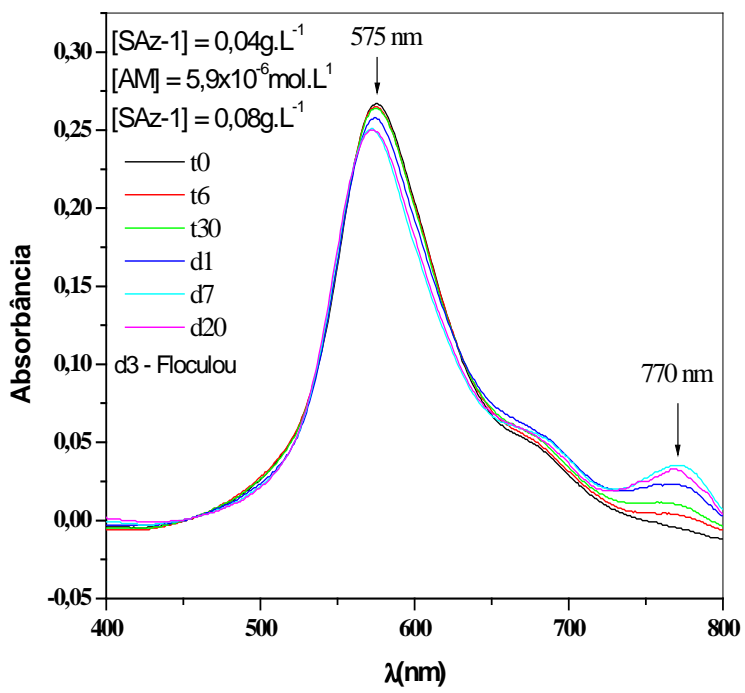

(d) 


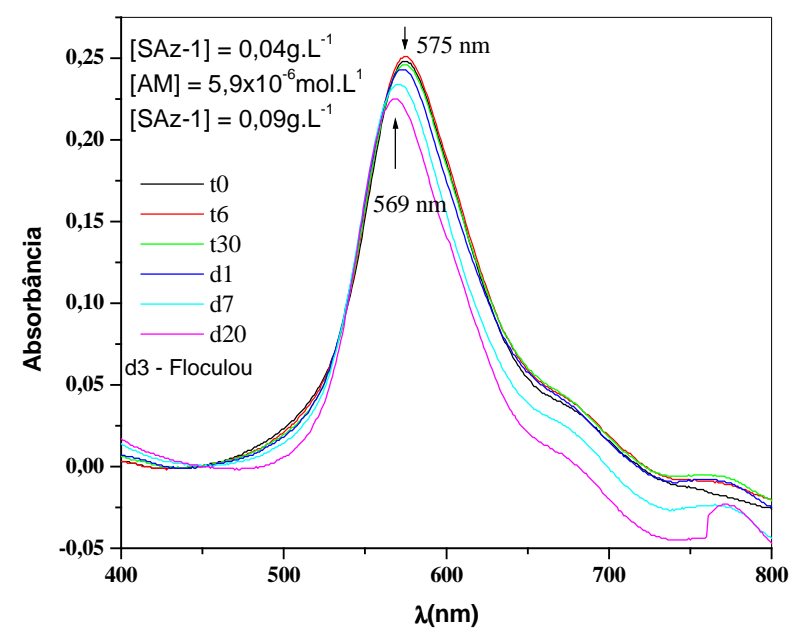

(e)

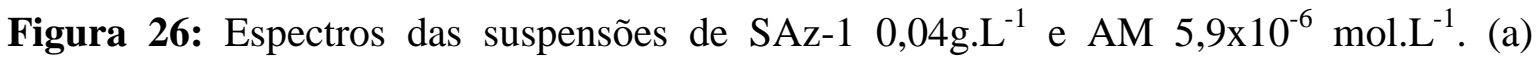
Adição de água. (b) Adição de SAz-,1, concentração final de 0,01g.L $\mathrm{L}^{-1}$. (c) Adição de SAz1 , concentração final de $0,02 \mathrm{~g} \cdot \mathrm{L}^{-1}$. (d) Adição de SAz-1, concentração final de $0,08 \mathrm{~g} \cdot \mathrm{L}^{-1}$. (e) Adição de SAz-1, concentração final de $0,09 \mathrm{~g} \cdot \mathrm{L}^{-1}$. Os tempos $\mathrm{t}$ estão expressos em minutos e d em dias.

Na Figura 26, observa-se que os espectros são semelhantes. A adição de SAz-1 ao sistema corante argila não causou alterações espectrais significativas, e as amostras apresentaram o mesmo comportamento que a amostra referência (com adição de água). São espectros típicos de AM adsorvido em partículas de SAz-1.

Na Figura 27 são apresentados os espectros-diferença. De forma geral a adição de SAz-1 ao sistema não causou alterações espectrais significativas. Uma observação importante é que as suspensões exibiram floculação em tempos entre dois e três dias, tempos esses relativamente pequenos, e a quantidade do floculado aumentou conforme a quantidade da argila adicionada aumentava. Isto indica que processos de interação partícula-partícula podem ser importantes, e a migração de moléculas de corante entre partículas de argila não acontece com intensidade suficiente para influenciar o comportamento espectral do sistema. 


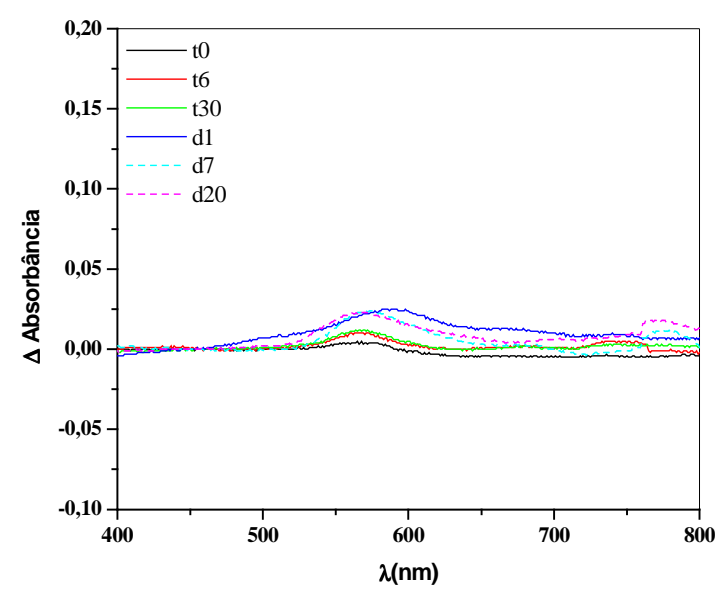

(a)

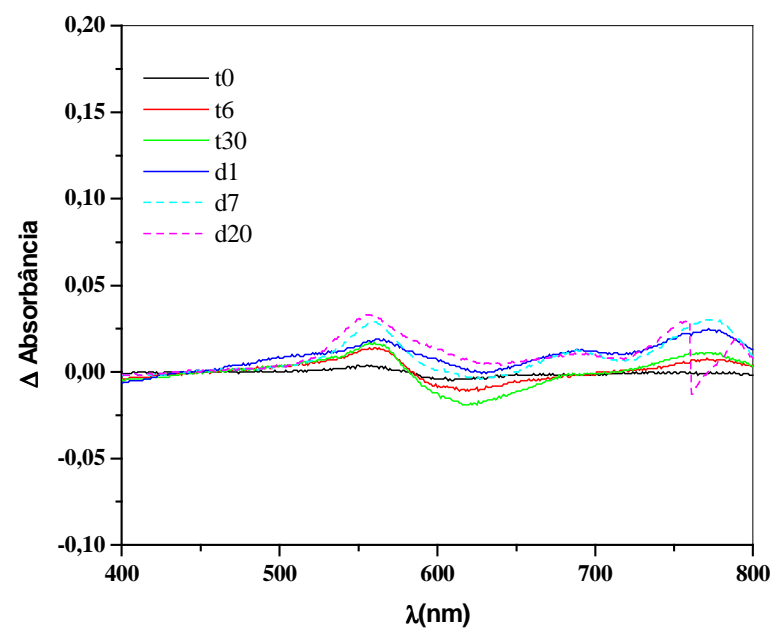

(c)

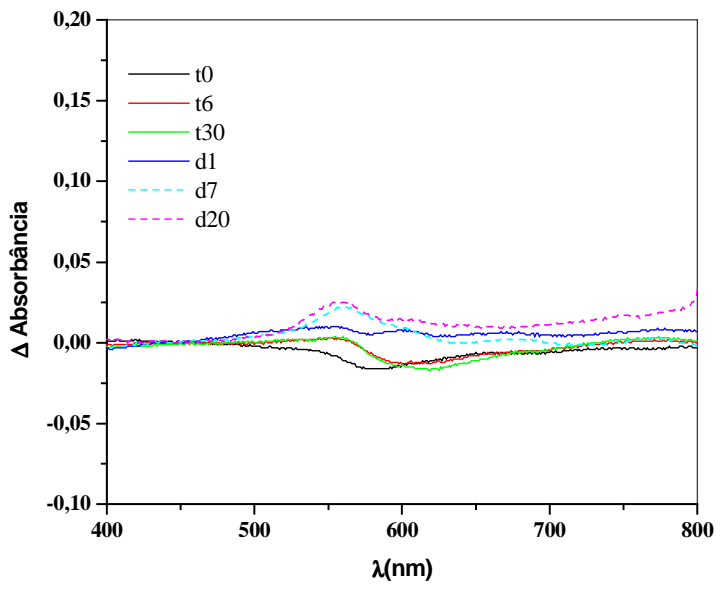

(b)

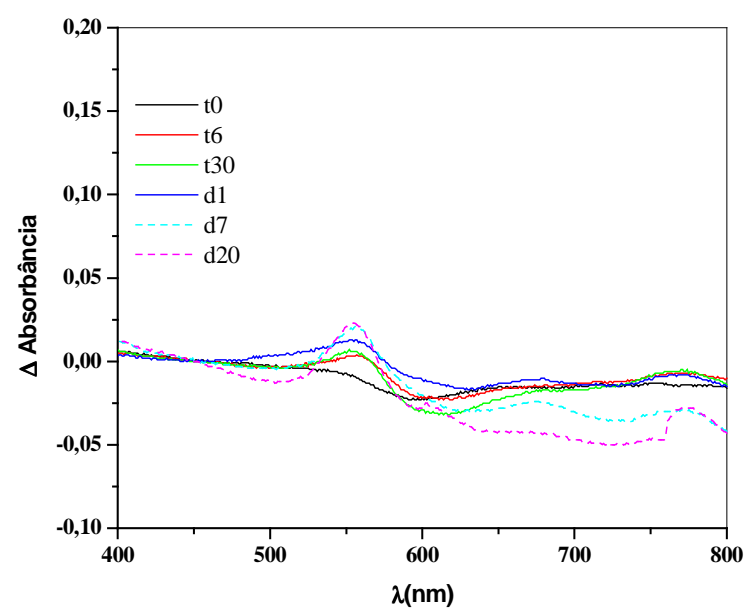

(d)

Figura 27: Espectro-diferença. (a) Espectro da Figura 26(b) menos 26(a). (b) Espectro da Figura 26(c) menos 26(a). (c) Espectro da Figura 26(d) menos 26(a ). (d) Espectro da Figura 26(e) menos 26(a). As linhas pontilhadas indicam floculação da suspensão.

A principal diferença entre o sistema SWy-1/AM com adição de SWy-1 e o sistema SAz-1/AM com adição de SAz-1, está relacionada as propriedades de cada uma das argilas. Conforme discutido na introdução, a argila SWy-1, apresenta regiões interlamelares disponíveis para a adsorção de moléculas de corante, isto faz com que as partículas de SWy-1 tenham uma grande capacidade de adsorver o corante, devido a disponibilidade das regiões interlamelares onde o corante pode ser adsorvido. A argila 
SAz-1 possui densidade de carga relativamente alta, e portanto energia de coesão entre as lamelas é maior em relação a energia de coesão das lamelas nas partículas da argila SWy1 .

A adição de SWy-1 ao sistema representa a adição de uma superfície de grande extensão (superfície interlamelar) disponível para adsorção das moléculas de corante. Entretanto, a adição de SAz-1 ao sistema não representa um aumento tão significativo nas áreas superficiais disponíveis para a adsorção do corante.

Portanto, os resultados indicam que neste sistema a migração de moléculas de uma partícula para outra não é significativa, como no sistema anteriormente estudado. As variações espectrais são pequenas e podem ser atribuídas as interações partículapartícula. A Figura 28 representa de forma esquemática o processo de interação partículapartícula.

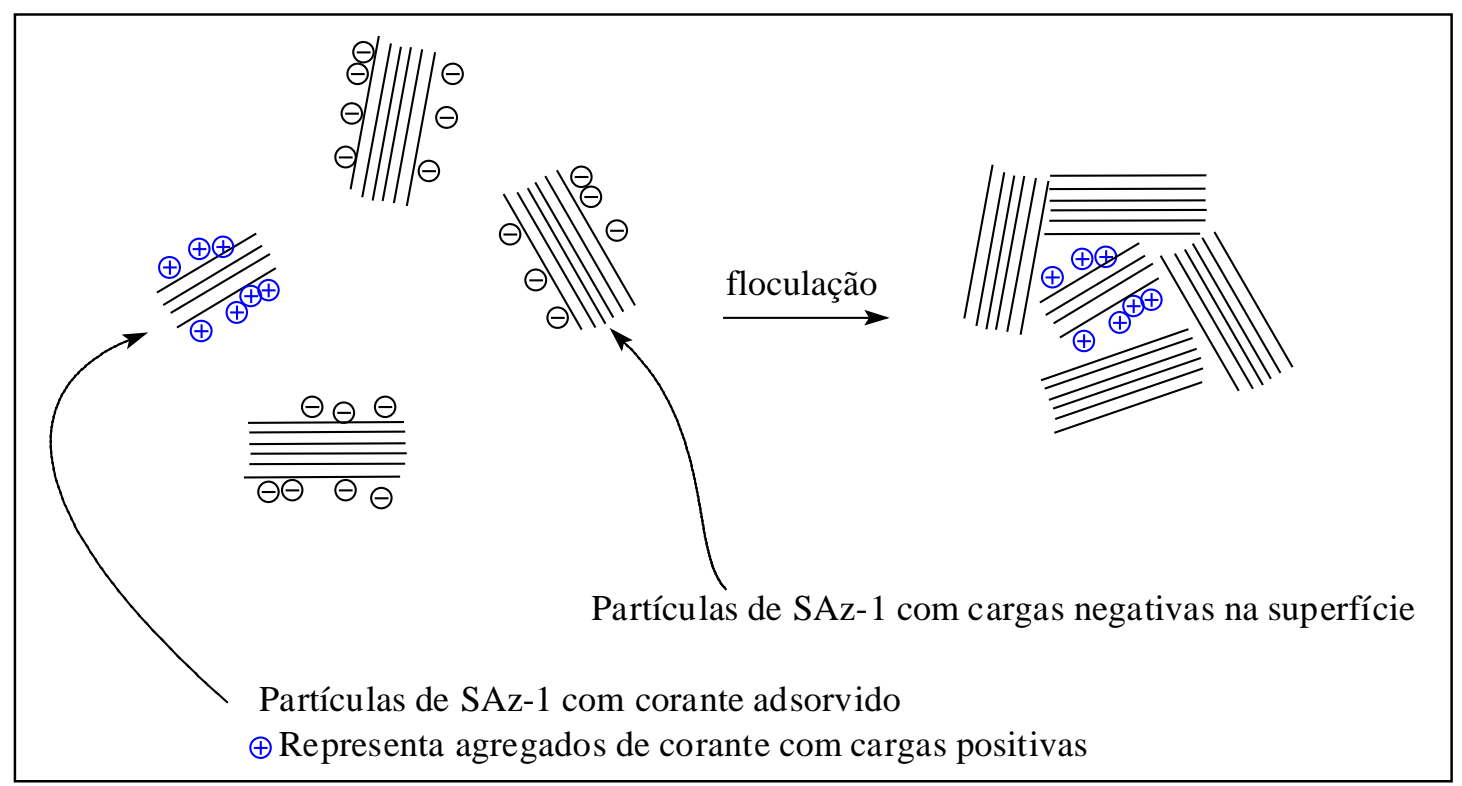

Figura 28: Esquema representando o processo de interação partícula - partícula.

A Figura 28 representa o processo de interação entre partículas de argila em suspensão, sendo uma partícula contendo moléculas de corante adsorvidas (suspensão antes da adição de argila) e outras partículas livres de corante. Conforme discutido na introdução, as partículas de argila apresentam densidade de carga superficial negativa. A adição de solução de corante catiônico a uma suspensão de argila causa uma inversão deste potencial instantaneamente, a argila passa a apresentar densidade de carga superficial positiva. Por outro lado, as partículas adicionadas posteriormente apresentam densidade de carga negativa, e devido a ausência de corante em solução, esta densidade é mantida. Esta 
diferença de potencial causa o surgimento de interação de atração eletrostática, promovendo a interação entre as partículas, formando espécies como "clusters" (aglomerados de partículas de argila).

As diferentes propriedades dos argilominerais representam um fator adicional, impedindo que a migração seja o processo principal. A argila SWy-1, apresenta superfícies interlamelares disponíveis para a adsorção de moléculas de corante, isto proporciona a esta argila uma superfície de grande extensão. Entretanto, a adição de SAz-1 ao sistema não representa um aumento significativo nas áreas superficiais e internas disponíveis para a adsorção do corante.

Portanto as variações espectrais detectadas após a adição da argila SAz-1 ao sistema AM/SAz-1 podem ser atribuída a interação atrativa entre as partículas das argilas (partículas de SAz-1 com AM Adsorvido e partículas de SAz-1 adicionadas à suspensão). Uma observação importante é a de que as suspensões exibem floculação em tempos entre um e dois dias, e que a quantidade do floculado aumentou conforme a quantidade da argila adicionada aumentava.

\subsection{Estudo do sistema Laponita - B /AM com adição de Laponita - B}

As amostras utilizadas no estudo deste sistema foram preparadas como descrito anteriormente. O corante AM encontra-se todo adsorvido nas partículas de Laponita - B, posteriormente houve adição de partículas de Laponita - B ao sistema, variando-se a concentração da argila adicionada de $0,00 \mathrm{~g} . \mathrm{L}^{-1}$ (adição de água) até $0,09 \mathrm{~g} . \mathrm{L}^{-}$ ${ }^{1}$. Os espectros, determinados em função do tempo para as diferentes amostras, são apresentados na Figura 29. 


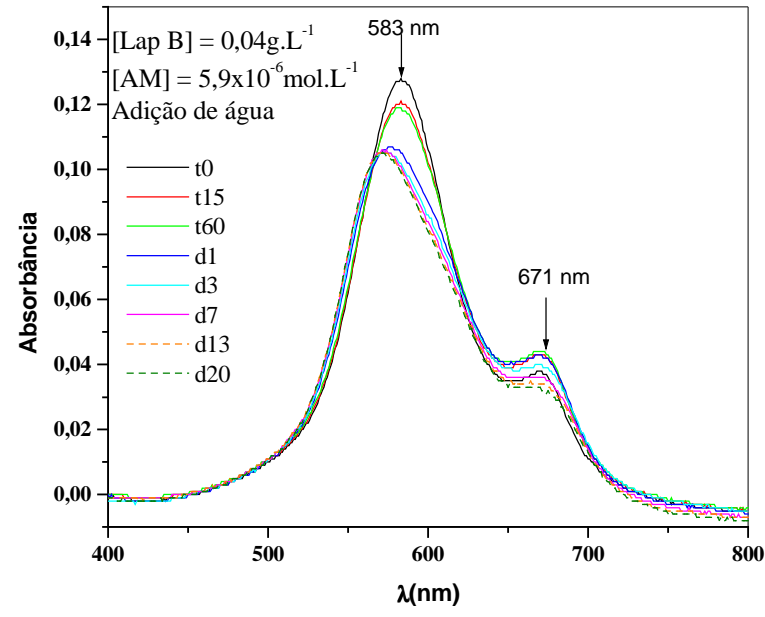

(a)

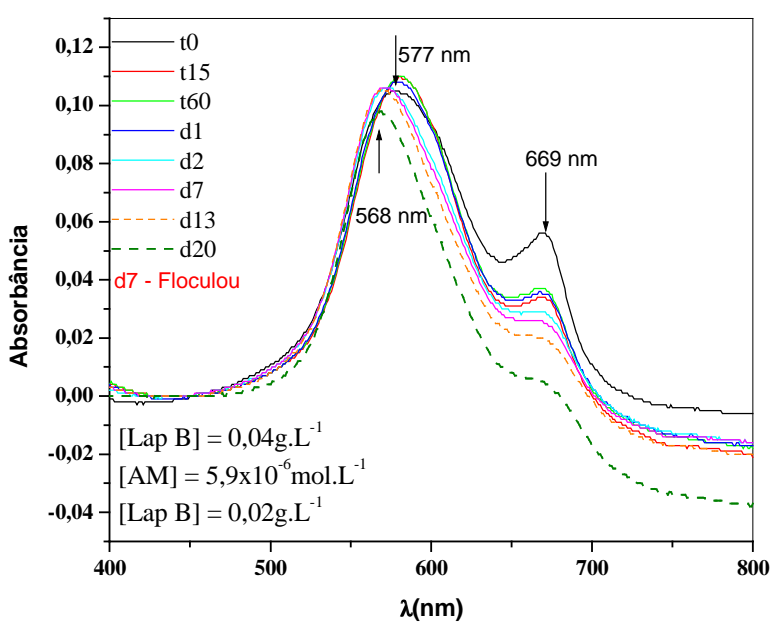

(c)

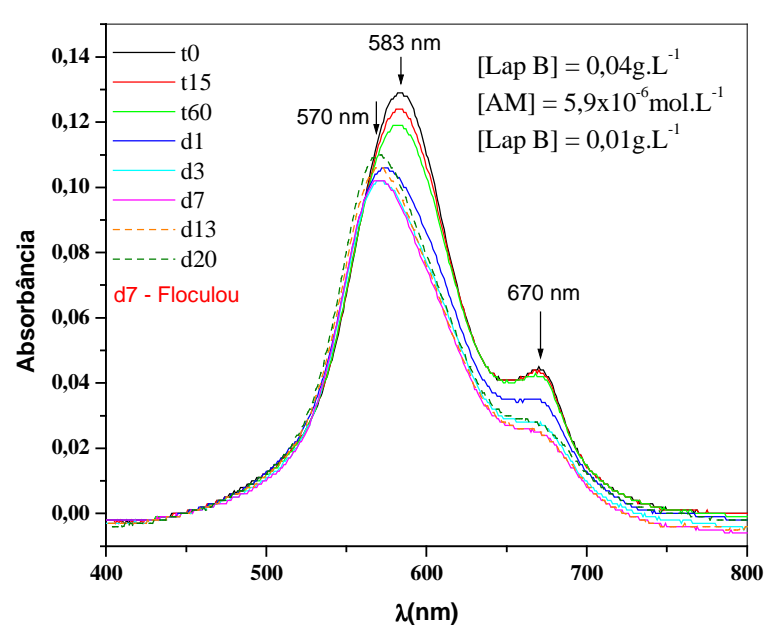

(b)

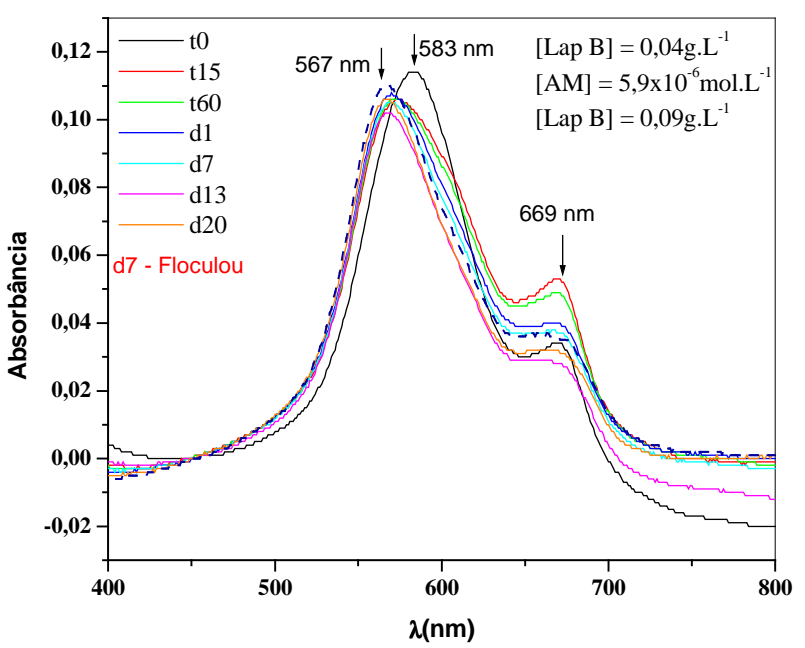

(d)

Figura 29: Espectros das suspensões de Laponita - B 0,04g. $\mathrm{L}^{-1}$ e AM 5,9x $10^{-6}$ mol.L ${ }^{-1}$. (a) Adição de água. (b) Adição de Laponita - B, concentração final de 0,01g. $L^{-1}$. (c) Adição de Laponita - B, concentração final de 0,02g.L.-1. (d) Adição de Laponita - B, concentração final de $0,09 \mathrm{~g} \cdot \mathrm{L}^{-1}$. Os tempos t estão expressos em minutos e d em dias.

Na Figura 29, observa-se variações espectrais típicas de AM adsorvido em partículas de Laponita -B. Verifica-se uma banda intensa na região de 580nm, a qual com o passar do tempo desloca-se para comprimentos de onda menores. Este comportamento é característico das suspensões de Laponita - B e é um indicativo dos processos de interação partícula - partícula que ocorrem no sistema. Verifica-se também que a adição de Laponita - B às amostras não causa mudanças nos espectros. Entretanto, há o aumento da floculação das amostras, o qual aumenta conforme a quantidade de Laponita - B adicionada aumenta. 
Na Figura 30 estão apresentados os espectros - diferença, obtidos da mesma forma que nos itens anteriores.

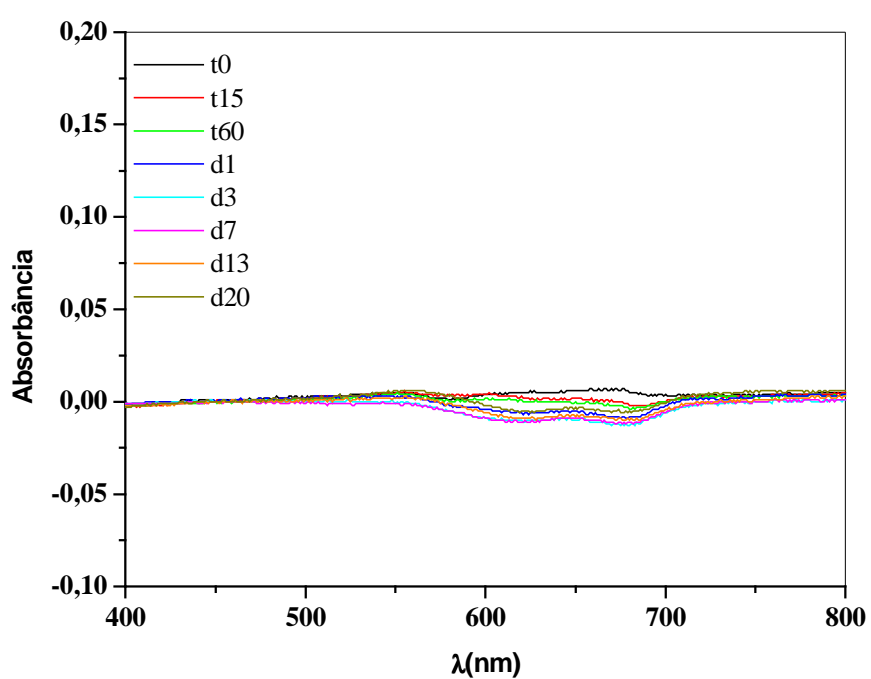

(a)

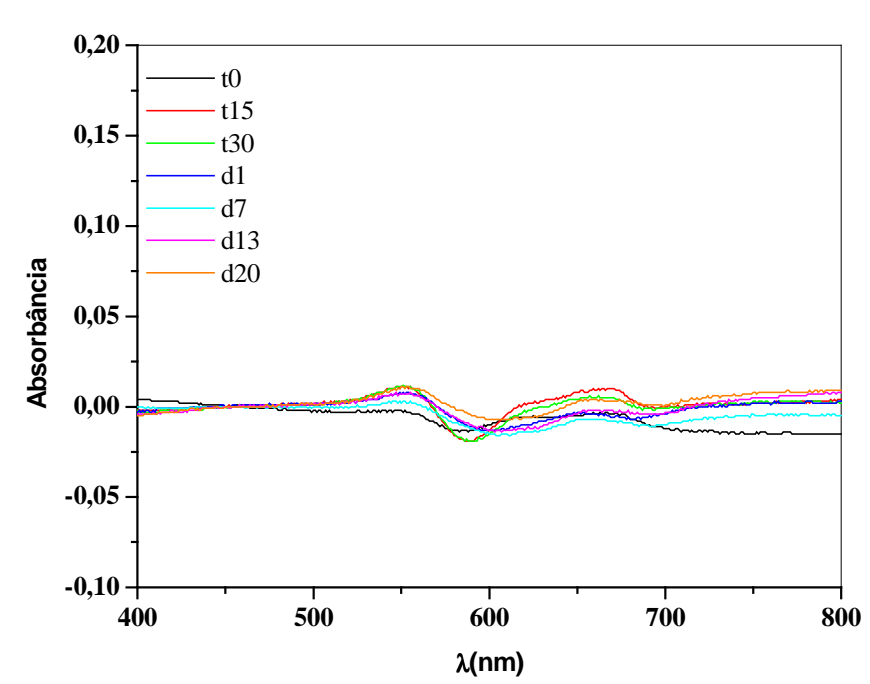

(c)

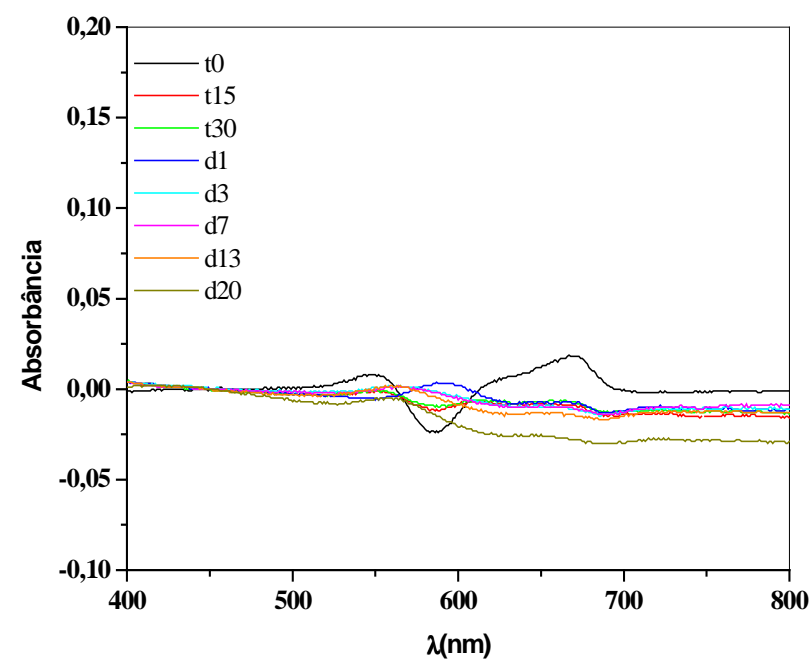

(b) 
concentração de $0,1 \mathrm{~g} \cdot \mathrm{L}^{-1}$, na qual se adicionou uma solução de corante azul de metileno, obtendo-se a concentração de $1,7 \times 10^{-5} \mathrm{~mol} \cdot \mathrm{L}^{-1}$. Esta suspensão corante-argila foi divida em alíquotas de mesmo volume nas quais adicionou-se um volume fixo da argila SWy-1 em diferentes concentrações, obtendo-se concentrações que variam de $0,00 \mathrm{~g} . \mathrm{L}^{-1}$ (adição de água) até $0,09 \mathrm{~g} \cdot \mathrm{L}^{-1}$. Os espectros dessas suspensões foram registrados em função do tempo e estão representados na Figura 31.

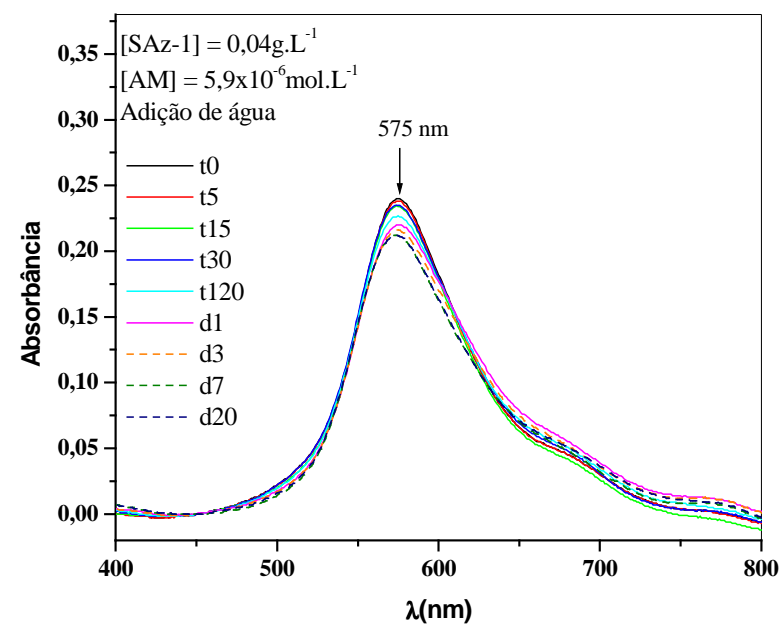

(a)

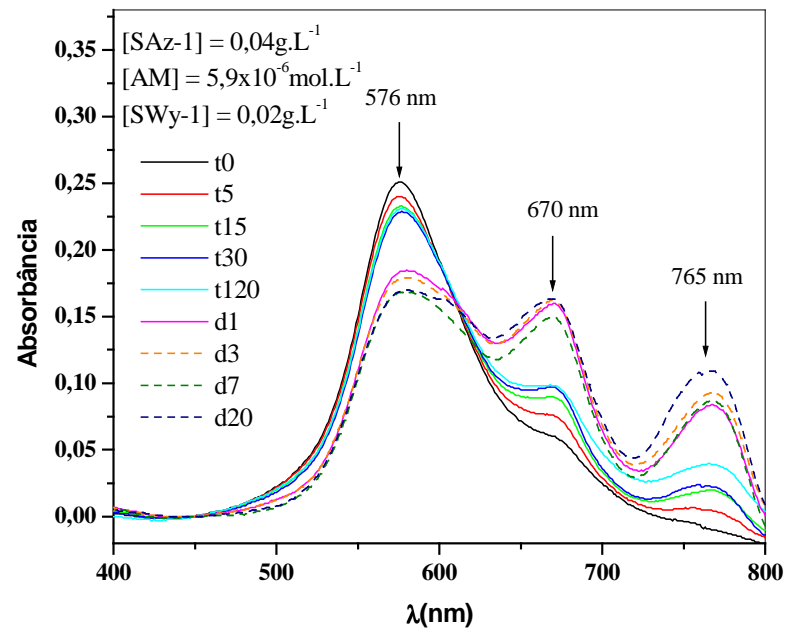

(c)

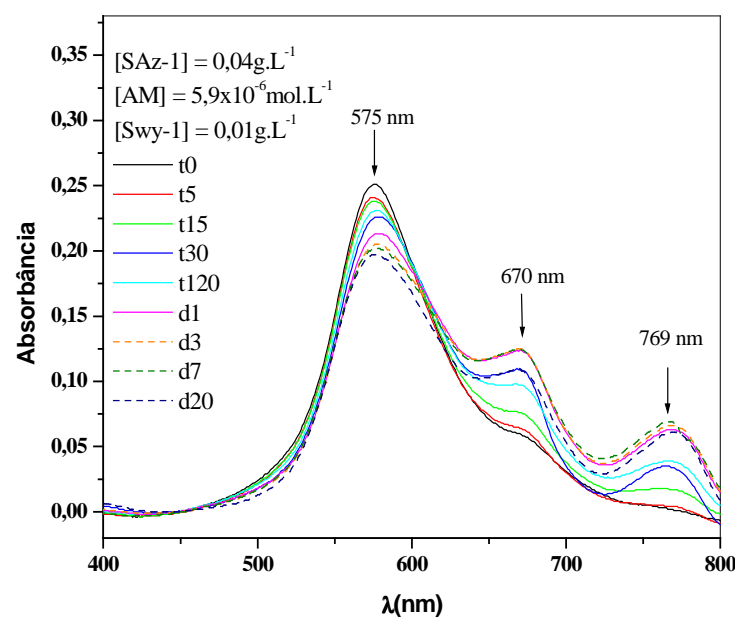

(b)

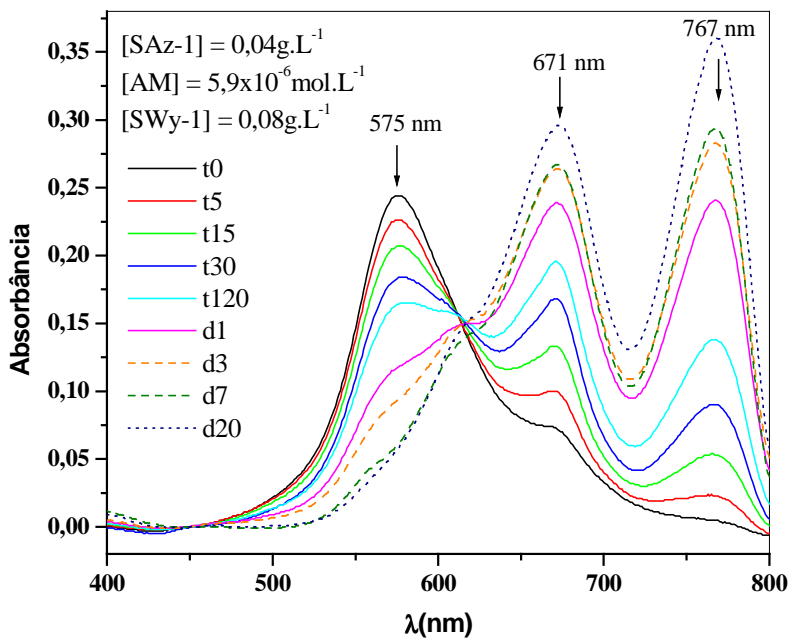

(d) 


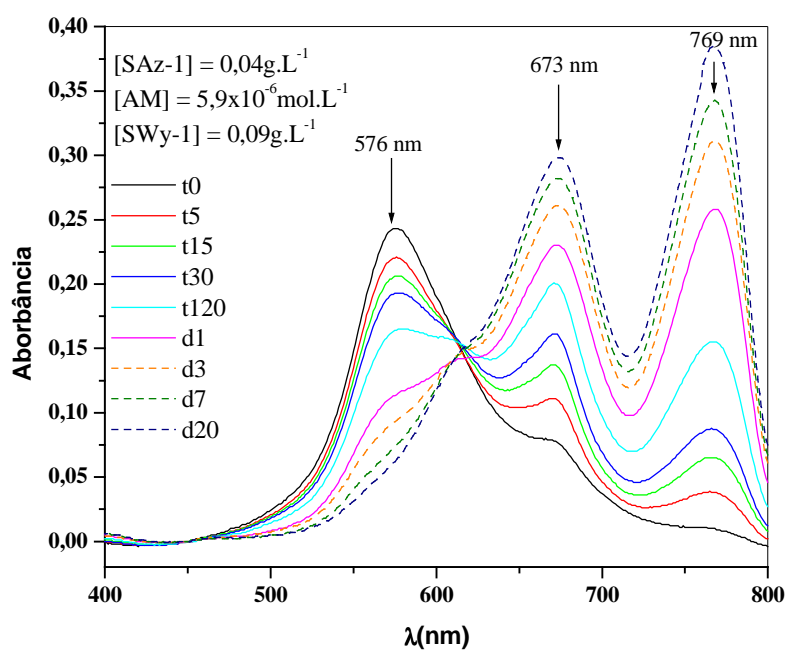

(e)

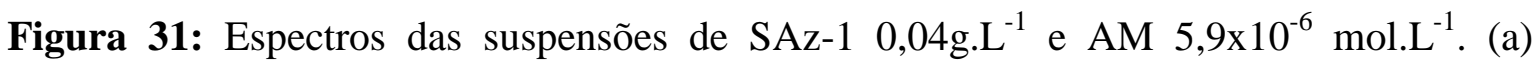
Adição de água. (b) Adição de SWy-1, concentração final de $0,01 g . L^{-1}$. (c) Adição de SWy-1, concentração final de 0,02g. $\mathrm{L}^{-1}$. (d) Adição de SWy-1, concentração final de 0,08g. $\mathrm{L}^{-1}$. (e) Adição de SWy-1, concentração final de $0,09 \mathrm{~g} \cdot \mathrm{L}^{-1}$. Os tempos $\mathrm{t}$ estão expressos em minutos e $\mathrm{d}$ em dias.

Na Figura 31(a) estão mostrados os espectros da amostra referência (SAz1/AM com adição de água). Nesta Figura observa-se o comportamento espectral de AM adsorvido em partículas de SAz-1. Nota-se uma banda intensa na região de $575 \mathrm{~nm}$, a qual corresponde aos agregados de AM adsorvidos nas partículas de SAz-1. As alterações espectrais com o tempo são mínimas.

Após a adição de 0,01g.L. $\mathrm{L}^{-1}$ de SWy-1 (Figura 31(b)), nota-se o surgimento de bandas de absorção na regiões de 670 e 769nm (monômeros e monômeros protonados). Ao mesmo tempo acontece uma gradual redução na banda de absorção em 575nm. Essas alterações espectrais tornam-se mais intensas à medida que a concentração de SWy-1 nas amostras aumenta, conforme pode ser observado nas Figuras 31(b) à 31(e). Essas alterações causadas devido a adição de SWy-1 ao sistema podem ser melhor visualizadas nos espectros - diferença, representados na Figura 32, os quais representam a diferença entre o espectro da amostra na qual adicionou-se SWy-1 e o espectro da referência, na qual adicionou-se água.

Observando a Figura 32, verifica-se que a adição de SWy-1 ao sistema SAz-1/AM provoca variações espectrais significativas. As variações das absorbâncias na regiões em torno de $670 \mathrm{~nm}$ e de $770 \mathrm{~nm}$ são positivas e isso indica que as amostras 
apresentam maior quantidade de monômeros e monômeros protonados de AM em relação à referência. A variação da absorbância na região de 570nm é negativa, indicando que na referência a quantidade de agregados é maior que nas amostras. É interessante ressaltar que no tempo t0, o resultado da diferença entre os espectros é praticamente nulo, o que indica que as diferenças espectrais surgem e se intensificam com o tempo. Verifica-se que o aumento da concentração de SWy-1 nas amostras torna as alterações mais intensas.

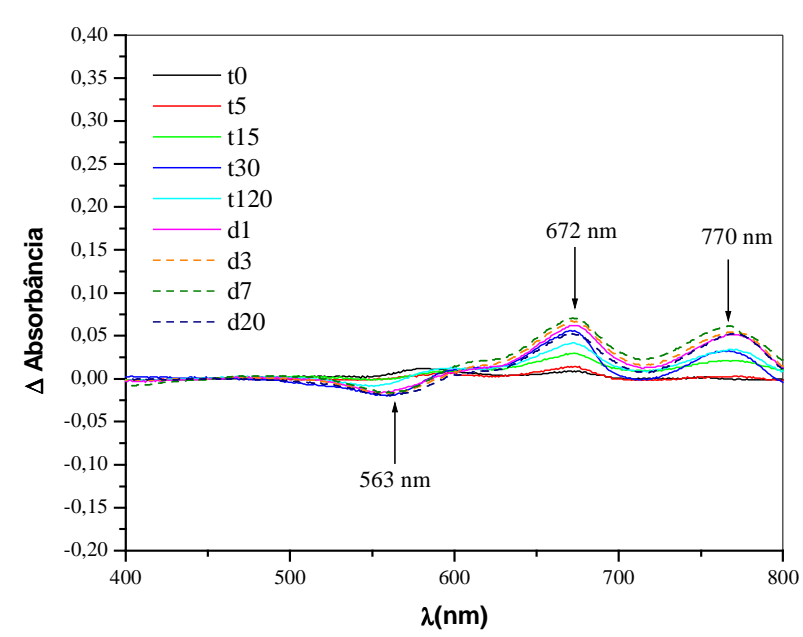

(a)

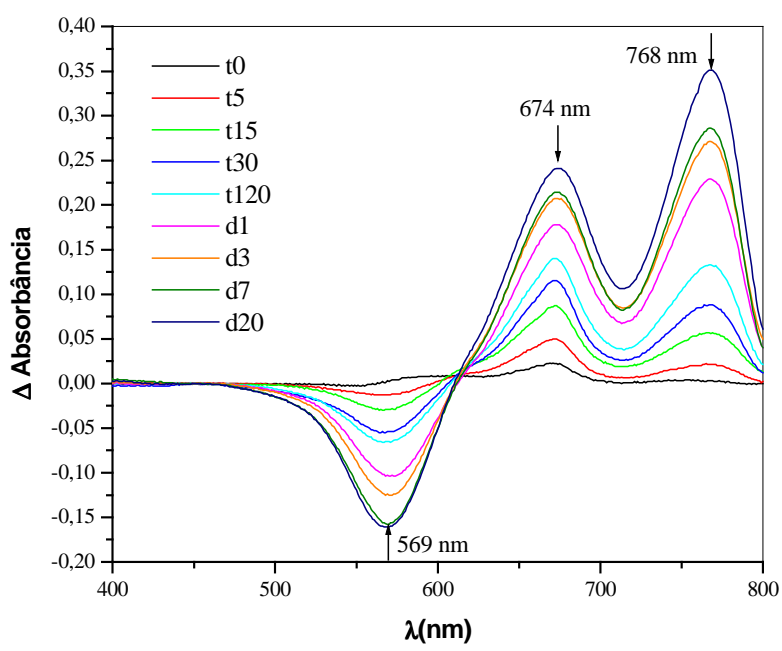

(c)

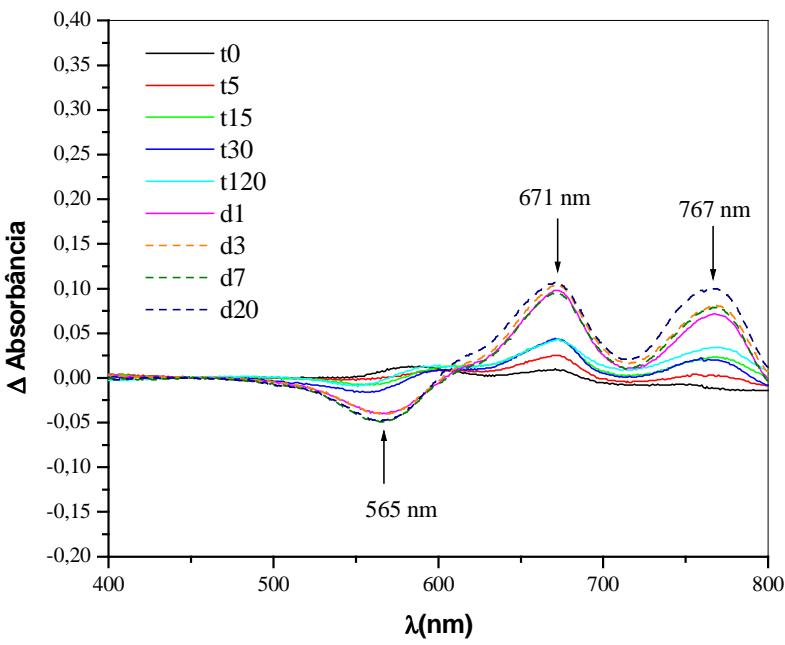

(b)

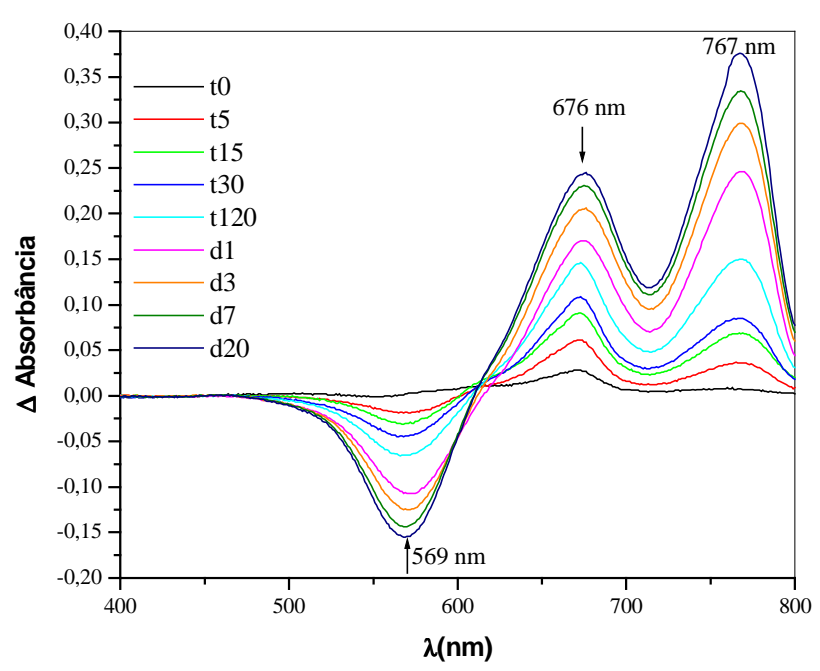

(d)

Figura 32: Espectro-diferença. (a) Espectro da Figura 31(b) menos 31(a). (b) Espectro da Figura 31(c) menos 31(a). (c) Espectro da Figura 31(d) menos 31(a ). (d) Espectro da Figura 31(e) menos 31(a). 
A Figura 33 mostra a variação da absorbância nos comprimentos de onda característicos das diferentes espécies do corante adsorvidas na argila $(575 \mathrm{~nm}, 670 \mathrm{~nm}$ e 769nm, referentes aos agregados, monômeros e monômeros protonados de AM, respectivamente).

Na Figura 33(a), vê-se que após adição de água ao sistema SAz-1/AM (linha preta), a absorbância das espécies agregadas de AM praticamente não apresenta alteração com o passar do tempo. Porém, a adição de SWy-1 à amostra, promove diminuição da intensidade da banda de absorção dos agregados, indicando que está havendo o consumo dessas espécies. Além disso, verifica-se que na amostra não houve detecção de monômeros e monômeros protonados, entretanto após a adição de SWy-1, ocorre o surgimento dessas bandas, e o aumento da intensidade dessas é proporcional ao aumento da concentração de SWy-1 (Figuras 33(b) e 33(c)).

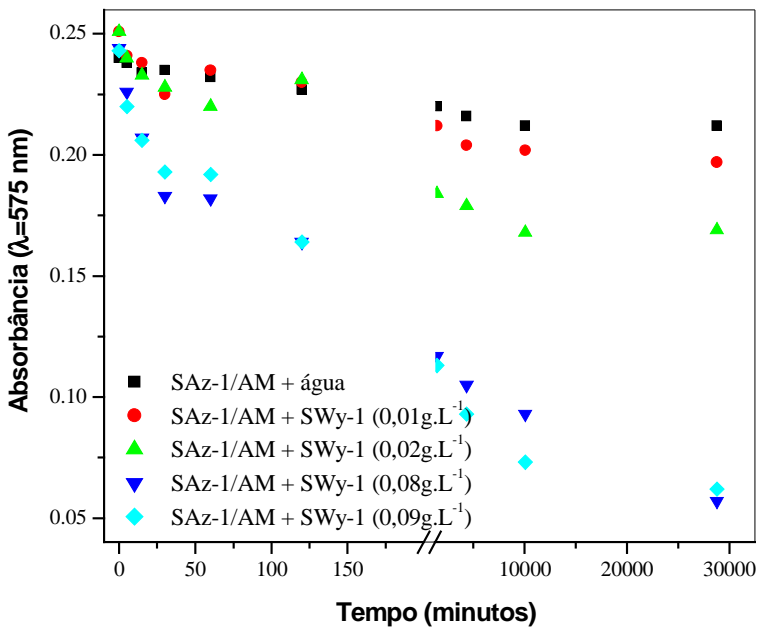

(a)

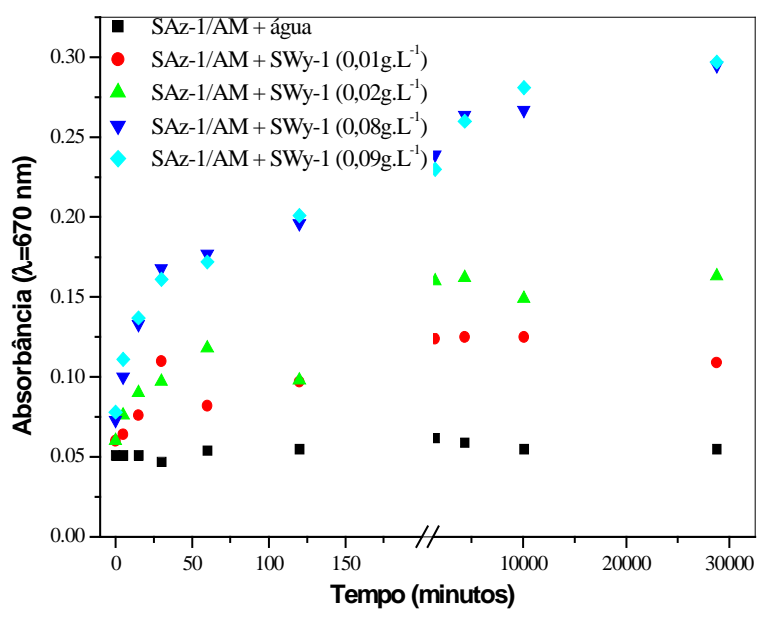

(b) 


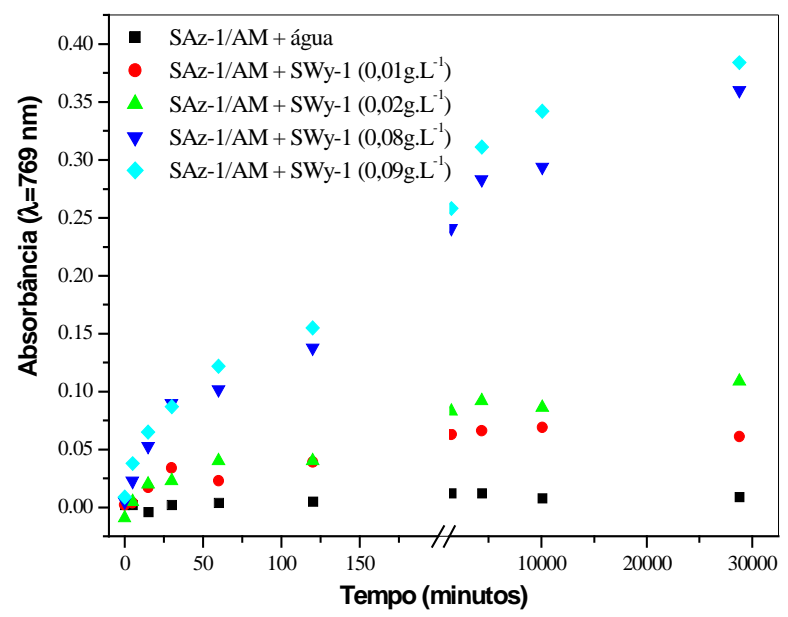

(c)

Figura 33: Variação da intensidade da absorção em função do tempo dos (a) agregados (575nm), (b) monômeros (670nm) e (c) monômeros protonados (769nm), para os sistemas analisados após a adição de SWy-1 em diferentes concentrações.

Como já citado nas discussões para os sistemas anteriormente apresentados, todo o corante adicionado a suspensão está adsorvido nas partículas de argila, ou seja não existe corante em solução. Portanto caso as alterações espectrais fossem atribuídas ao rearranjo intrapartícula das moléculas de corante, ou as interação partícula-partícula descritos na Figura 11, as amostras e a referência teriam o mesmo comportamento espectral e o $\Delta$ absorbância da Figura 32 seria igual a 0,00 .

As alterações espectrais observadas neste estudo podem ser justificadas considerando-se o processo de migração das moléculas de AM entre partículas de argila, processo este representado na Figura 24. As partículas de SWy-1 apresentam menor densidade de carga superficial quando comparada com a SAz-1.

Logo, a adição de partículas de SWy-1 ao sistema SAz-1/AM representa o aumento das superfícies (externas e internas) disponíveis para adsorção do corante. Essa disponibilidade de superfícies aliada a maior estabilidade adquirida pelas moléculas de AM quando são protonadas, favorece a migração das moléculas de corante das partículas de SAz-1 para as partículas de SWy-1. 


\subsection{Estudo do sistema $S W y-1 / A M$ com adição de SAz-1}

As amostras utilizadas nos estudos desse sistema foram preparadas conforme descrito para os sistemas anteriores. O sistema estudado é semelhante ao anterior, com a diferença de que o corante está inicialmente todo adsorvido nas partículas da argila SWy-1, sendo adicionadas ao sistema partículas da argila SAz-1. O estudo foi conduzido da mesma forma que os realizados anteriormente e as variações espectrais determinadas para as diferentes amostras estão mostradas na Figura 34.

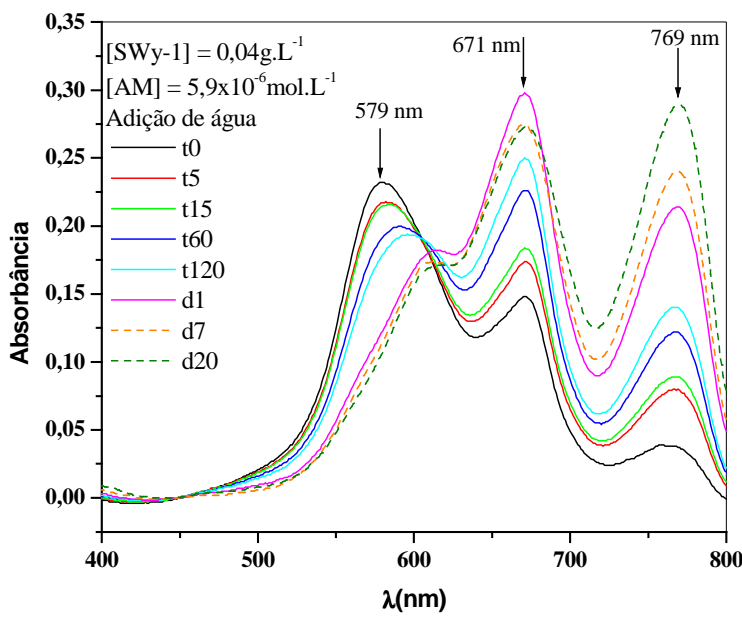

(a)

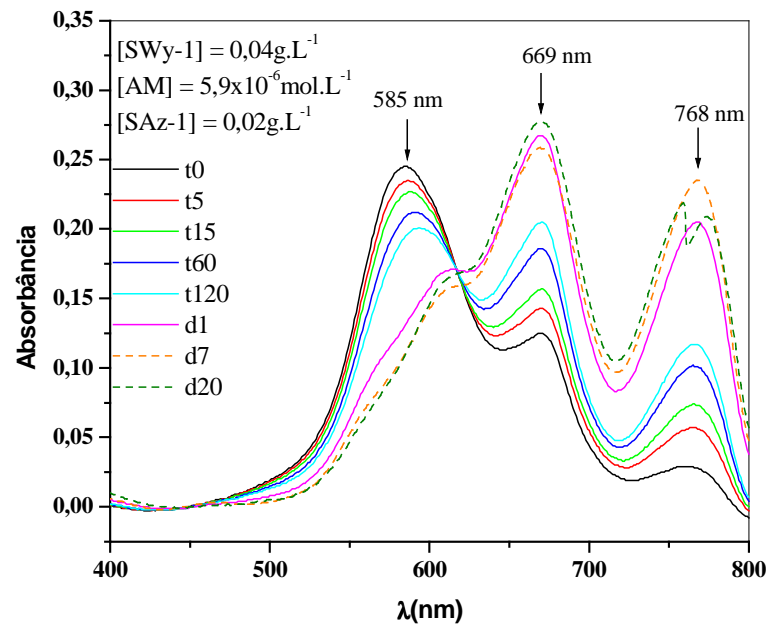

(c)

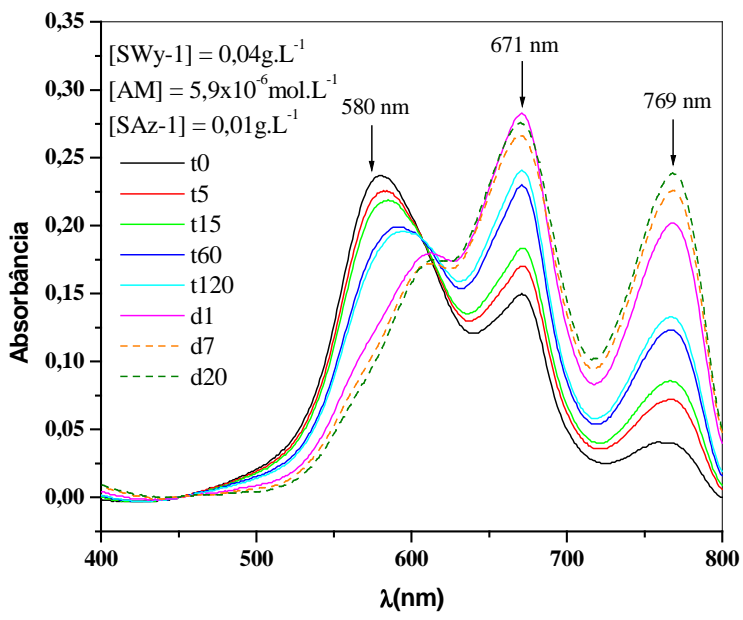

(b)

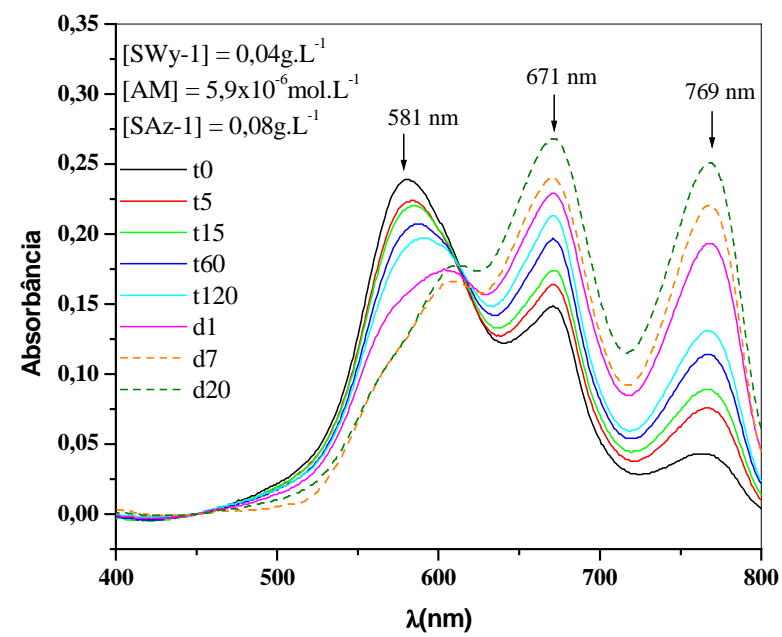

(d) 


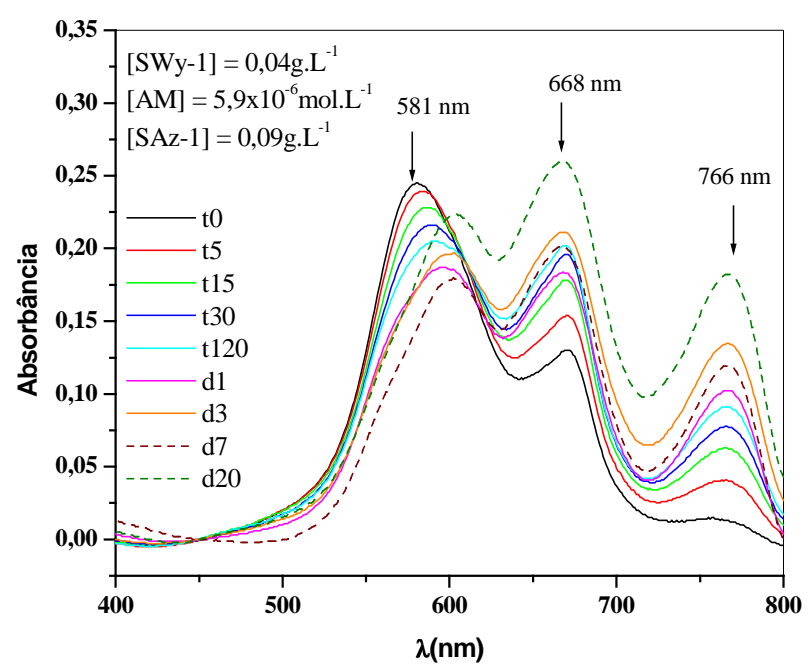

(e)

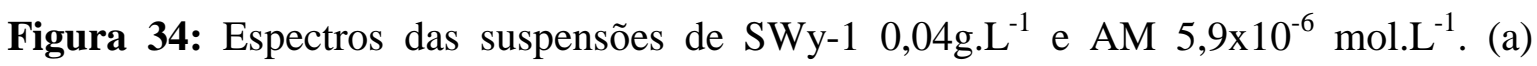
Adição de água. (b) Adição de SAz-1, concentração final de $0,01 \mathrm{~g} \cdot \mathrm{L}^{-1}$. (c) Adição de SAz1, concentração final de $0,02 \mathrm{~g} \cdot \mathrm{L}^{-1}$. (d) Adição de SAz-1, concentração final de $0,08 \mathrm{~g} . \mathrm{L}^{-1}$. (e) Adição de SAz-1, concentração final de $0,09 \mathrm{~g} \cdot \mathrm{L}^{-1}$. O tempo está expresso em minutos (t) e em dias (d).

Na Figura 34(a) tem-se a variação espectral temporal típica para o AM adsorvido em partículas de SWy-1 em suspensão aquosa, já analisada anteriormente. Nos demais espectros mostrados na Figura 34, pode ser visualizado que ocorrem alterações nas variações espectrais, porém menos perceptíveis que no sistema no qual o AM estava inicialmente adsorvido nas partículas de SAz-1, e adicionou-se partículas de SWy-1. Essas alterações podem ser melhor visualizadas nos espectros-diferença, mostrados na Figura 35.

De forma geral, as diferenças aumentam conforme o tempo passa, e também conforme a concentração da argila adicionada aumenta. As variações positivas na absorbância na região correspondente aos agregados do corante indicam que nas amostras existe uma maior quantidade de agregados de moléculas de corante em relação à referência. As variações negativas na região correspondente aos monômeros e monômeros protonados indicam que essas espécies existem em maior quantidade (concentração) na referência em comparação com as amostras. Essas variações positivas e negativas reveladas nos espectros-diferença aumentam, conforme a quantidade de SAz-1 adicionada aumenta. Fica evidente que conforme a quantidade de argila adicionada aumenta, os processos de migração das moléculas de AM adsorvidas nas superfícies externas das 
partículas de SWy-1, para as regiões interlamelares, e a conseqüente protonação, ficam inibidos.

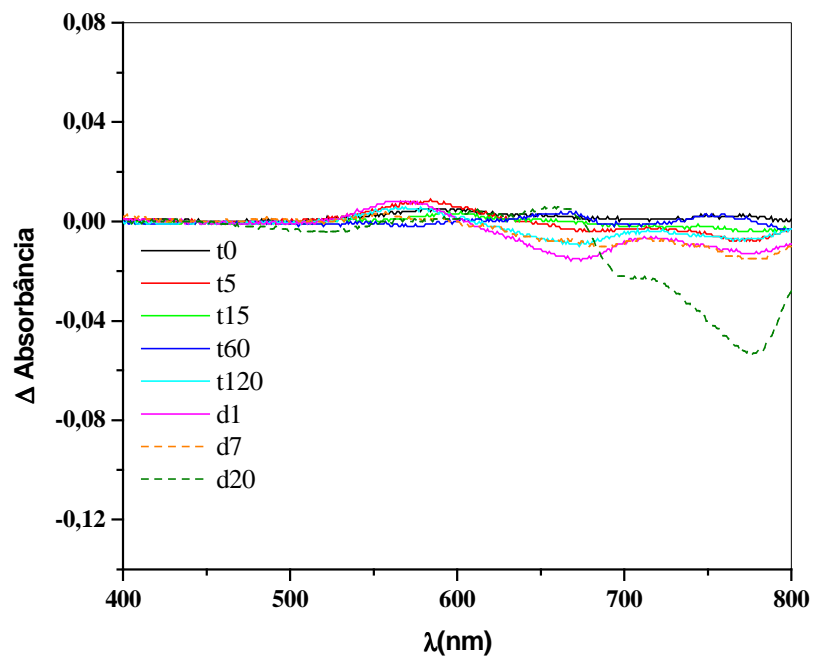

(a)

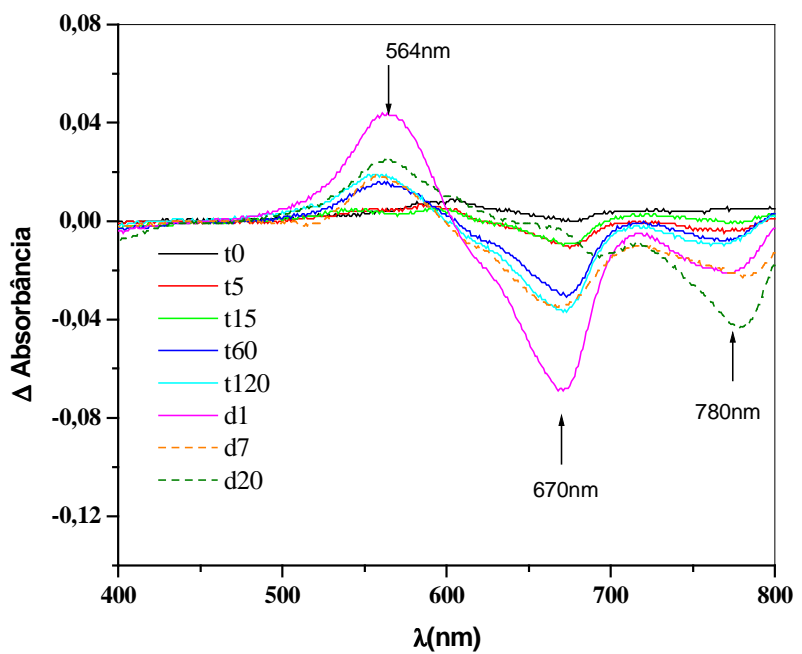

(c)

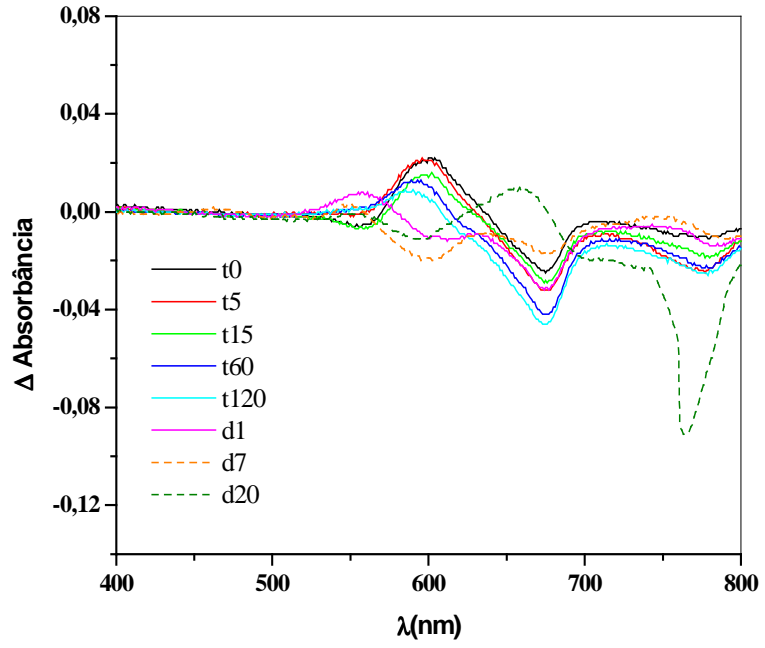

(b)

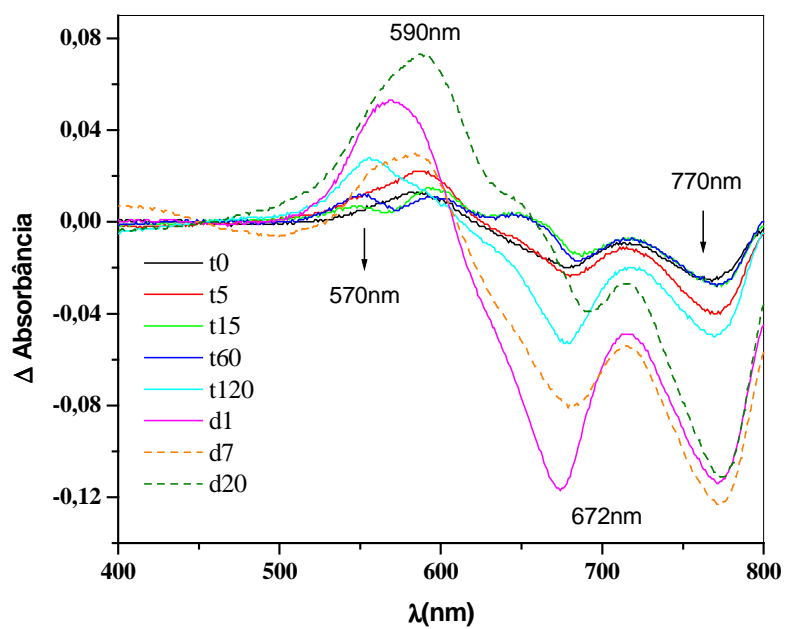

(d)

Figura 35: Espectro-diferença. (a) Espectro da Figura 34(b) menos 34(a). (b) Espectro da Figura 34(c) menos 34(a). (c) Espectro da Figura 34(d) menos 34(a). (d) Espectro da Figura 34(e) menos 34(a).

Fica claro que a adição de partículas de SAz-1 à suspensão contendo AM adsorvido em SWy-1, causa inibição do processos de migração das moléculas do corante adsorvidas nas superfícies externas para as regiões interlamelares, e a sua conseqüente protonação. Este efeito também é observado na Figura 36, a qual mostra a variação da 
absorbância em comprimentos de onda característicos em função do tempo, para as suspensões contendo diferentes quantidades de SAz-1 adicionadas as amostras.

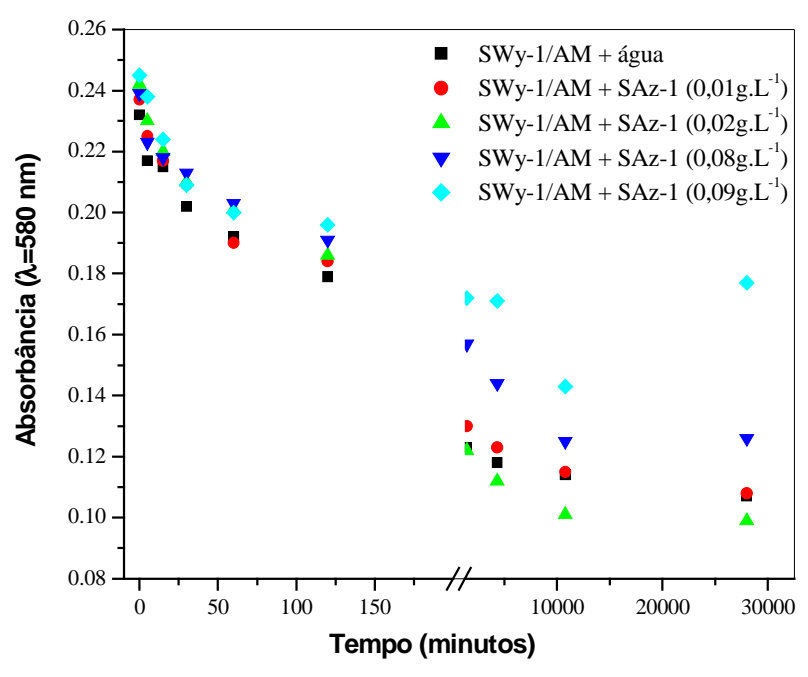

(a)

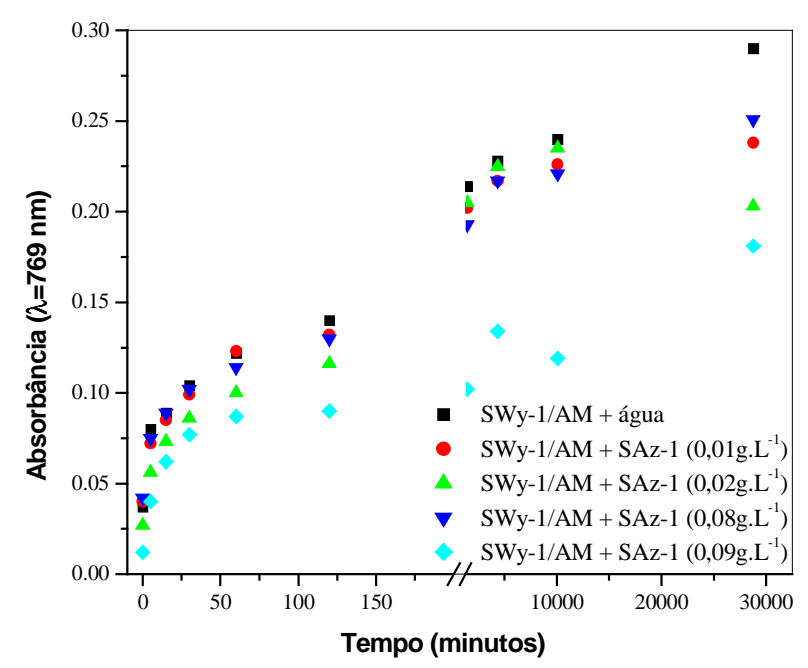

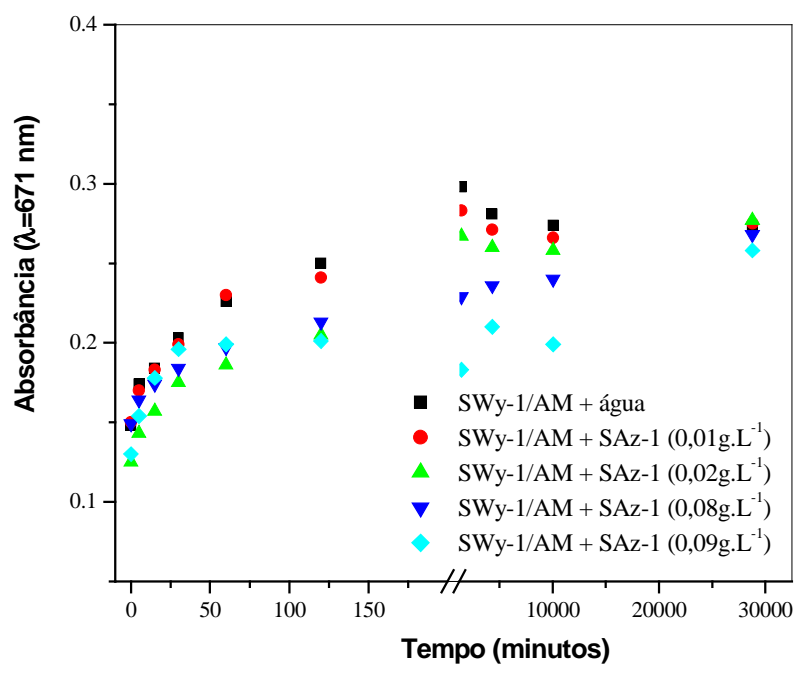

(b)

(c)

Figura 36: Variação da intensidade da absorção em função do tempo dos (a) agregados (580nm), (b) monômeros $(671 \mathrm{~nm})$ e (c) monômeros protonados $(769 \mathrm{~nm})$, para os sistemas analisados após a adição de SAz-1 em diferentes concentrações.

A Figura 37 permite uma melhor comparação das variações espectrais que ocorrem na suspensão SWy-1/AM com adição de SAz-1 e na suspensão SAz-1/AM com adição de SWy-1. 


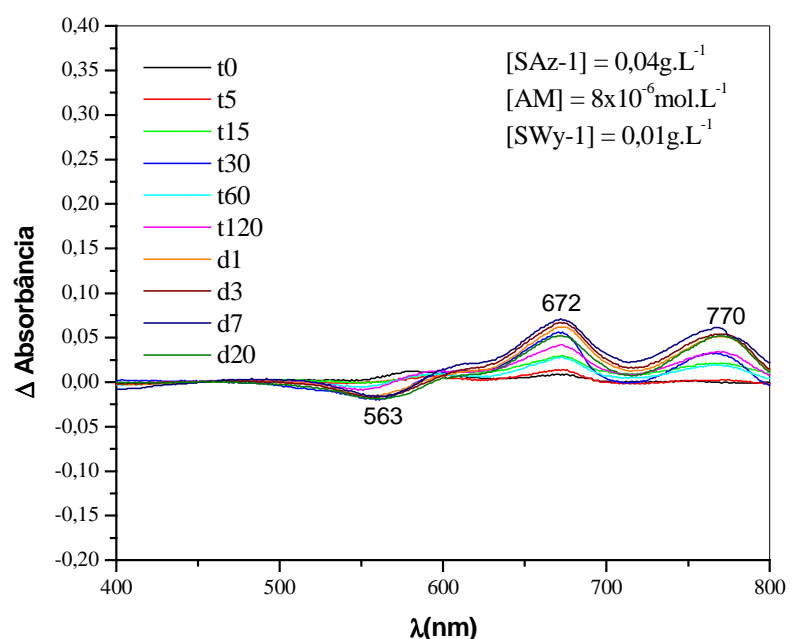

(a)

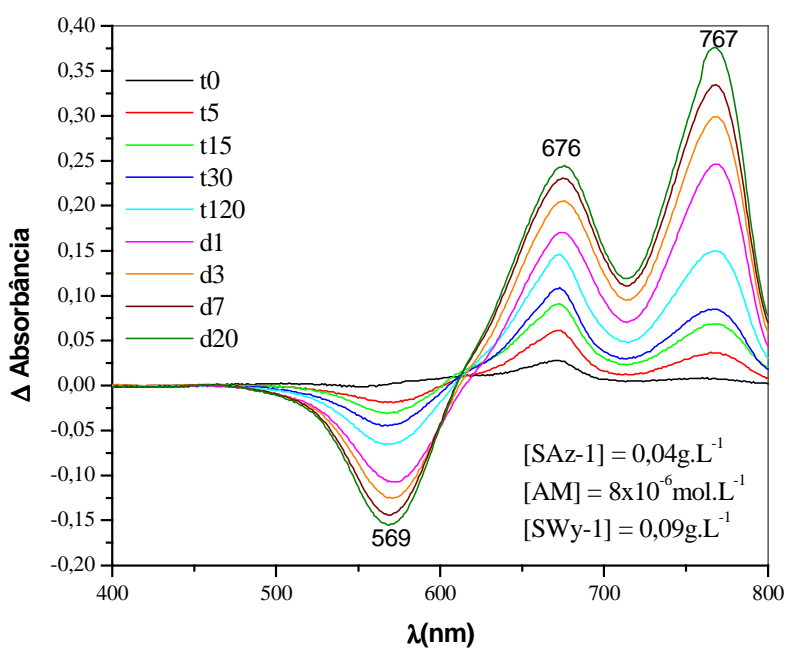

(c)

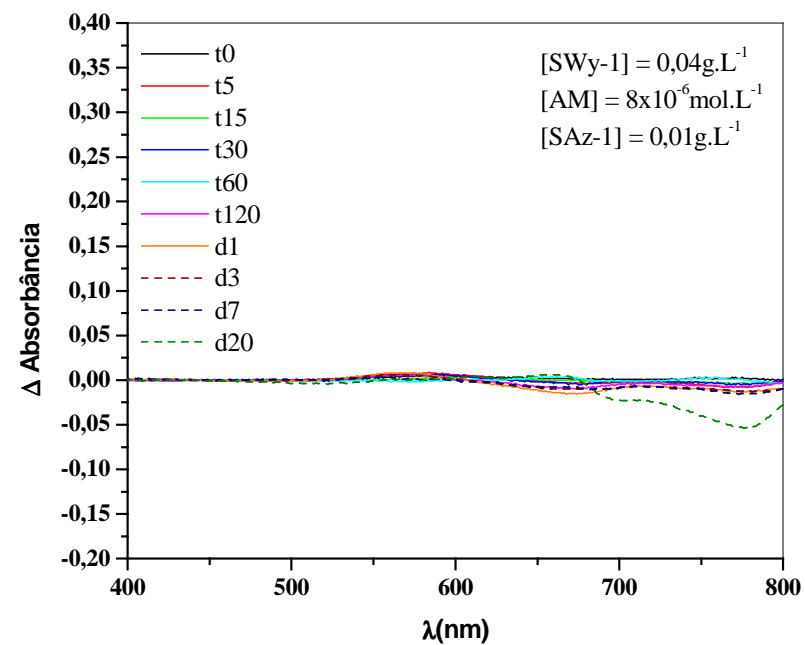

(b)

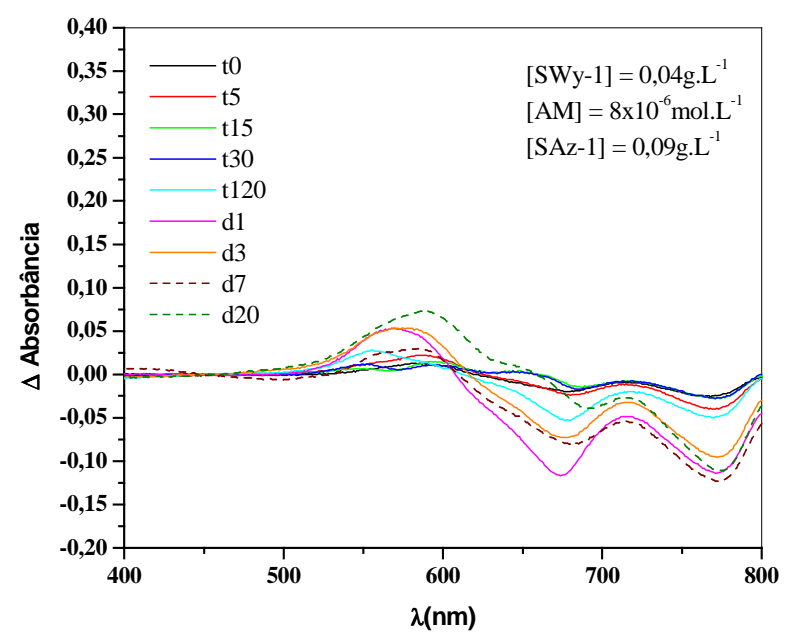

(d)

Figura 37: Espectros - diferença. (a) Espectro -diferença Figura 32(a). (b) Espectro diferença Figura 35(a). (c) Espectro -diferença Figura 32(d). (d) Espectro -diferença Figura 35(d). Plotados em escalas semelhantes para comparação.

Na Figura 37, pode ser feita uma analise comparativa dos sistemas SAz/AM com adição de SWy-1 e do sistema SWy-1/AM com adição de SAz-1. A adição de SWy-1 ao sistema SAz-1/AM causa alterações mais significativas em relação as alterações causadas devido a adição de SAz-1 na suspensão SWy-1/AM. Além disso as variações que ocorrem em um sistema são opostas as variação que ocorrem no outro sistema. Por exemplo, a adição de $S W y-1$ a suspensão SAz-1/AM induz um processo de migração das moléculas de AM adsorvidas nas partículas de SAz-1 para as partículas de SWy-1, na qual 
ocorrem os processos de reorganização (migração intrapartícula). Entretanto a adição de SAz-1 a suspensão SWy-1/AM causou a inibição dos processos intrapartícula, prevalecendo os processos de interação partícula-partícula.

\subsection{Estudo do sistema Lap B/AM com adição de SWy-1}

As amostras utilizadas no estudo desse sistema foram preparadas como descrito para as amostras anteriores. Neste sistema as moléculas de corante encontram-se totalmente adsorvidas nas partículas de Laponita - B, sendo adicionadas partículas de SWy-1 ao sistema. As variações espectrais temporais deste sistema são mostradas na Figura 38.

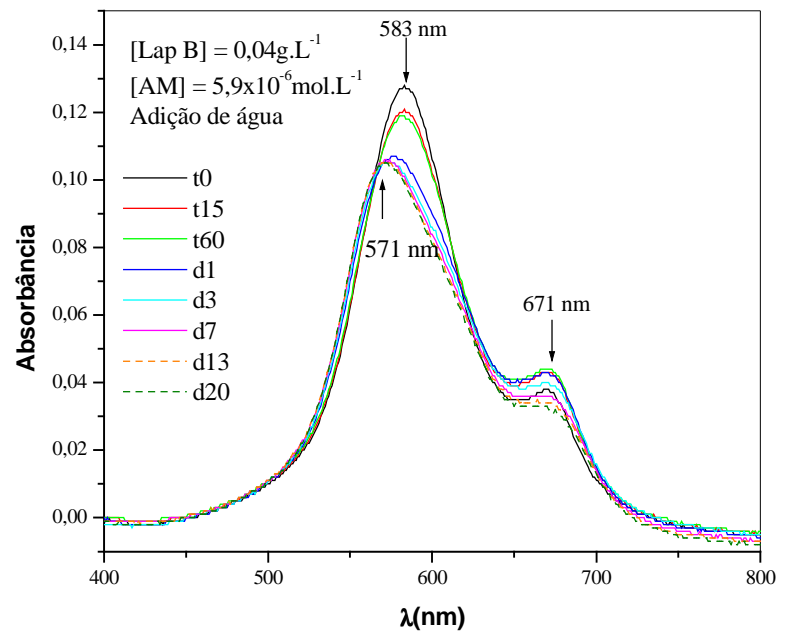

(a)

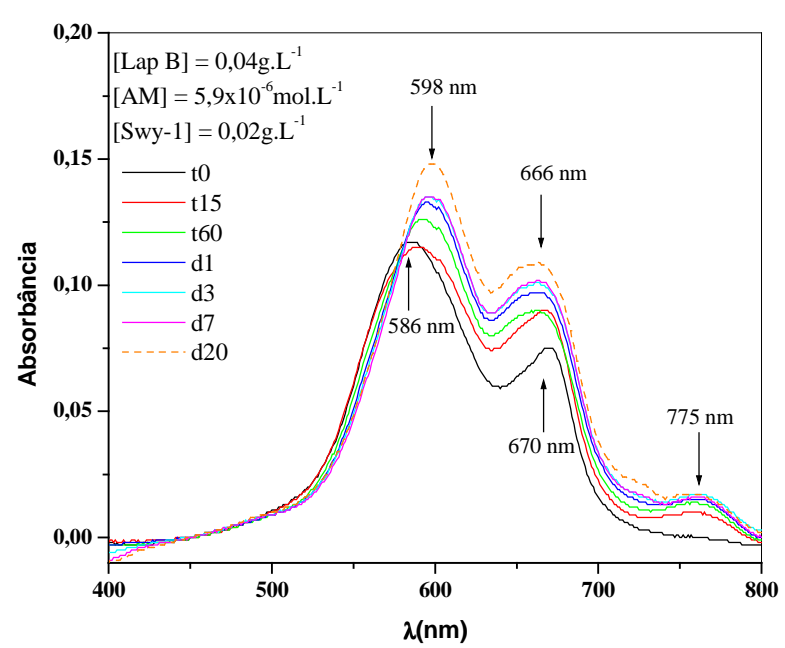

(c)

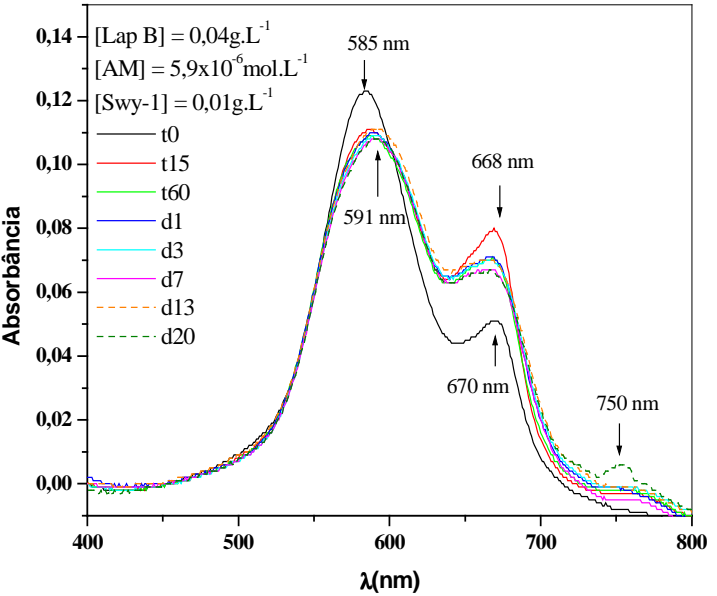

(b)

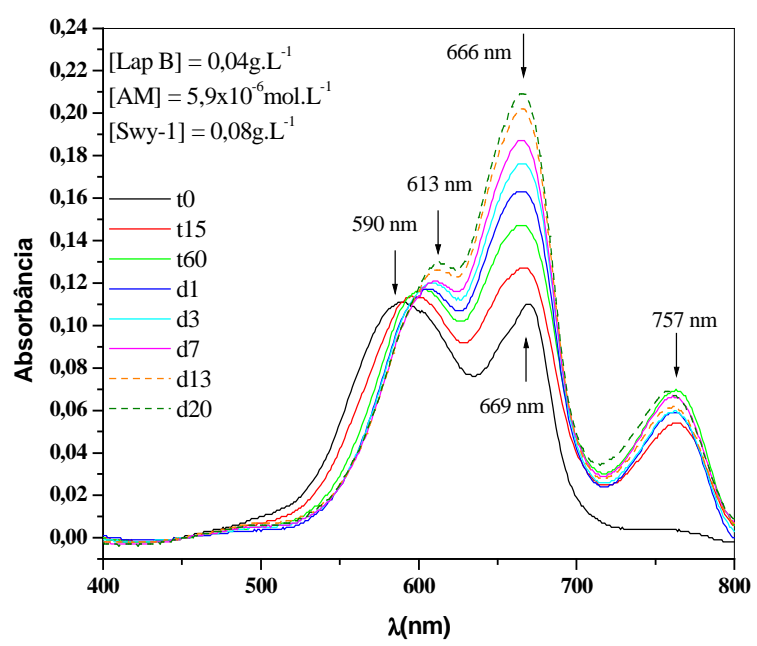

(d) 


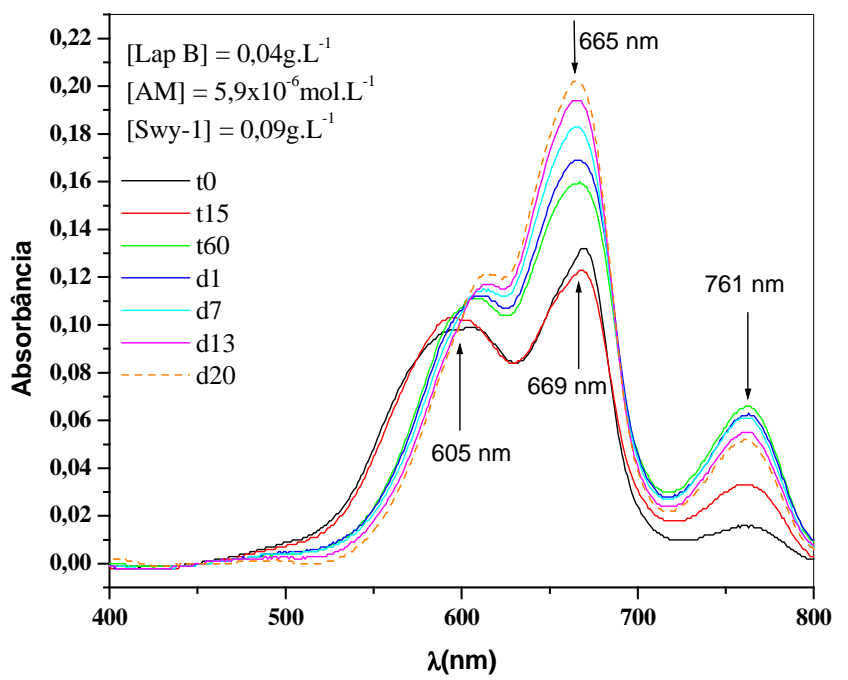

(e)

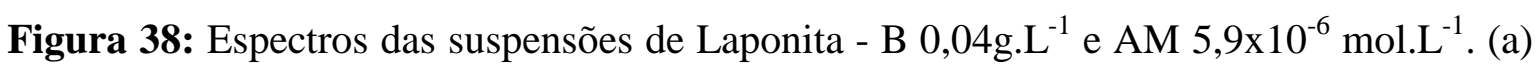
Adição de água. (b) Adição de SWy-1, concentração final de $0,01 \mathrm{~g} \cdot \mathrm{L}^{-1}$. (c) Adição de SWy-1, concentração final de 0,02g. $\mathrm{L}^{-1}$. (d) Adição de SWy-1, concentração final de 0,08g. $\mathrm{L}^{-1}$. (e) Adição de SWy-1, concentração final de $0,09 \mathrm{~g} \cdot \mathrm{L}^{-1}$. Os tempos $\mathrm{t}$ estão expressos em minutos e $\mathrm{d}$ em dias.

Os espectros representados na Figura 38 (a) são referentes à suspensão de AM adsorvido em Laponita - B. Nota-se a presença de uma banda intensa em 582nm referente aos agregados de AM e outra banda de menor intensidade em 670nm que pode ser atribuída às moléculas de AM adsorvidas na superfície das partículas de argila na forma monomérica. Com o tempo a intensidade da banda em 582nm diminui e sofre um deslocamento para comprimentos de onda menores, característica típica de Laponita - B. Este deslocamento ocorre como conseqüência das espécies formadas devido aos processos de interação partícula - partícula.

Nas Figuras de 38(b) a 38(e), observa-se os espectros das suspensões nas quais se adicionou diferentes quantidades de SWy-1. Pode se observar que a adição de SWy-1 ao sistema causou significativas alterações espectrais no sistema que contem AM adsorvido em partículas de Laponita - B. A banda atribuída aos monômeros de AM aumenta consideravelmente, ao mesmo tempo, se observa o surgimento e aumento da intensidade da banda referente aos monômeros protonados, em aproximadamente, $765 \mathrm{~nm}$.

De estudos anteriores sabe-se que as suspensões de Laponita - B contendo AM se caracterizam pela ausência da banda dos monômeros protonados (765nm). Porém, com a adição de SWy-1 ao sistema, nota-se a diminuição das intensidades das bandas 
atribuídas aos agregados, aumento da intensidade das bandas referentes ao monômeros e o surgimento da banda referentes aos monômeros protonados.

Verifica-se também que quanto maior a quantidade de SWy-1 adicionada ao sistema maior a intensidade das alterações espectrais. Tais alterações podem ser visualizadas nos espectros - diferença da Figura 39.

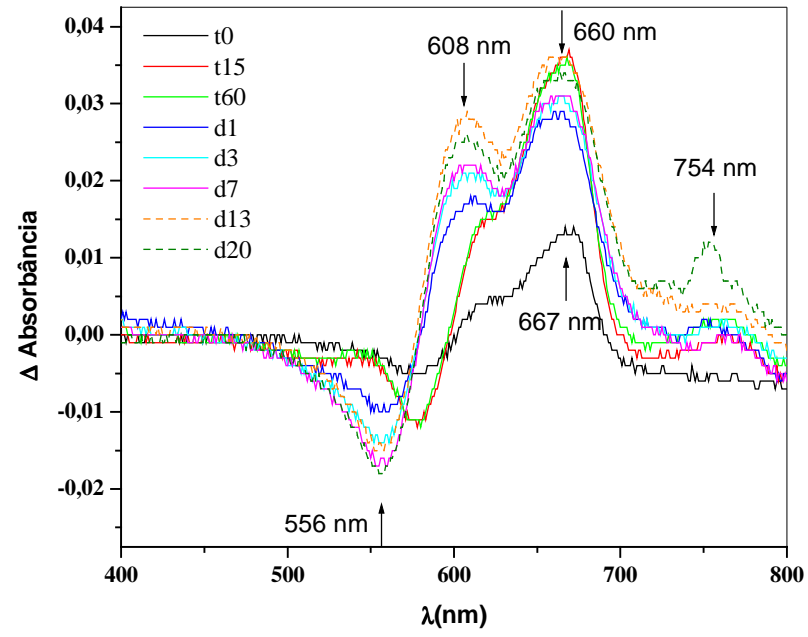

(a)

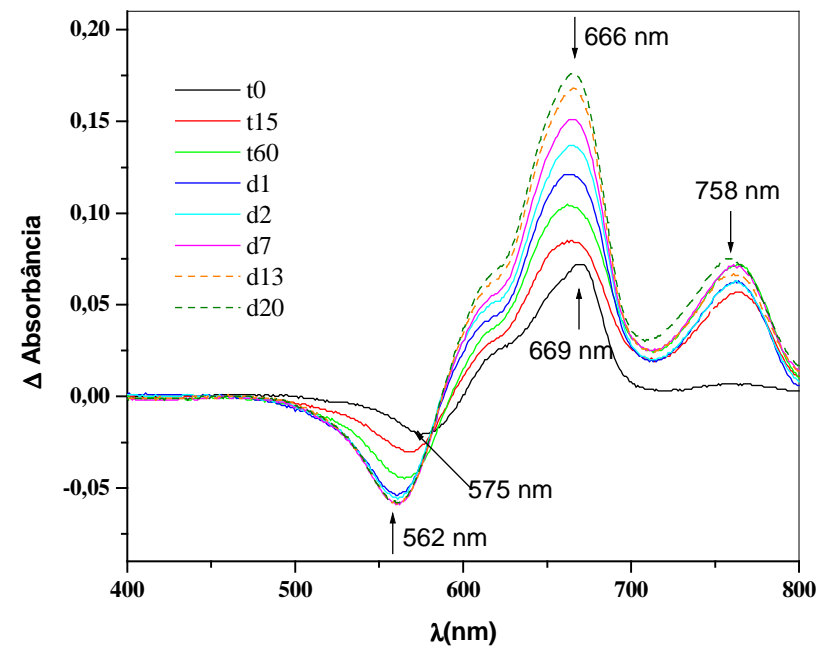

(c)

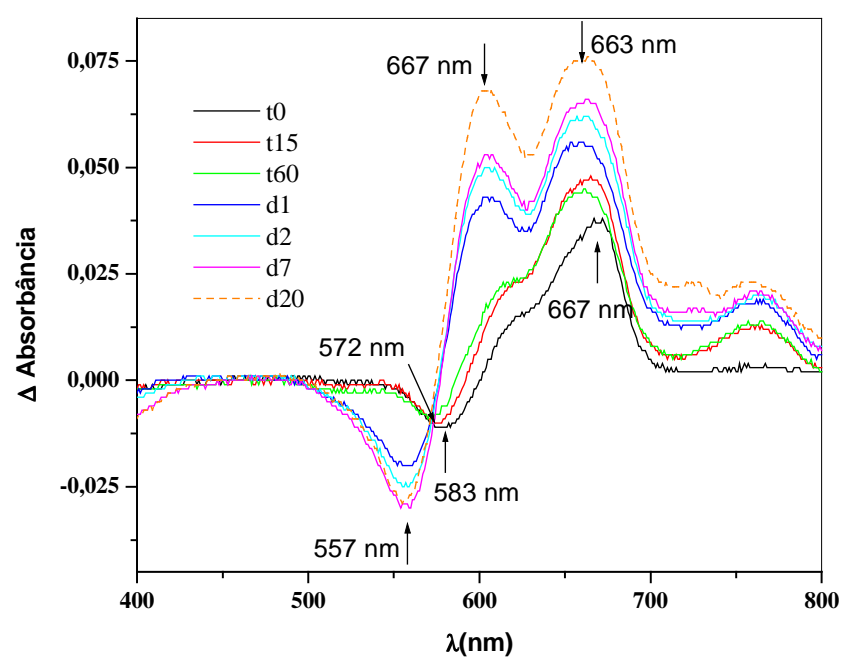

(b)

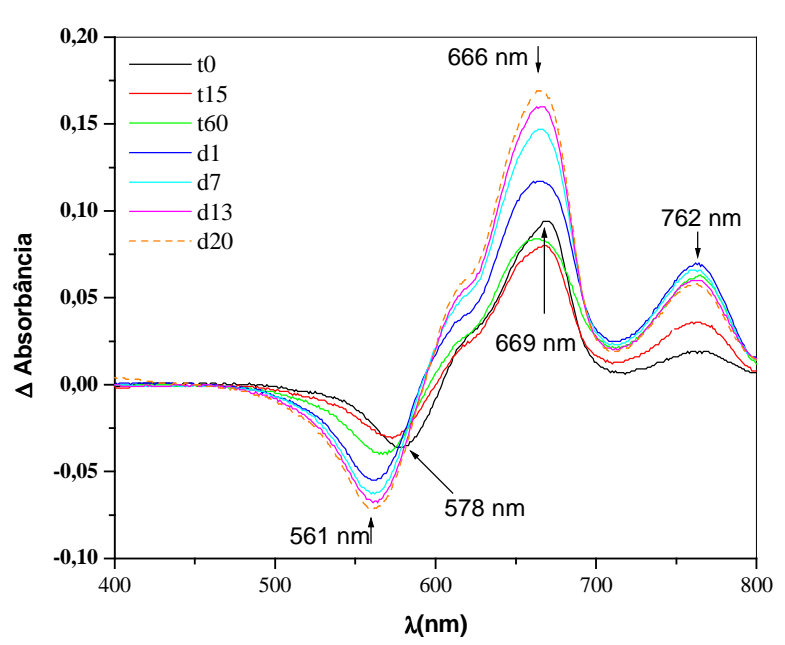

(d)

Figura 39: Espectro-diferença. (a) Espectro da Figura 38(b) menos 38(a). (b) Espectro da Figura 38(c) menos 38(a). (c) Espectro da Figura 38(d) menos 38(a ). (d) Espectro da Figura 38(e) menos 38(a).

Na Figura 39, verifica-se claramente que a adição de SWy-1 ao sistema causou significativas alterações espectrais. Na região dos agregados houve uma variação negativa, indicando que a referência apresenta maior quantidade de agregados que as 
amostras. Entretanto, na região dos monômeros e monômeros protonados houve uma variação positiva, isto significa que na amostra há maior quantidade de monômeros e monômeros protonados quando compara-se com a referência.

Outra informação importante que obtemos da analise dos espectros diferença, se refere ao fato das alterações ocorrerem significativamente até 60 minutos (t60), acima deste intervalo de tempo, as variações não são significativas, em especial na região dos monômeros protonados.

Na Figura 40 são apresentados os gráficos que mostram a variação das absorbâncias das espécies de AM agregadas, monômeros e monômeros protonados em função do tempo, para as diferentes amostras.

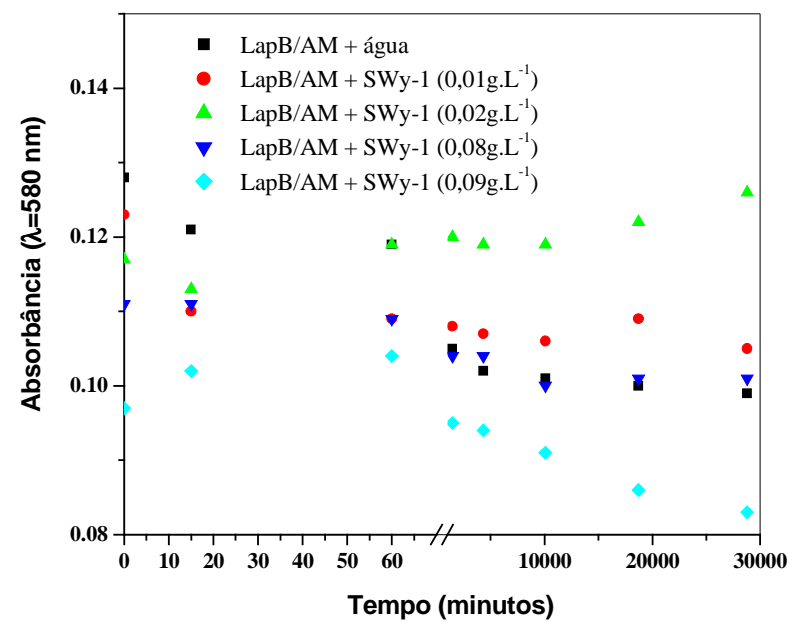

(a)

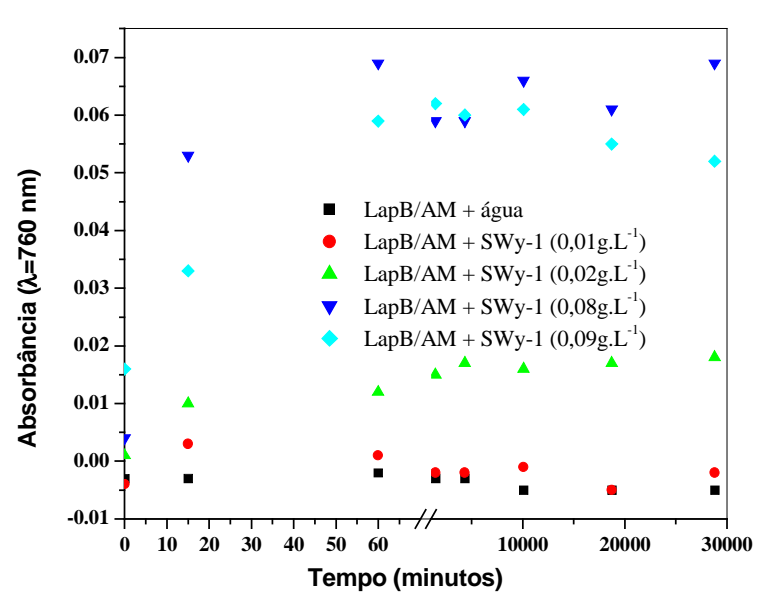

(c)

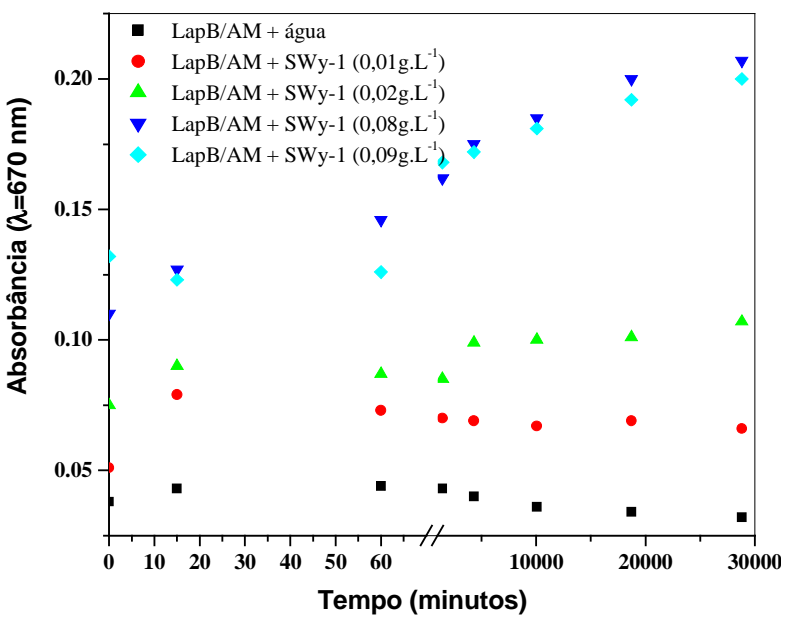

(b)

Figura 40: Variação em função do tempo da intensidade da banda de (a) agregados (580nm), (b) monômeros $(670 \mathrm{~nm})$ e (c) monômeros protonados $(760 \mathrm{~nm})$, para os sistemas nos quais se adicionou SWy-1 obtendo-se diferentes concentrações. 
Na Figura 40(a), observa-se que quanto maior a quantidade de SWy-1 adicionada ao sistema maior é a redução da intensidade da absorbância em 580nm, ou seja, a adição de SWy-1 ao sistema promove a desagregação das moléculas de corante. As bandas em $670 \mathrm{~nm}$ e $760 \mathrm{~nm}$ tornam-se mais intensas, na medida em que a quantidade de SWy-1 adicionada ao sistema aumenta, isto é observado para tempos iguais a 60 minutos. Após 60 minutos, as alterações são menos significativas.

Com base nos resultados obtidos pode-se determinar que para intervalos de tempo até 60 minutos, o processo predominante neste sistema é a migração das moléculas de AM adsorvidas nas partículas de Laponita - B para as partículas de SWy-1. Em tempos superiores a 60 minutos predomina o processo de interação partícula - partícula. Esses processos são representados na Figura 41.

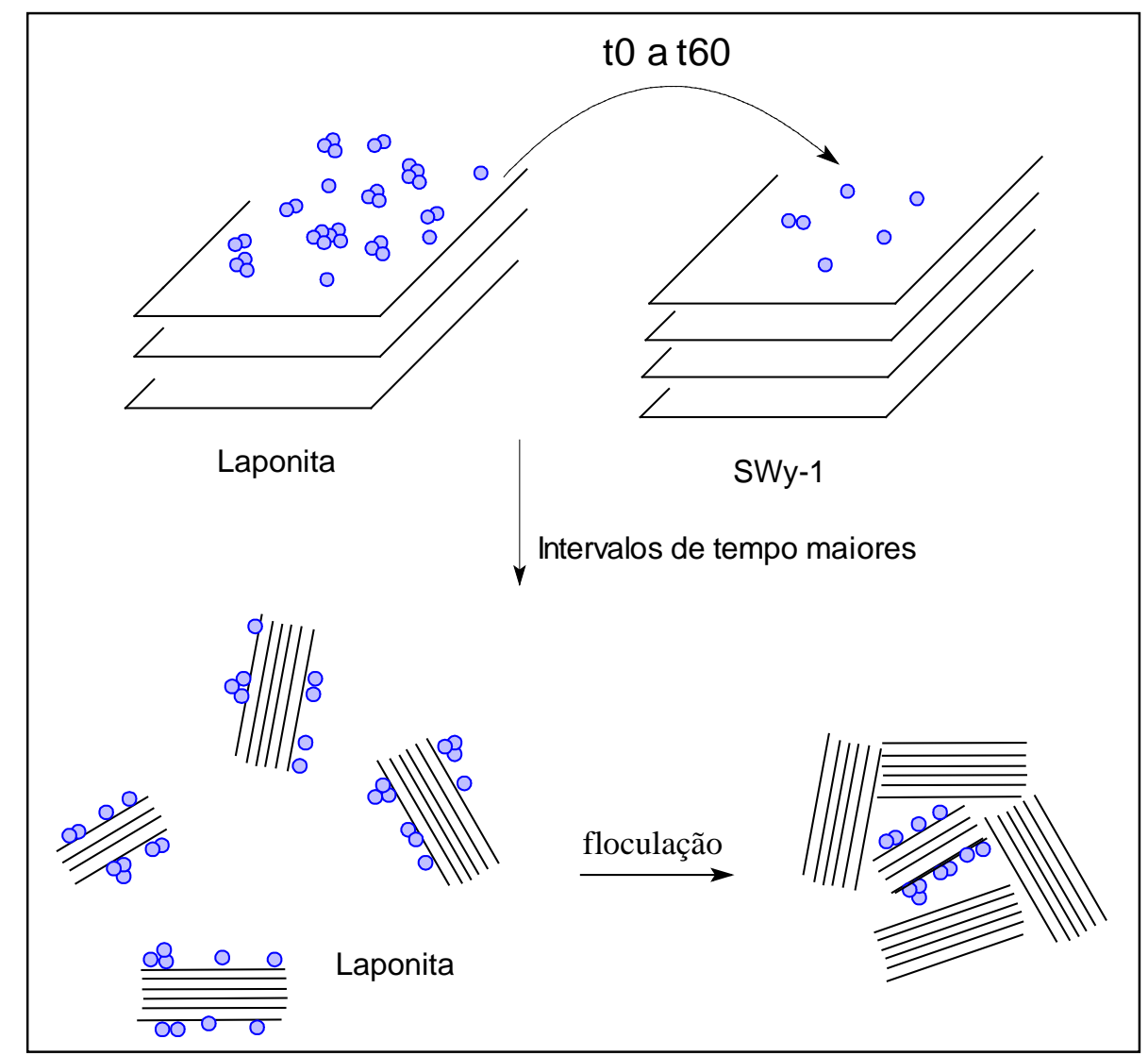

Figura 41: Esquema representado os processos que ocorrem no sistema laponita - B/AM com adição de SWy-1. 


\subsection{Estudo do sistema SW/AM com adição de Lap B}

O preparo das amostras utilizadas no estudo do sistema SWy-1/AM + Lap-

B, foi realizado da mesma forma que para os sistemas anteriores. As variações espectrais temporais deste sistema são mostradas na Figura 42.

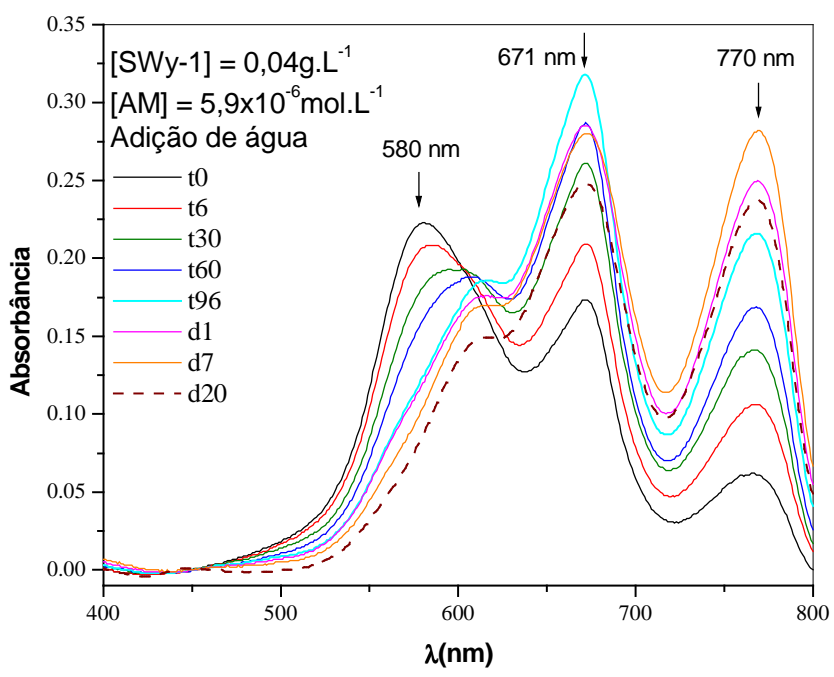

(a)

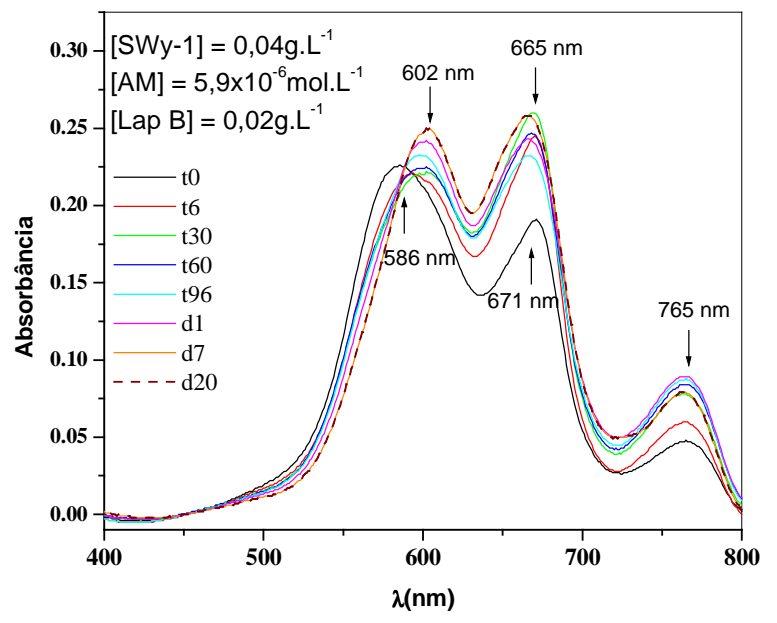

(c)

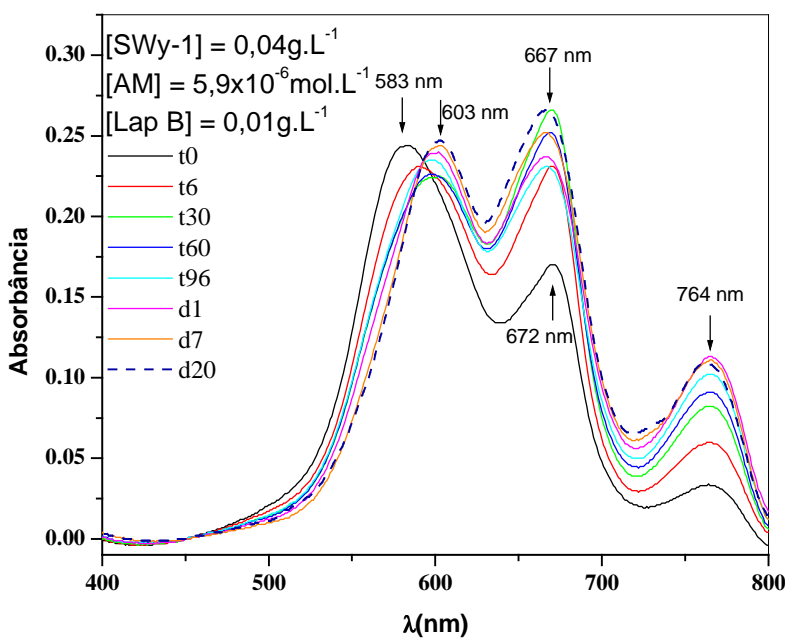

(b)

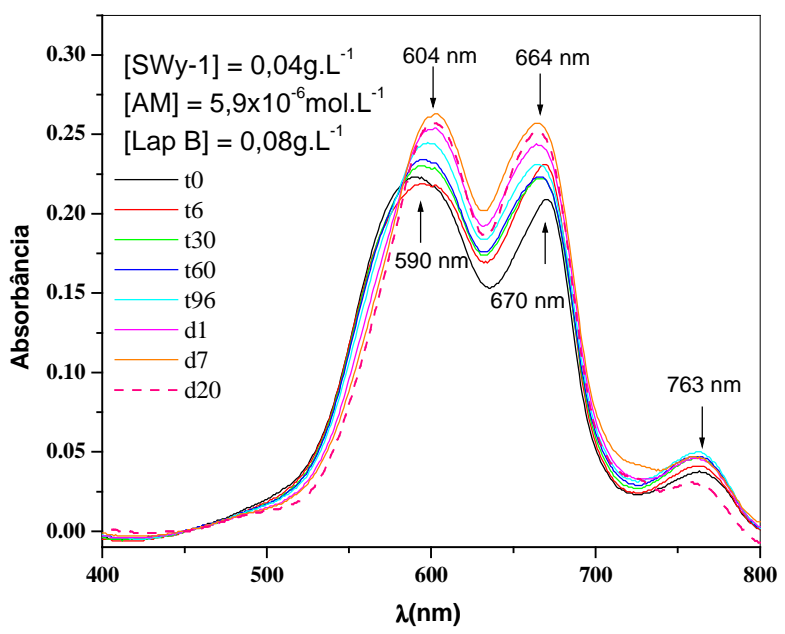

(d) 


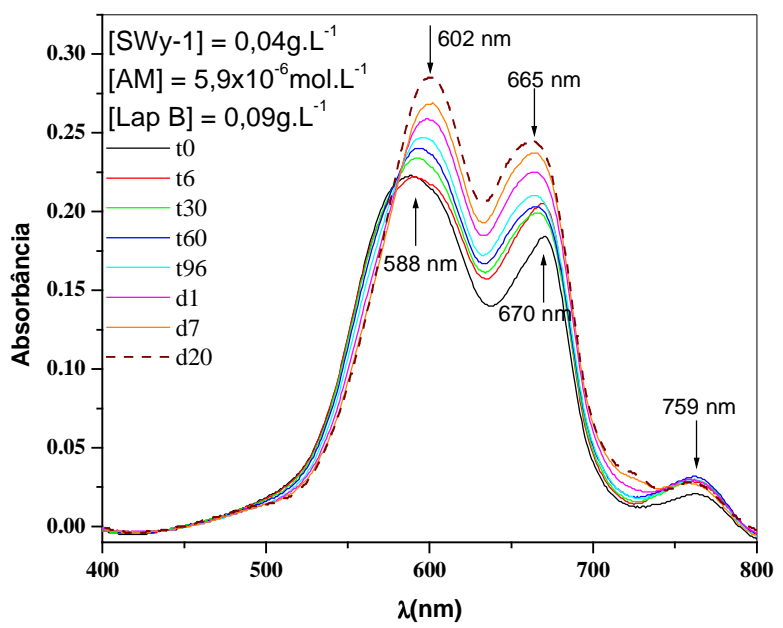

(e)

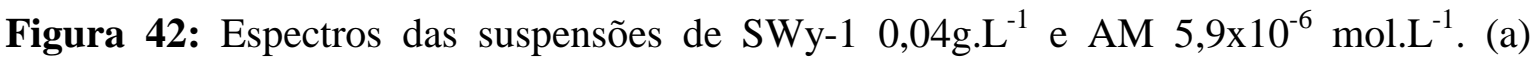
Adição de água. (b) Adição de Laponita - B, concentração final de 0,01g.L $\mathrm{L}^{-1}$. (c) Adição de Laponita - B, concentração final de $0,02 \mathrm{~g} \cdot \mathrm{L}^{-1}$. (d) Adição de Laponita - B , concentração final de $0,08 \mathrm{~g} \cdot \mathrm{L}^{-1}$. (e) Adição de Laponita - B, concentração final de $0,09 \mathrm{~g} \cdot \mathrm{L}^{-1}$.Os tempos $\mathrm{t}$ estão expresso em minutos e d em dias.

Os espectros da Figura 42(a) apresentam características típicas de AM adsorvido em partículas de SWy-1, sendo possível identificar os processos que ocorrem nessa suspensão.

Nas Figuras 42(b) a 42(e), tem-se os espectros referentes às suspensões nas quais se adicionou diferentes quantidades de Laponita - B, obtendo-se concentrações que variaram de $0,01 \mathrm{~g} . \mathrm{L}^{-1}$ à $0,09 \mathrm{~g} . \mathrm{L}^{-1}$, nas cubetas,. Quando comparamos esses espectros com o da Figura 42 (a), nota-se claramente que as características espectrofotométricas das suspensões são distintas. Nos espectros apresentados na Figura 42(b), a intensidade da banda referente aos monômeros protonados de AM não apresenta a mesma evolução que a observada na Figura 42(a). E observa-se que na medida em que a quantidade de SWy-1 adicionada ao sistema aumenta, essas alterações tornam-se mais intensas. O mesmo comportamento é observado para a banda referente aos monômeros de AM. Portanto a adição de Laponita - B ao sistema inibiu os processos de migração que ocorrem nas partículas de SWy-1.

Outra observação importante se refere às absorbâncias na região dos agregados ( 570-580nm). Percebe-se que a intensidade dessas absorbâncias é maior quando comparadas com a referência e há um deslocamento da banda dos agregados para 
comprimentos de onda maiores, sendo este deslocamento típico dos processos que ocorrem nas partículas de Laponita - B.

Essas diferenças podem ser mais bem observadas através do gráfico que mostra o espectro diferença representado na Figura 43.

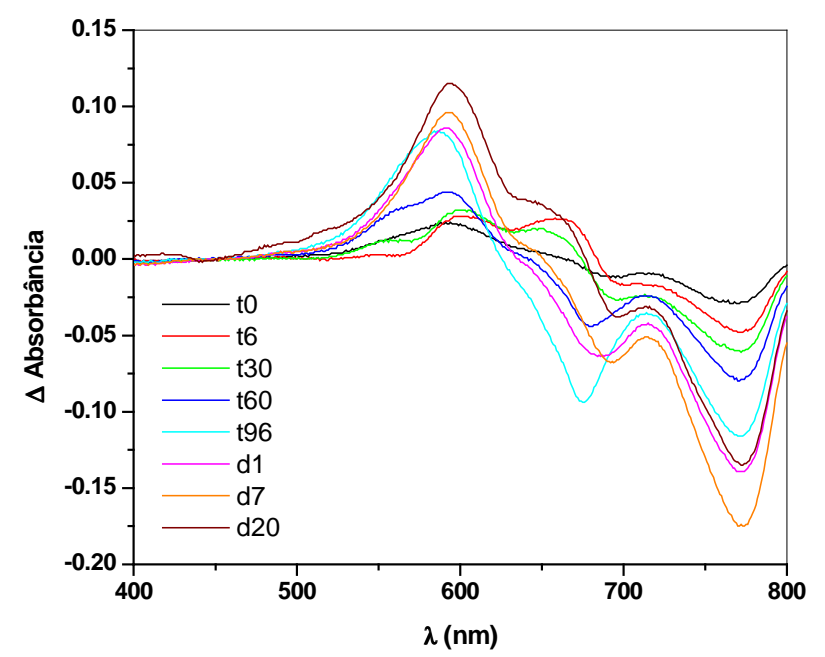

(a)

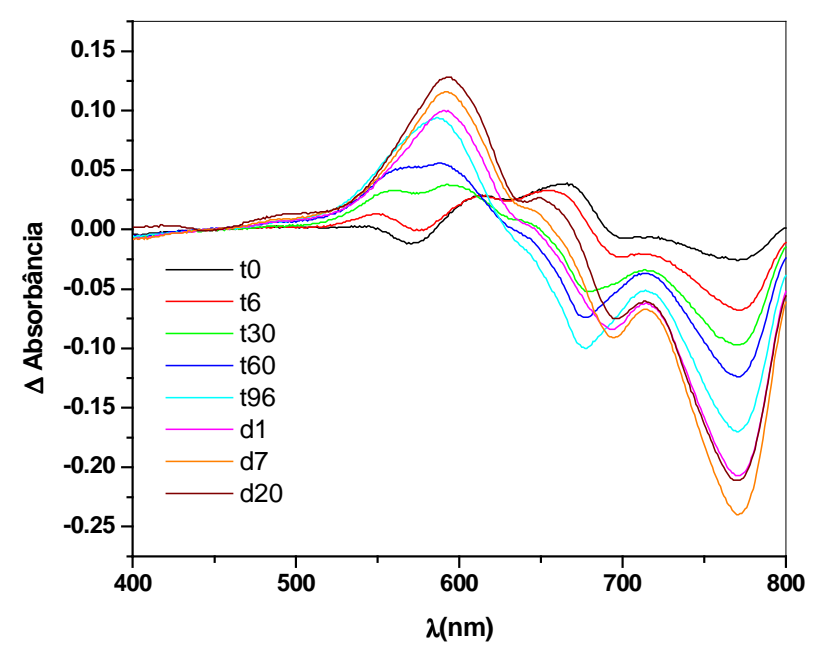

(c)

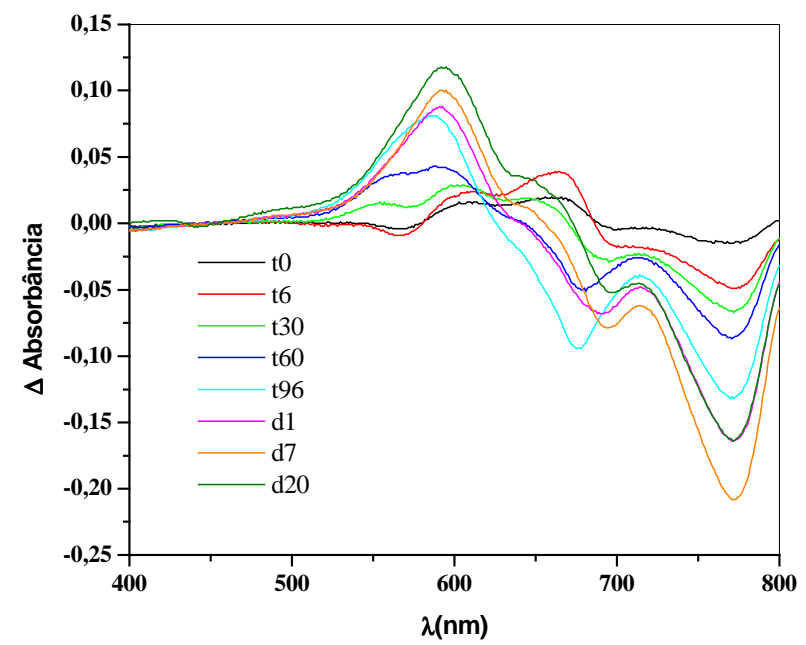

(b)

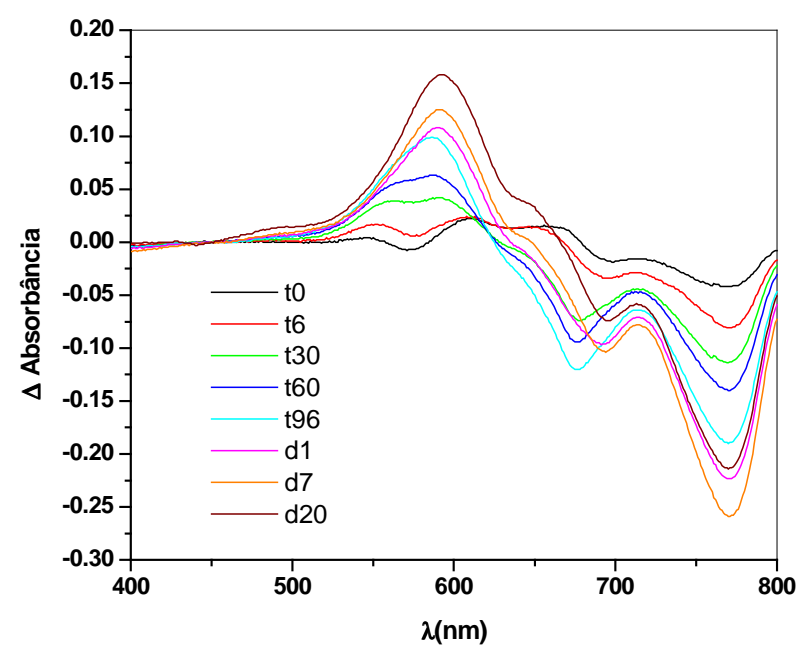

(d)

Figura 43: Espectro-diferença. (a) Espectro da Figura 42(b) menos 42(a). (b) Espectro da Figura 42(c) menos 42(a). (c) Espectro da Figura 42(d) menos 42(a). (d) Espectro da Figura 42(e) menos 42(a).

Na Figura 43 percebe-se claramente que a adição de Laponita - B ao sistema provou a inibição dos processos de migração que ocorrem nos tactóides de SWy-1. Houve uma variação positiva na região dos agregados, indicando que as amostras apresentam maior quantidade de agregados que a referência. Na região dos monômeros e 
monômeros protonados houve uma variação negativa, indicando que a referência apresenta maior quantidade dessas espécies que a amostra.

Na Figura 44, pode-se observar os gráficos que mostram a variação das absorbâncias das espécies de AM agregadas, monômeros e monômeros protonados em função do tempo, para os diferentes sistemas. Na Figura 44(a), observa-se que a adição de Laponita - B ao sistema inibe o processo de desagregação das moléculas de AM .As bandas em $671 \mathrm{~nm}$ e $770 \mathrm{~nm}$ tornam-se menos intensas, na medida em que a quantidade de Laponita - B adicionada ao sistema aumenta. Essas observações indicam que deve ocorrer um processo de interação partícula - partícula (entre partículas de SWy-1 com AM adsorvido e partículas de LapB) muito intenso e rápido, o qual inibe o processo que envolve adsorção das moléculas de AM na região interlamelar que ocorre nas partículas de SWy-1.

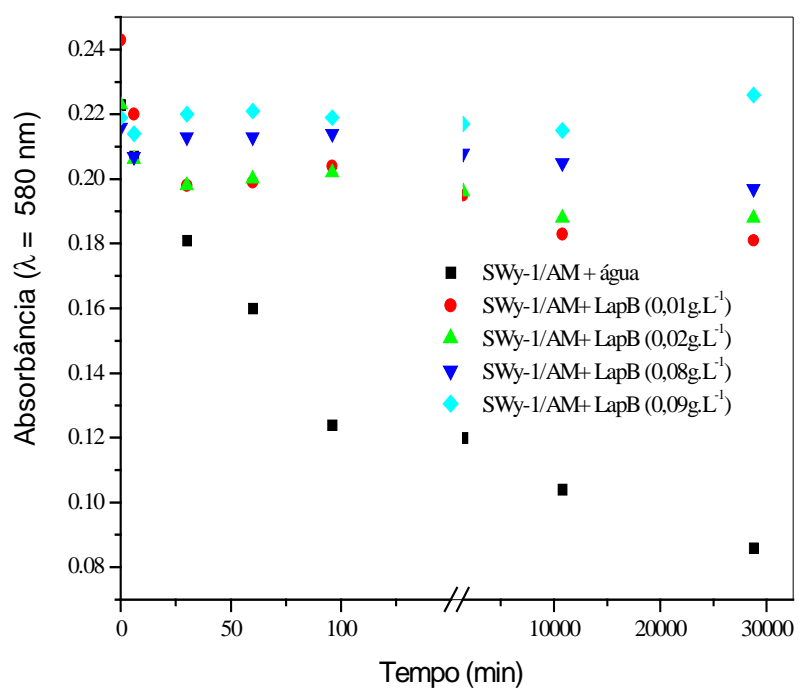

(a)

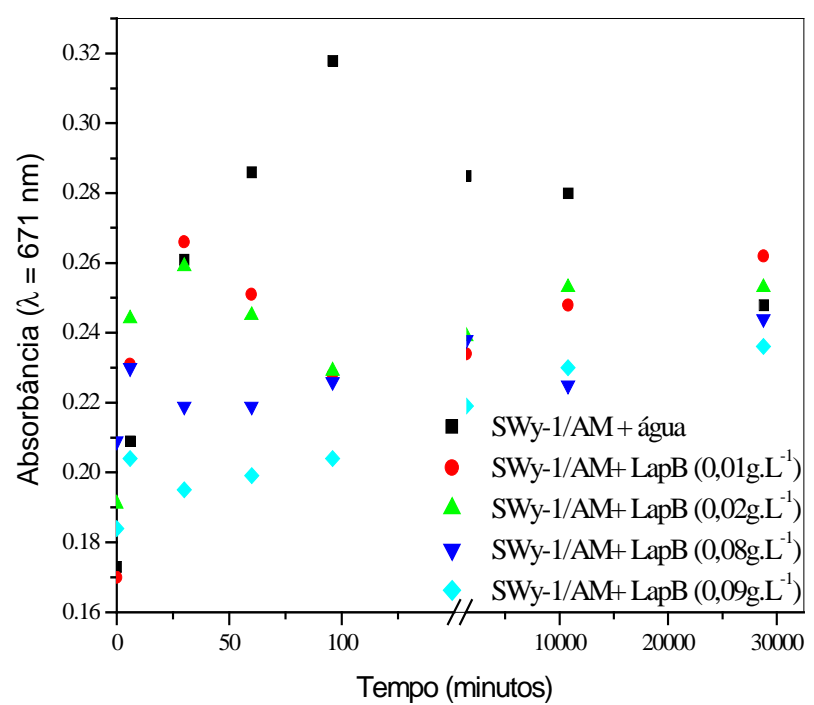

(b) 


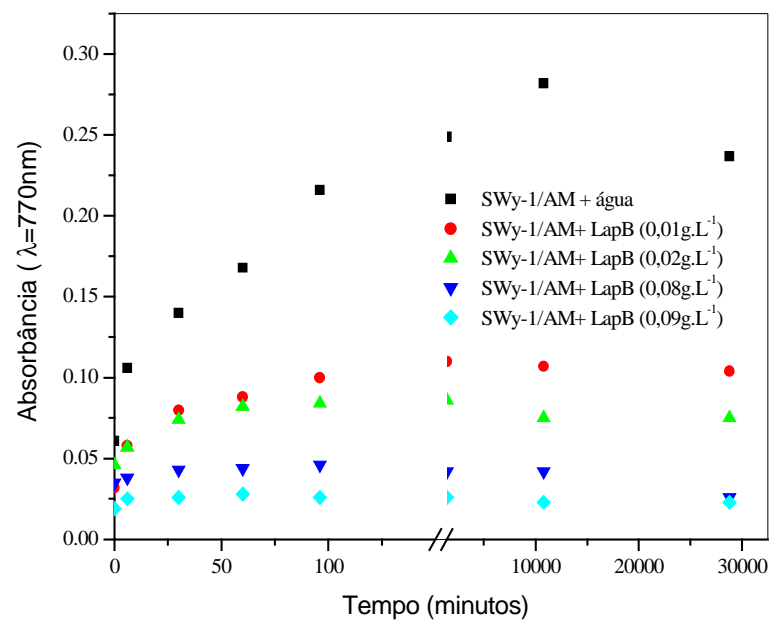

(c)

Figura 44: Variação em função do tempo da intensidade da banda de (a) agregados (580nm), (b) monômeros (671nm) e (c) monômeros protonados (770nm), para os sistemas nos quais se adicionou Laponita - B obtendo-se diferentes concentrações.

As alterações espectrais observadas na Figura 42, são compatíveis com as detectadas quando se adiciona sal a uma suspensão de SWy-1. A adição de sal à suspensão promove o aumento da força iônica do meio, ocasionando a compressão da dupla camada, intensificando os processos de interação partícula-partícula. $\mathrm{O}$ espectro do azul de metileno nessas condições apresenta bandas que são atribuídas às espécies de corante aprisionadas nos espaços internos criados pela associação das partículas de argila.

As alterações espectrais detectadas para este sistema são conseqüência, principalmente, dos processos de interação partícula - partícula.

\subsection{Estudo do sistema SAz-1/AM com adição de Lap-B}

As amostras utilizadas no estudo deste sistema foram preparadas como descrito para os sistemas já estudados. Adiciona-se o corante AM à suspensão de SAz-1, sendo que este é instantaneamente e totalmente adsorvido. Posteriormente adiciona-se partículas de Laponita B ao sistema, variando-se a concentração da argila adicionada de 0,00g. $\mathrm{L}^{-1}$ (adição de água) à $0,09 \mathrm{~g} \cdot \mathrm{L}^{-1}$. Os espectros determinados em função do tempo para as diferentes amostras são apresentados na Figura 45. 


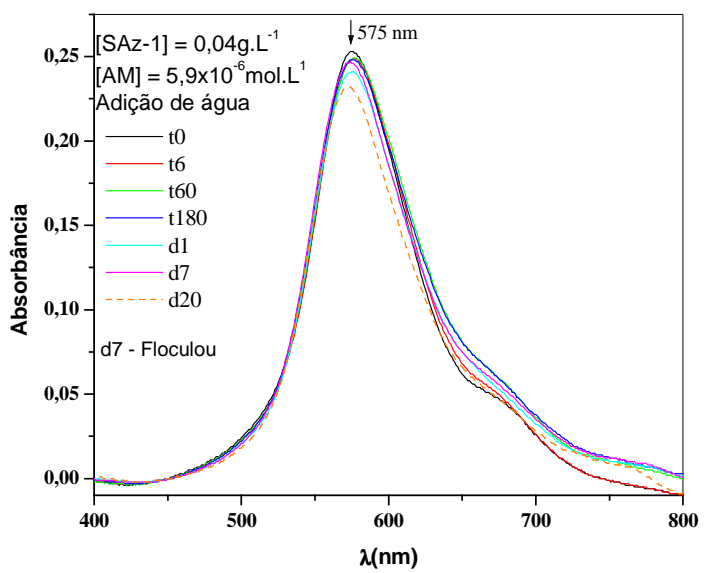

(a)

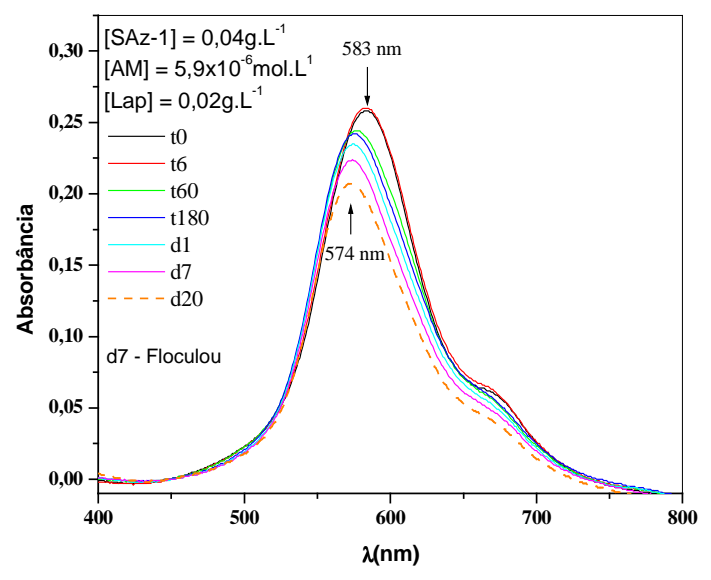

(c)

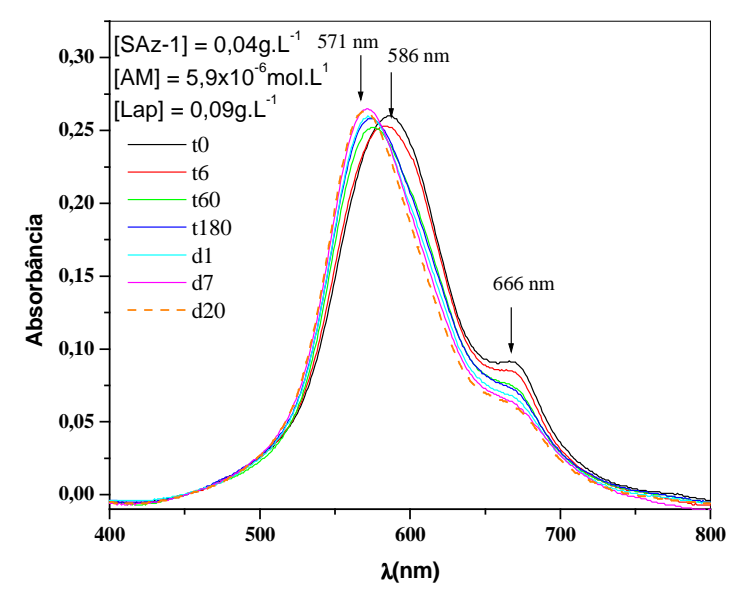

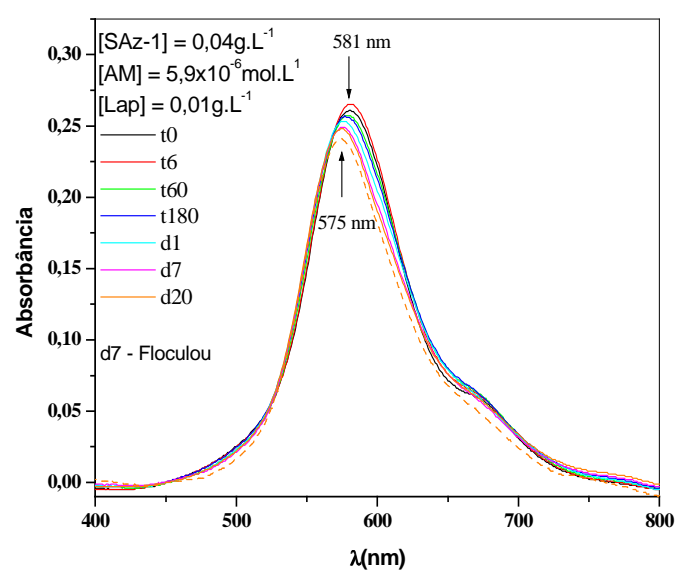

(b)

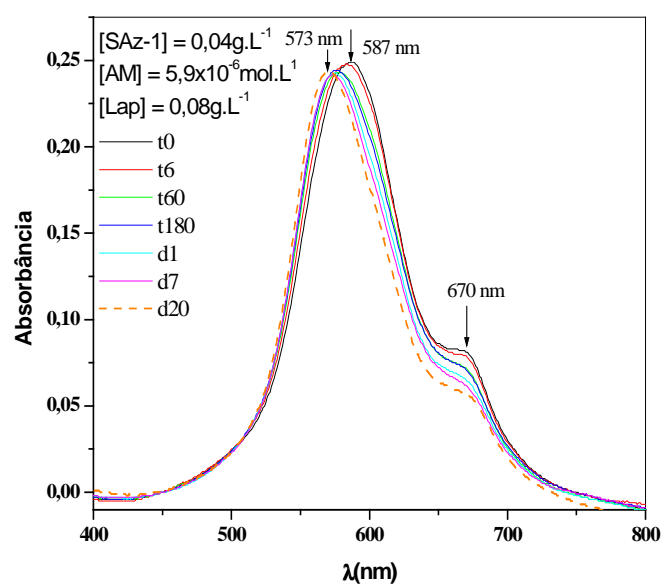

(d)

(e)

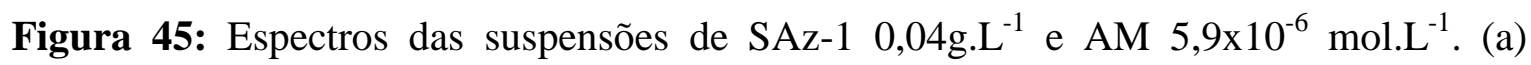
Adição de água. (b) Adição de Laponita - B, concentração final de 0,01g.L $\mathrm{L}^{-1}$. (c) Adição de Laponita - B, concentração final de 0,02g.L $\mathrm{L}^{-1}$. (d) Adição de Laponita - B, concentração 
final de $0,08 \mathrm{~g} \cdot \mathrm{L}^{-1}$. (e) Adição de Laponita - B, concentração final de 0,09g.L $\mathrm{L}^{-1}$. O tempo está expresso em minutos (t) e em dias (d).

$\mathrm{Na}$ Figura 45(a) está representado o espectro de AM adsorvido nas partículas de SAz-1 (amostra referência). Nas Figuras 45(b) a 45(e) estão apresentados os espectros das suspensões de SAz-1/AM com adição de Laponita - B. As mudanças espectrais não são significativas. Nota-se apenas que na região de aproximadamente 580nm há um deslocamento para comprimentos de onda menores e na região de $670 \mathrm{~nm}$ surge uma banda de pequena intensidade. Essas mudanças tornam-se mais intensas à medida que a concentração de Laponita - B adicionada ao sistema aumenta. No entanto essas mudanças são de pequena intensidade.

Na Figura 46 estão apresentados os espectros - diferença, os quais foram obtidos da mesma forma que nos itens anteriores.

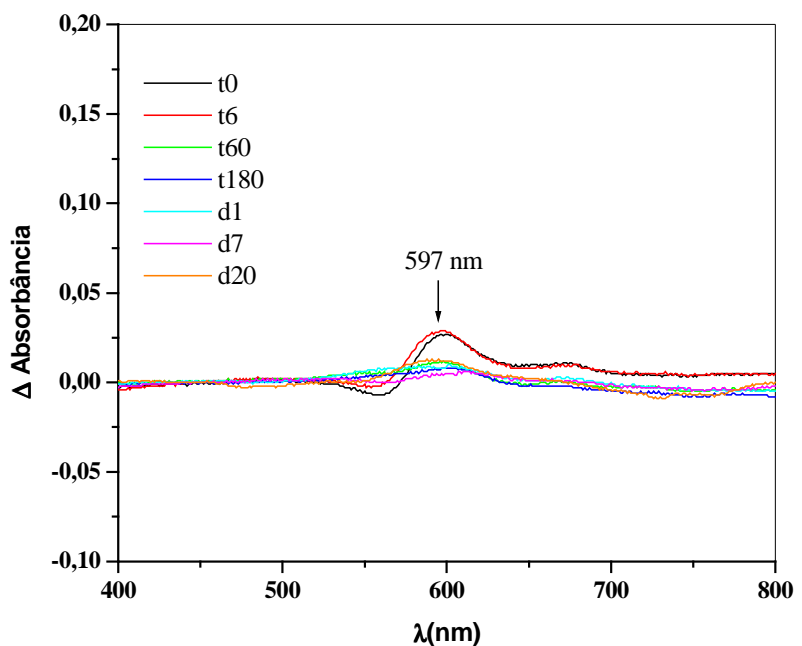

(a)

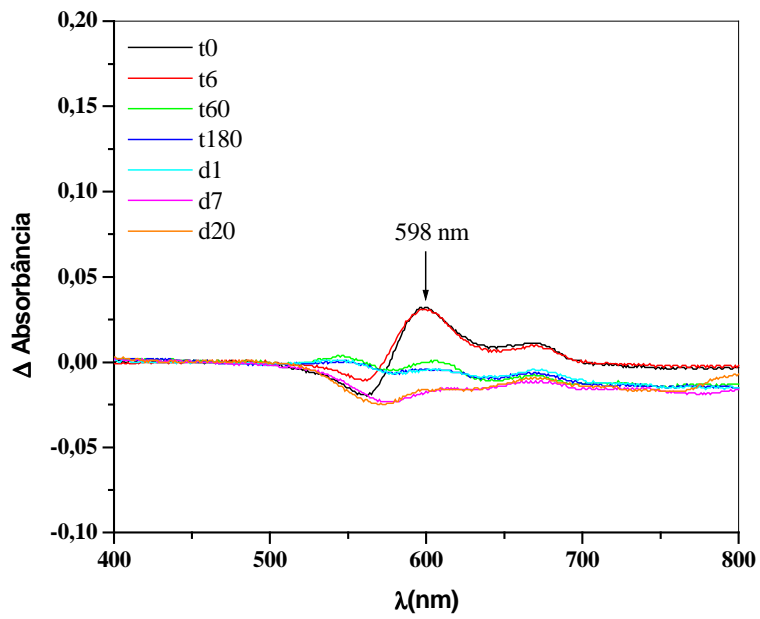

(b) 


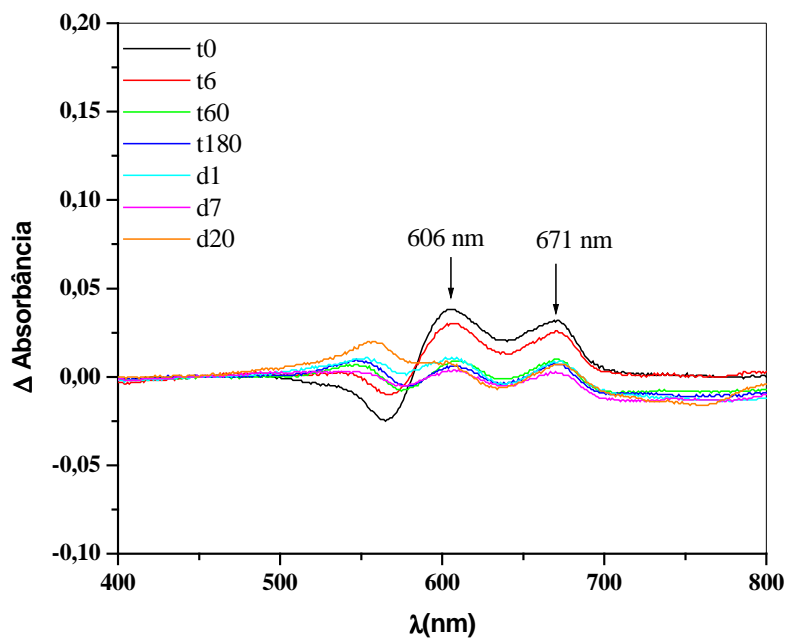

(c)

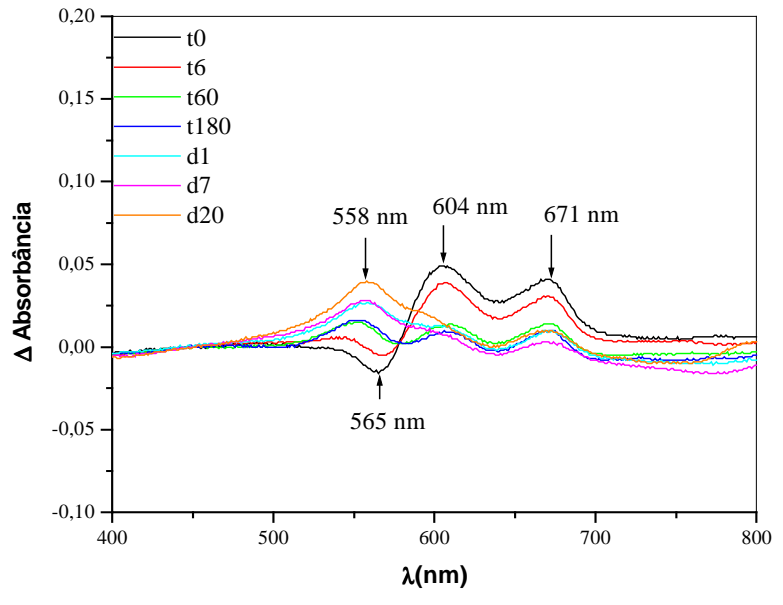

(d)

Figura 46: Espectro-diferença. (a) Espectro da Figura 45(b) menos 45(a). (b) Espectro da Figura 45(c) menos 45(a). (c) Espectro da Figura 45(d) menos 45(a ). (d) Espectro da Figura 45(e) menos 45(a).

Na Figura 46 nota-se que as alterações espectrais são mínimas, em especial nas Figuras 46(a) e 46(b). Nas Figuras 46(c) e 46(d), nota-se que nos dez primeiros minutos ocorre diminuição na quantidade de agregados e houve aumento da quantidade de dímeros e monômeros com relação à referência, indicando que está ocorrendo um processo de desagregação, possivelmente as moléculas de AM estariam sendo adsorvidas nas superfícies livres das partículas de Laponita - B adicionadas. Entretanto, após dez minutos, o processo de interação partícula - partícula prevalece, causando o aumento na quantidade de agregados e o deslocamento para comprimentos de onda menores, características típicas dos processos de interação partícula - partícula levando a formação das espécies de AM aprisionadas.

A Figura 47 representa os possíveis processos que justificam as alterações espectrais detectadas para as amostras do sistema SAz-1/AM com adição de laponita - B. Um desses processos, o processo representado pela letra (a), consiste na migração das moléculas de AM das partículas de SAz-1 para as partículas de Laponita - B. Este processo é predominante nos dez minutos após a adição da argila laponita - B ao sistema, e é caracterizado pelo surgimento da banda de absorção em 670nm, referente aos monômeros de AM, os quais não são detectados nas suspensões de SAz. Passados dez minutos, o processo (b), o qual representa a interação partícula-partícula passa a ser o 
predominante no sistema, levando a formação das espécies de AM aprisionadas, as quais são caracterizadas pelo deslocamento da banda de absorção na região de 585nm para comprimentos de onda menores (570nm).

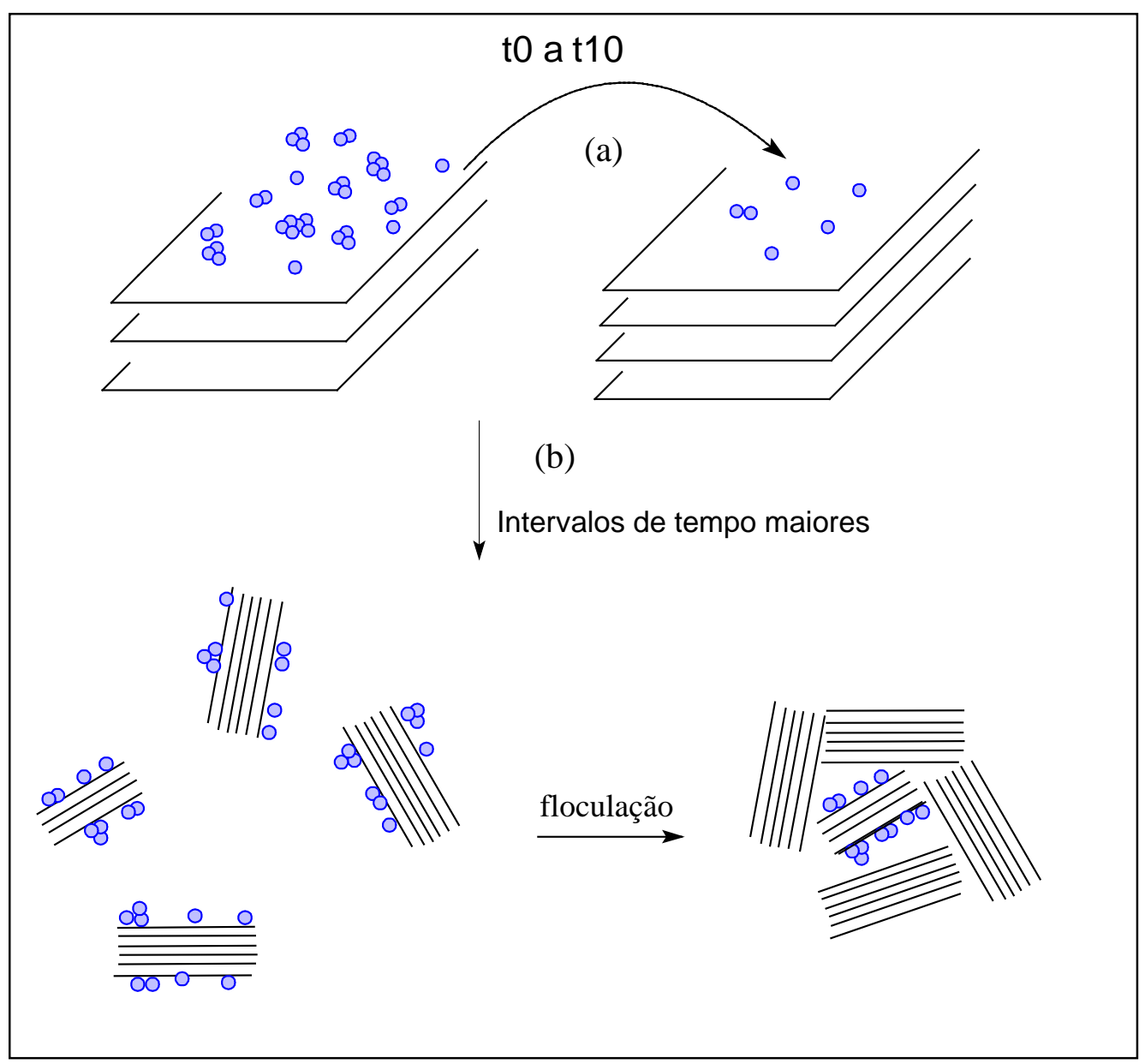

Figura 47: Esquema representado os processos que ocorrem no sistema SAz-1/AM com adição de Laponita - B. 


\subsection{Experimentos com diálise.}

Com a realização dos experimentos descritos anteriormente, verificamos que em determinados sistemas deve ocorrer o processo de migração de moléculas de corante entre partículas de argila. Por exemplo, foi visto ser possível que moléculas de AM adsorvidas em partículas de SAz-1 migrem para partículas de SWy-1 adicionadas a suspensão.

É possível imaginar diferentes formas pelas quais a migração pode ocorrer. Na Figura 48 tem-se a ilustração de duas formas pelas quais esse processo poderia ocorrer.
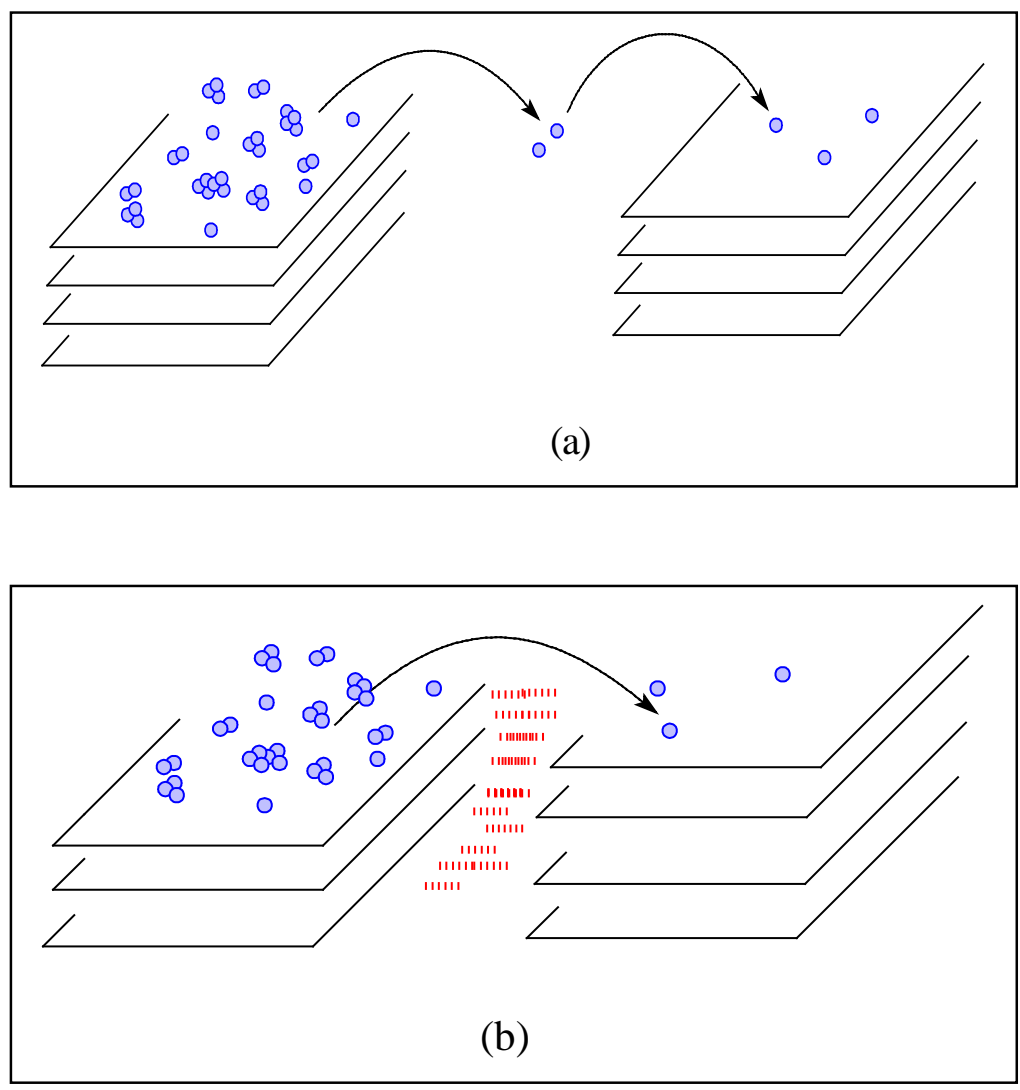

Figura 48: Possíveis mecanismos para a migração da molécula de AM entre partículas de argila. (a) Migração indireta (Passagem das moléculas de AM para a solução e posterior adsorção). (b) Migração direta (Passagem das moléculas de AM de uma partícula para outra partícula). ○ Representa as espécies (monômeros, agregados, dímeros) de AM. :::::: Representa interações entre as partículas. 
Como ilustrado na Figura 48(a), as moléculas de corante poderiam migrar de partícula para outra passando pela fase aquosa. Poderia ser estabelecido um equilíbrio entre moléculas adsorvidas e moléculas na fase aquosa, que por sua vez poderiam adsorver nas partículas de argila que foram adicionadas.

Na Figura 48(b) a migração de moléculas de uma partícula para outra seria favorecida pela interação entre essas partículas. Para haver migração seria então necessária uma aproximação até uma distância crítica, podendo ocorrer então a migração das moléculas de corante. Essa interação seria em princípio facilitada devido à atração entre as partículas com corante adsorvido que possuem "potencial positivo" e as partículas sem o corante, que possuem "potencial negativo". Esses potenciais são os estabelecidos pela dupla camada elétrica formada nas partículas e nos arredores das mesmas.

Para obter informações a respeito do processo de migração foram realizados experimentos utilizando as suspensões separadas por membranas de diálise. Foram utilizadas membranas permeáveis ao corante, mas não às partículas de argila. Antes de realizar os experimentos com as suspensões, foram realizados experimentos para se determinar como seriam as mudanças espectrais com o corante passando pela membrana e adsorvendo nas partículas de argila.

Foi preparada uma suspensão de argila na concentração de $0,11 \mathrm{~g} \cdot \mathrm{L}^{-1}$ e uma solução de $\mathrm{AM}$, concentração de $1 \times 10^{-5} \mathrm{~mol} \cdot \mathrm{L}^{-1}$. A suspensão e a solução permaneceram separadas pela membrana, conforme pode ser visualizado na figura 49. Foram realizadas medidas espectrofotométricas temporais das suspensões. Os espectros determinados são mostrados na Figura 50.

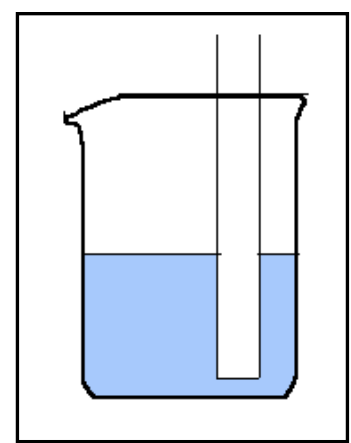

Figura 49: Representação do sistema utilizado nos experimentos com membrana.

O béquer contem solução de corante e a membrana contem suspensão de argila. 


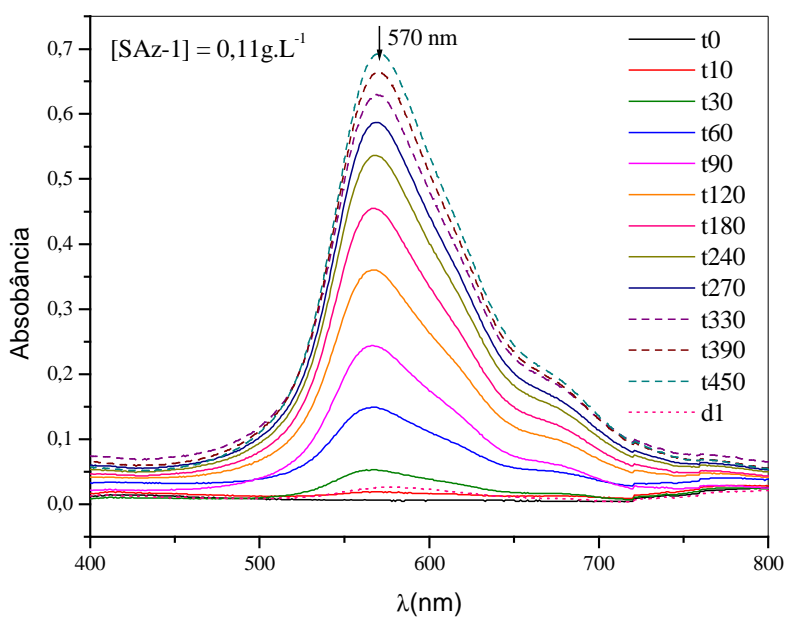

(a)

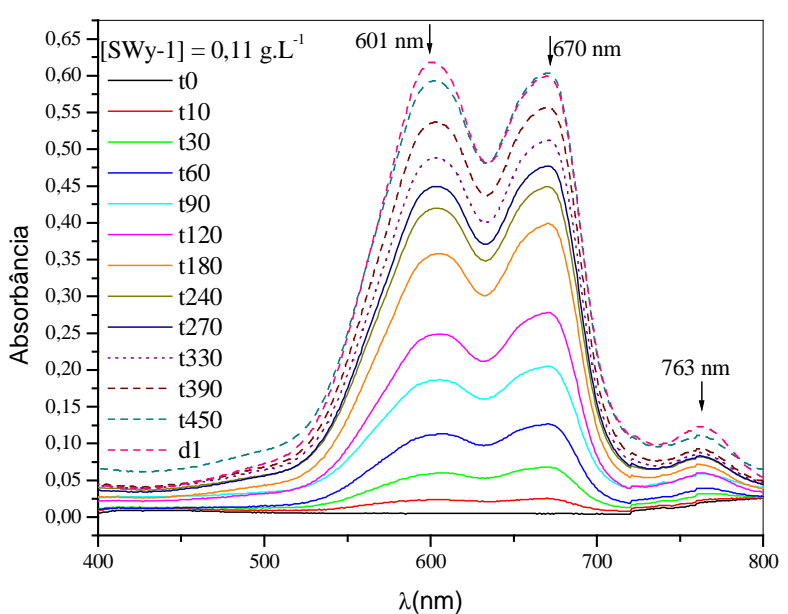

(b)

Figura 50: Espectros das suspensões de argila com adição de corante através da membrana de diálise. (a) Suspensão de SAz-1 0,11g.L - $^{-1}$ (b) Suspensão de SWy-1 0,11g.L ${ }^{-1}$. A concentração de $\mathrm{AM}$ na solução $1 \times 10^{-5} \mathrm{~mol} \cdot \mathrm{L}^{-1}$. O tempo t está expresso em minutos e d em dias.

Na Figura 50 tem se a variação espectral das suspensões de argila com adição de AM através da membrana de diálise. No tempo inicial (t0), verifica-se que não há corante nas suspensões de argila. A passagem de AM através da membrana e sua adsorção nas partículas de argila é evidente. Na Figura 49(a) tem-se a suspensão de SAz-1, comparando-se o comportamento espectral deste sistema com o caso da adição direta, verifica-se que ambos apresentam o mesmo comportamento espectral. Entretanto, no caso da suspensão de SWy-1 (Figura 50(b)) com adição indireta de AM verifica-se que os espectros são consideravelmente diferentes dos espectros determinados no caso da adição direta (Figura 13). A principal diferença entre esses dois modos de adição do corante consiste na velocidade em a solução é adicionada. A adição de corante através da membrana é lenta.

Na Figura 50(b) observa-se que a intensidade da banda na região de 760nm não varia significativamente como no caso da adição instantânea. Entretanto, as bandas em 601 e 670nm, referente aos dímeros e monômeros de AM, apresentam-se com maior intensidade e tem a mesma evolução com o passar do tempo.

Esta característica espectrofotométrica pode ser atribuída aos efeitos de interação entre as partículas. Como discutido na introdução as argilas apresentam uma densidade de carga superficial negativa quando dispersas. Quando se adiciona corante catiônico à suspensão ocorre a adsorção instantânea dessas moléculas nas superfícies das 
partículas de argila, promovendo a inversão rápida do potencial, ou seja, as argilas passam a apresentar uma densidade de carga superficial positiva após a adsorção das moléculas de AM. Isso permite a manutenção da força repulsiva entre as partículas, mantendo-as dispersas em suspensão. Quando o corante é adicionado lentamente, as forças de repulsão entre as partículas são diminuídas progressivamente, acelerando os processos de associação partícula-partícula. À medida que o corante está se adsorvendo, as partículas de argila estão se agregando, reduzindo o acesso aos sítios ácidos. Assim concluímos que na adição instantânea o processo de reorganização nos tactóides predomina, entretanto, na adição lenta, há predomínio dos processos de interação partícula-partícula.

Esses experimentos também revelaram que a membrana de diálise permite a passagem somente das moléculas de AM. É importante ressaltar que após um dia praticamente todo o corante da solução passou através da membrana e foi adsorvido pelas partículas de argila.

O experimento descrito a seguir foi idealizado com o objetivo de verificar se o processo de migração ocorre com as suspensões separadas pela membrana de diálise. Neste experimento prepararam-se duas suspensões, sendo que uma delas continha a argila SWy-1 e a outra continha a argila SAz-1. Na suspensão de SAz-1 adicionou-se solução de AM. As concentrações finais de argila foram de $0,11 \mathrm{~g} \cdot \mathrm{L}^{-1}$ e de corante de $1 \times 10^{-5} \mathrm{~mol} . \mathrm{L}^{-1}$. Essas suspensões foram mantidas separadas por uma membrana de diálise. Determinaramse os espectros das suspensões em função do tempo, os quais estão apresentados na Figura 51. 


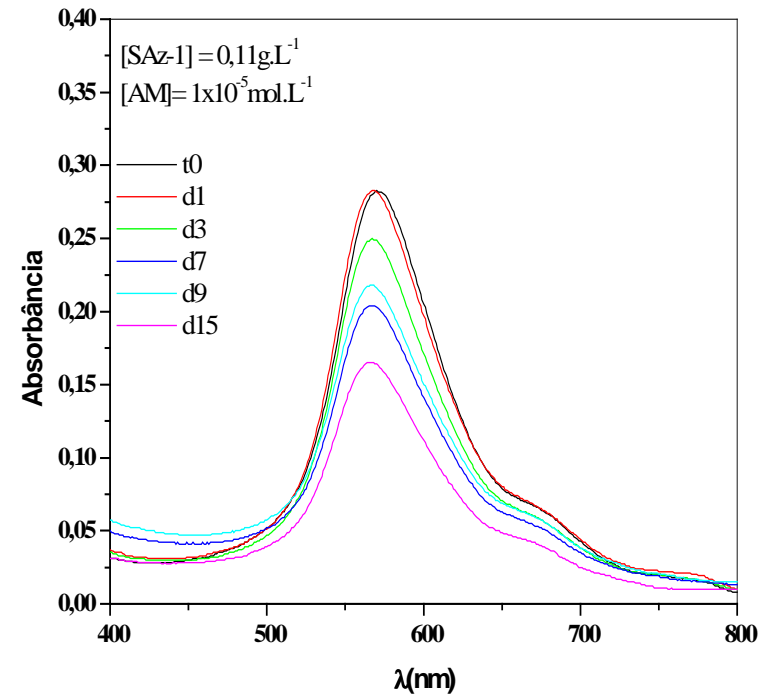

(a)

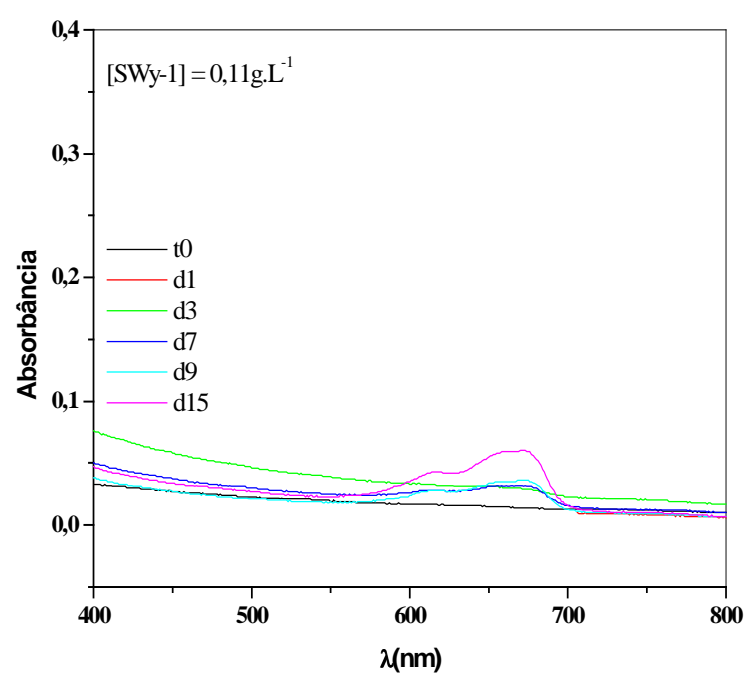

(b)

Figura 51: Espectros das suspensões separadas pela membrana de diálise. (a) Espectro da suspensão de SWy-1 (0,11g.L $\left.\mathrm{L}^{-1}\right)$. (b) Espectro da suspensão de SAz-1 $\left(0,11 \mathrm{~g} . \mathrm{L}^{-1}\right)$ com $\operatorname{AM}\left(1 \times 10^{-5} \mathrm{~mol} \cdot \mathrm{L}^{-1}\right)$.

Na Figura 51(a) são mostrados os espectros de AM adsorvido nas partículas de SAz-1. Verifica-se que não ocorrem alterações espectrais com o tempo. Nos espectros apresentados na Figura 51(b) não houve detecção significativa de AM na suspensão de SWy-1. Há apenas uma alteração na região de $669 \mathrm{~nm}$ da ordem de 0,05 unidades, passados 15 dias Esta alteração pode ser considerada insignificante quando comparada com os espectros da Figura 50(b). Portanto, não há migração significativa de AM quando essas suspensões estão separadas pela membrana de diálise. É importante ressaltar que não há AM na fase aquosa (ausência da banda em 665nm).

Com a realização desses experimentos verifica-se que quando as suspensões estão separadas pela membrana de diálise não ocorre migração de moléculas de AM entre as partículas de argila, portanto o processo de migração através da membrana é descartado (Figura 48(a)), e conclui-se que é necessário uma interação entre as partículas (Figura 48(b)) para que a migração entre partículas ocorra. 


\section{Considerações Finais}

Neste trabalho foi possível, através das mudanças espectrais, detectar processos de migração de moléculas de corante entre partículas de argilas em alguns dos sistemas estudados.

O corante catiônico azul de metileno foi utilizado como sonda, e se mostrou muito eficiente para o estudo das interações corante-argila. O azul de metileno foi rapidamente adsorvido pelas partículas de argila, formando diferentes espécies cujos espectros foram facilmente identificados.

A metodologia utilizada neste estudo consistiu na adição de suspensão de argila à suspensão argila-corante. Após a mistura, seria possível em princípio, acontecer três processos: i) migração intra-partícula, com as moléculas de corante indo para as regiões interlamelares, ii) migração entre partículas, com as moléculas de corante migrando das partículas onde estava inicialmente adsorvido, para as partículas adicionadas à suspensão, iii) processos de interação partícula-partícula, onde as interações entre as partículas de argila promovem a floculação da suspensão. Esses processos poderiam ser detectados através de medidas espectrofotométricas realizadas ao longo do tempo, após a mistura das suspensões. Os espectros determinados para as amostras foram comparados com os espectros determinados para a referência, a qual foi obtida pela adição de água á suspensão corante argila.

Os sistemas estudados neste trabalho e os principais resultados são apresentados nas Figurass 52,53 e 54. 


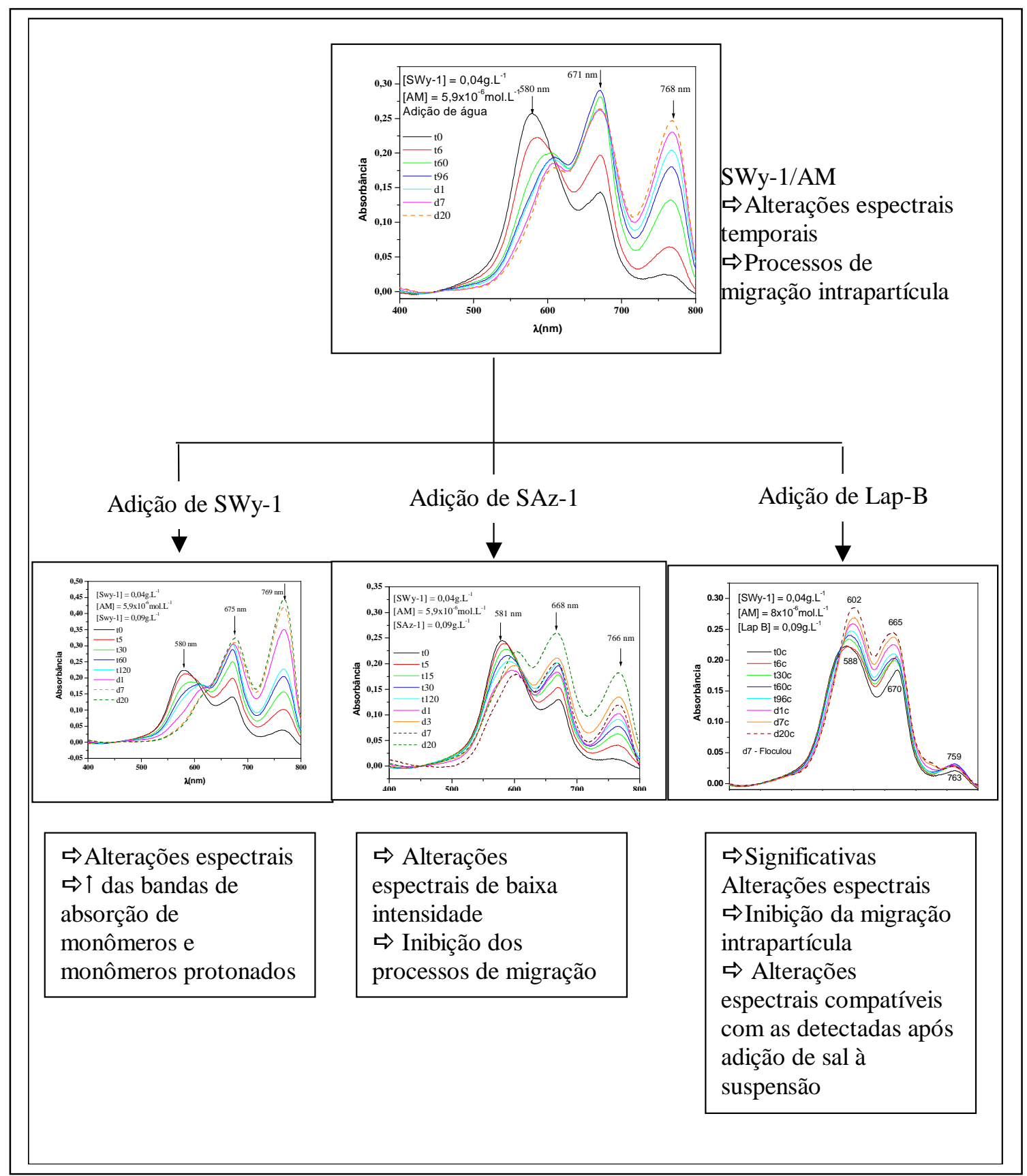

Figura 52: Esquema sumarizando os processos que ocorrem na suspensão de SWy-1/AM após adição de suspensão de argila. 


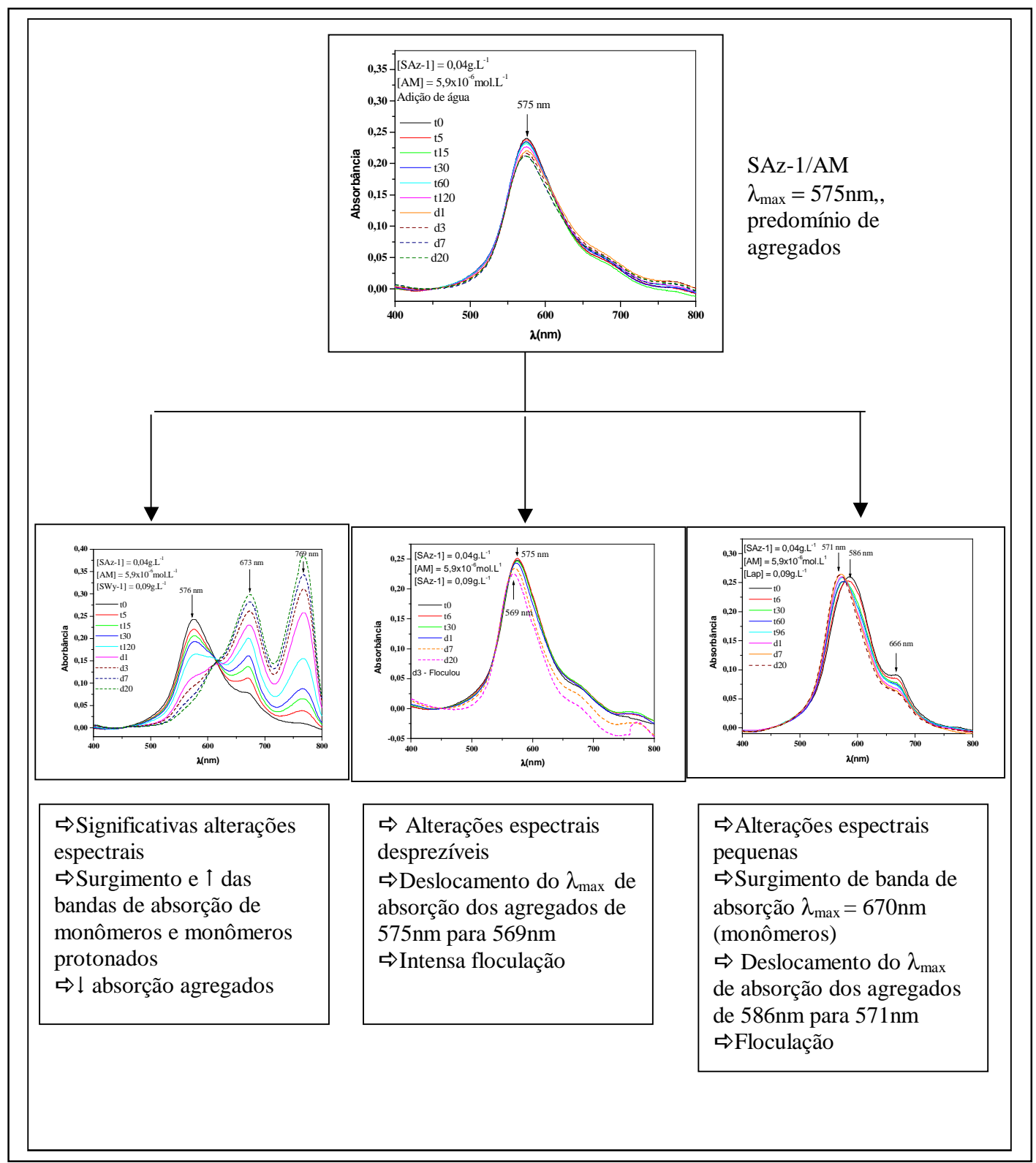

Figura 53: Esquema sumarizando os processos que ocorrem na suspensão de SAz-1/AM após adição de suspensão de argila. 


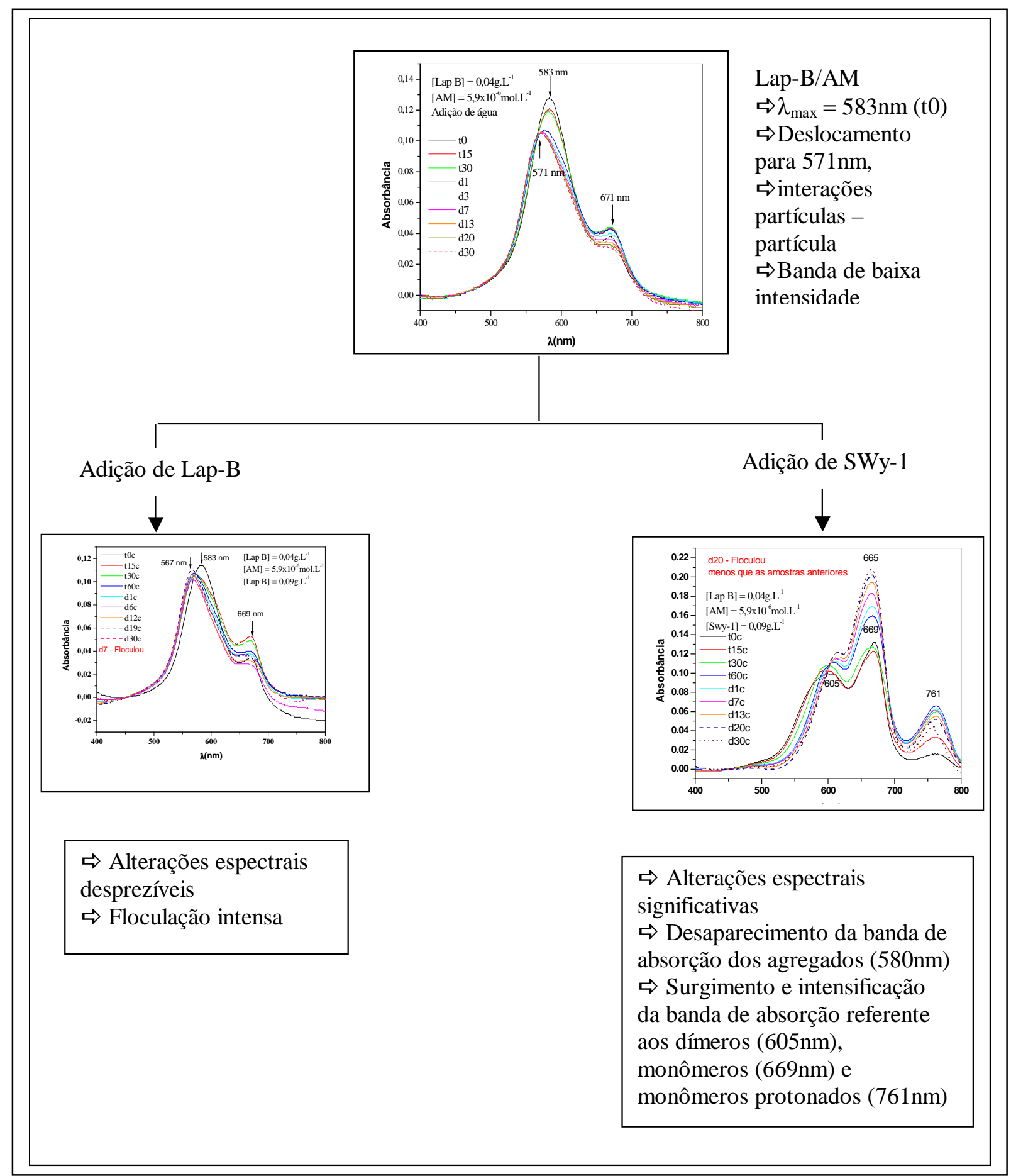

Figura 54: Esquema sumarizando os processos que ocorrem na suspensão de Lap-B/AM após adição de suspensão de argila. 
Na Figura 52, encontra-se de forma resumida as principais características da suspensão SWy-1 antes e após a adição das suspensões de SAz-1, SWy-1 e Laponta-B ao sistema.

A suspensão de SWy-1/AM se caracteriza pelas alterações espectrais que ocorrem com o tempo devido aos processos de reorganização das moléculas de AM nas partículas de SWy-1 (processos de migração intrapartícula)

A adição de SAz-1 e Laponita-B causaram alterações espectrais pequenas. Notou-se que houve uma inibição dos processos de migração intrapartícula. Essa inibição é mais intensa no sistema em que houve adição de Laponita-B, sendo que os espectros determinados para este sistema apresentam o mesmo comportamento detectado após a adição de sal à suspensão SWy-1/AM. Sabe-se que o aumento da força iônica favorece o processo de interação partícula - partícula. Portanto o processo de interação partícula partícula é predominante nesses sistemas.

A adição de $\mathrm{SWy}-1$, causou a redução da banda de absorção dos agregados e o aumento considerável da banda de absorção dos monômeros e monômeros protonados, indicando que prevalecem os processos de migração entre partículas.

$\mathrm{Na}$ Figura 53, tem-se de forma resumida as principais características da suspensão SAz-1/AM antes e após a adição das suspensões de SAz-1, SWy-1 e Laponita B.

Os espectros da suspensão de SAz-1/AM apresentaram como principal característica uma banda de absorção intensa na região de $575 \mathrm{~nm}$ referente aos agregados de AM. Ao longo do tempo, as alterações espectrais foram mínimas.

A adição de SAz-1 ao sistema não causou alterações espectrais significativas, porém favoreceu os processos de interação partícula - partícula, os quais foram detectados visualmente pela floculação da amostra e através dos espectros pelo deslocamento da banda de absorção do agregados de AM para comprimentos de onda menores, além do espalhamento detectado. Para este sistema predomina o processo de interação partícula-partícula.

Quando se adicionou Laponita-B, também não foram detectadas alterações espectrais significativas. Notou-se o surgimento da banda de absorção na região de $670 \mathrm{~nm}$ referente aos monômeros de AM. Como visto na introdução, os espectros determinados para a suspensão SAz-1/AM não apresentam banda de absorção referente aos monômeros. Esta alteração espectral poderia ser atribuída a migração de moléculas de AM das 
partículas de SAz-1 para as partículas de Laponita-B. No entanto, este processo não foi predominante para os tempos maiores que 10 minutos. Após este intervalo de tempo, notou-se o deslocamento da banda de absorção dos monômeros para comprimentos de onda menores. Este comportamento espectral, aliado a observação visual da intensa floculação apresentada pela amostra, permitiu concluir que o processo de interação partícula-partícula passa a ser predominante neste sistema.

A adição de SWy-1 ao sistema causou variações espectrais significantes, as quais aumentaram com o passar do tempo. Notou-se o surgimento e o aumento de intensidade das bandas de absorção referentes aos monômeros e monômeros protonados. A região interlamelar da argila SAz-1 não é disponível para a intercalção das moléculas de $\mathrm{AM}$, portanto, concluiu-se que o processo predominante neste sistema é a migração entre partículas, com as moléculas de corante indo das partículas de SAz-1 para as partículas de SWy-1.

A Figura 54 representa resumidamente as alterações espectrais detectadas para o sistema Lap-B/AM antes e após a adição de suspensões de SWy-1 e Lap-B.

Os espectros da suspensão de lap-B/AM apresentaram uma banda intensa na região de $585 \mathrm{~nm}$, referente aos agregados de AM, esta banda sofreu um deslocamento para comprimentos de onda menores com o passar do tempo, característico dos processos de interação partícula-partícula. Há também uma banda de pequena intensidade na região de 670nm, referente aos monômeros de AM.

As medidas espectrofotométricas da suspensão de Lap-B/AM após a adição de lap-B não revelaram alterações espectrais significativas, nota-se que houve espalhamento, resultado da floculação da amostra, a qual pode ser detectada visualmente também. Essas observações indicam que o processo predominante neste sistema deve ser a interação partícula-partícula.

A adição de SWy-1, causou variações espectrais significativas, notou-se o surgimento da banda de monômeros protonados, as quais não foram detectadas nos espectros de Lap-B/AM. Há também o aumento da intensidade da banda referente aos monômeros. Essas variações espectrais são atribuídas ao processo de migração entre partículas, o qual é predominante neste sistema.

De forma geral, verifica-se que a migração ocorre preferencialmente para as partículas da argila SWy-1, pois esta argila apresenta a região interlamelar disponível para 
a adsorção das moléculas de AM. A argila SAz-1 devido ao valor da densidade de carga superficial elevado, apresenta ,conseqüentemente, alta energia de coesão entre as lamelas, dificultando ou mesmo impedindo a adsorção das moléculas de AM na região interlamelar. A argila Laponita - B é uma hectorita, portanto, apresenta propriedades diferentes das montmorilonitas SWy-1 e SAz-1, e como pode ser observado nos espectros, não houve detecção de espécies protonadas de AM, indicando que sua região interlamelar não está disponível para a adsorção das moléculas de corante.

O processo de migração de corante entre partículas de argilas, ocorre entre as partículas de uma mesma suspensão, pois, uma suspensão de partículas de argila não é um sistema homogêneo, contém partículas com diferentes propriedades, como exemplo, pode ser citado a distribuição de tamanhos das partículas que compõem a suspensão. $\mathrm{O}$ fato das moléculas de corante apresentarem maior afinidade por partículas com determinadas propriedade, por exemplo, a disponibilidade da região interlamelar, favorece a migração entre partículas de argila em suspensão aquosa.

Os experimentos com membrana de diálise, revelaram que quando as suspensões estão separadas pela membrana, não ocorre migração das moléculas de corante entre partículas das suspensões. Para este estudo utilizou-se o sistema SAz-/AM com adição de SWy-1.

Conclui-se, então, que há necessidade de interação entre as partículas de argila para que a migração ocorra. 


\section{Conclus̃̃es}

Foram realizados estudos dos processos de interação entre partículas de argila e moléculas do corante catiônico azul de metileno em suspensão aquosa. Os experimentos foram planejados para detectar mudanças espectrais que pudessem ser atribuídas à migração de moléculas de corante de uma partícula para outra.

A analise dos resultados indicou que a migração do corante entre partículas pode ocorrer, e indicou, também que existe uma direção preferencial para a migração. Nos sistemas estudados, as moléculas de corante migraram preferencialmente para as partículas de SWy-1, comparadas às outras argilas utilizadas. Para os sistemas em que houve adição de partículas de Laponita-B ou SAz-1, predominaram os processos de interação partículapartícula.

Os resultados obtidos a partir dos experimentos com membrana, permitiram concluir ser necessário que as partículas estejam a uma distância mínima para que ocorra uma interação entre elas permitindo a migração de moléculas de corante entre as partículas de argila. Quando as suspensões estão separadas pela membrana de diálise, não foram detectadas alterações espectrais que pudessem ser atribuídas ao processo de migração das moléculas de corante de uma partícula para outra.

É importante mencionar que não foram detectadas moléculas de corante na fase aquosa. A concentração de corante atingiu no máximo $20 \%$ da quantidade necessária para saturar a argila tendo como base a CTC do mineral.

Com os resultados obtidos foi possível propor um mecanismo mais completo para descrever as interações entre corantes catiônicos e partículas de argila em suspensão aquosa, representado na Figura 55.

Inicialmente tem-se o processo de adsorção das moléculas de AM nas superfícies externas das partículas de argila, esta adsorção é rápida e é caracterizada espectrofotometricamente pelas bandas de absorção dos agregados ( 570-580) e monômeros adsorvidos de AM ( 670nm). Após a adsorção podem ocorrer três processos. $\mathrm{O}$ processo predominante depende das características do argilomineral. O processo em azul, representa a migração intrapartícula, que consiste na migração das moléculas de AM para a região interlamelar. Este processo é relativamente lento, ocorre na escala de minutos e horas, e é caracterizado por um equilíbrio que se estabelece rapidamente entre os monômeros e monômeros protonados de AM. O processo representado em rosa, consiste 
nas interações partícula-partícula, é caracterizado espectrofotometricamente pela absorção na região de 600-650nm, referente as espécies de AM aprisionadas. O processo ilustrado em vermelho, representa a migração de moléculas de AM entre partículas de argila.

Dependendo do sistema corante argila e das condições do experimento, determinado processo pode predominar em relação aos demais.

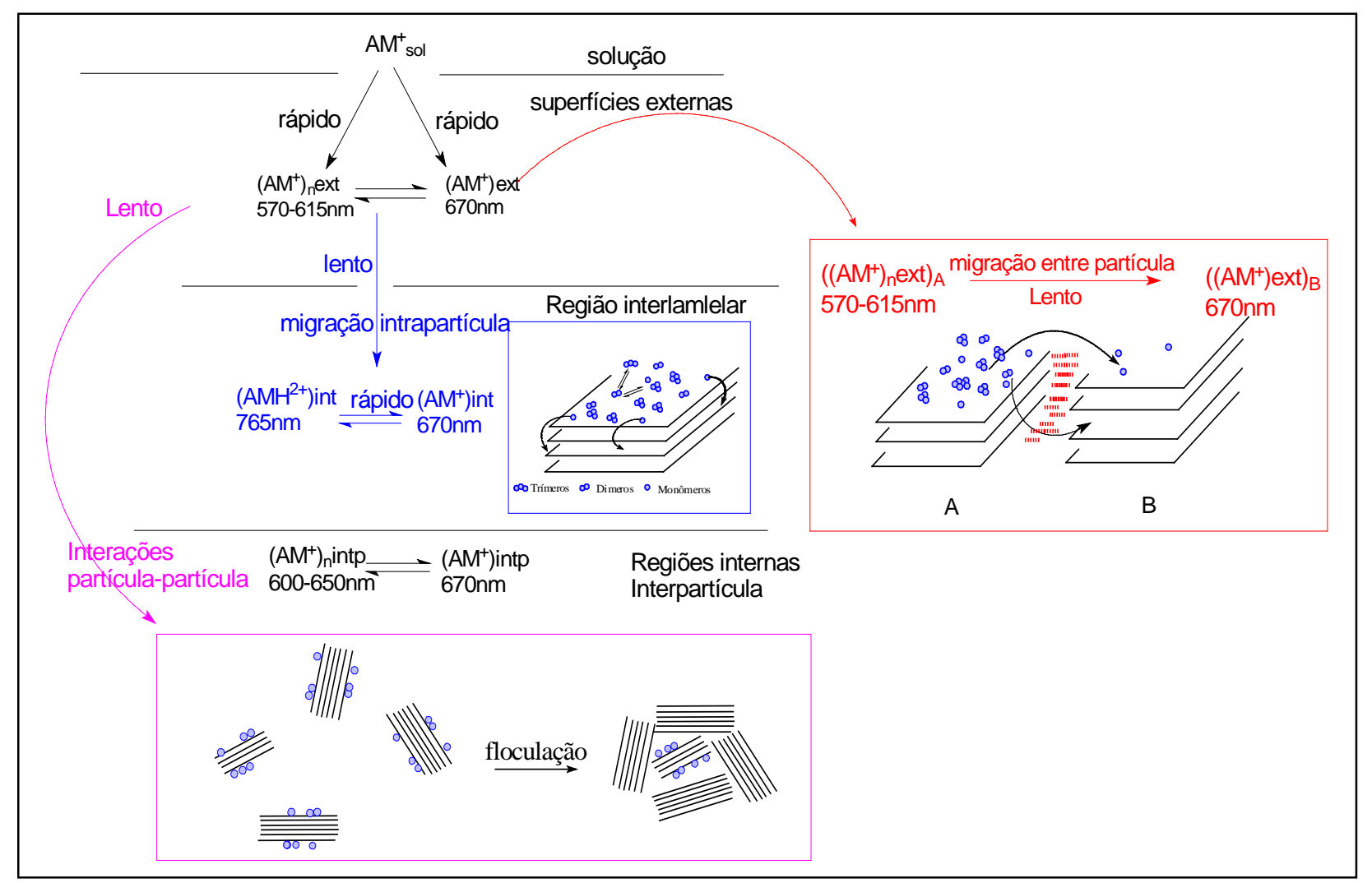

Figura 55: Esquema representando o mecanismo de interação entre o corante catiônico azul de metileno e partículas de argila em suspensão aquosa. 


\section{Referências Bibliográficas}

1. GOMES, C. F. Argilas: o que são e para que servem. Lisboa: Fundação. Kaloust Gulbenkian, 1988, p. 1-20.

2. SANTOS, P. S. Ciência e Tecnologia das Argilas. 2. ed. São Paulo: Edgard Blücher, 1989. v. 1.

3. HARVEY, C, C.; MURRAY, H. H. Industrial clays in the $21^{\text {st }}$ century: A perspective exploration technology and utilization. Appl. Clay Sci., v. 11, p. 285-310, 1997.

4. VAN OLPEHEN, H. An Introduction to Clay Colloid Chemistry. 2. ed. New York: Wiley Interscience, 1997, 10-20.

5. THE WONDERFUL world of clays. Disponível em :

<http://www.nature.berkeley.edu/ rsutton/clays.html> Acesso em: 21 nov. 2005.

6. THOMAS, J. K. Physical aspects of photochemistry and radiation-chemistry of molecules adsorbed on sio2, gamma-al2o3, zeolites, and clays. Chem. Rev., v.93, p. 301320, 1993.

7. NEVINS, M. J.; WEINTRIH, D. H. Determination of cation exchange capacity by methylene blue adsorption. Am. Ceram. Bull., v. 46, p. 587-592, 1967.

8. KUYKENDALL, V.G., THOMAS, J. K. Photophysical investigation of the degree of dispersion of aqueous colloidal clay. Langmuir, v. 6, p.1350-1356, 1990.

9. STUL, M.; UYTTERHOEVEN, J. B. Interlamelar sorption of ethanol on montmorillonites with different layer charges. J. Chem. Soc. Faraday 1, v. 71, p. 13961401, 1975.

10. CIONE, A. P. P. Estudo das interações entre corantes catiônicos com partículas de argila em suspensão aquosa: formação de agregados mistos. 1995. 121f. Dissertação (Mestrado Físico-Química) - Instituto de Química de São Carlos, Universidade de São Paulo, São Carlos, 1995.

11. RASHIN, A. A.; HONING, B. Reevaluation of the Born model of ion hydration. J. Phys. Chem., v. 89, p. 5588-5593, 1985.

12. DEVILLE, A.; LAZLO, P. The origin of the swelling of clays by water. Langmuir, $v$. 6, p. $1289-1294,1990$ 
13. LAGALY, G. Characterization of clays by organic-compounds. Clay Miner., v. 16, p. $1-21,1981$

14. LAGALY, G. Layer Charge Characteristics of 2:1 Silicate Clay Mineral Workshop Lectures. Clay Miner. Soc., v. 6, p 80-103, 1994

15. RABINOVICH, E.; EPISTEIN, L. F. Polymerization of Dyestuffs in Solution. Thionine and Methylene Blue. J. Am. Chem. Soc., v. 63, p. 69-78, 1941.

16. SCHUBERT, M.; LEVINE, A., A Qualitative Theory of Metachromasy in Solution. J. Am. Chem. Soc., v. 77, p. 4197, 1955.

17. HOHATGI, K. K.; SINGHAL, G. S. Nature of bonding in dye aggregates. J. Phys. Chem., v. 70, p. 1695-1701, 1966.

18. VITAGLIANO, V.; ORTONA, O.; PARRILI, M. Spectrophotometric behavior of a bifunctional acridine dye. J. Phys. Chem., v. 82, p. 2819-2823, 1978.

19. MUKERJEE, P.; GHOSH, A. K. Thermodinamic aspects of the self-association and hydrophobic bonding of methylene blue. Model system for staching interaction. J. Am. Chem. Soc., v. 96, p. 6419-6424, 1970.

20. GIESEKING, J. E.; JENNY, H. Behavior of polyvant Cations in Base Exchange. Soil Sci., v. 42, p. 273-280, 1936.

21. BERGMAN, K.; O’KONSKI, C.T. A Spectroscopic Study of Methylene Blue Monomer, dimmer and complexes with Montmorilonite. J. Phys. Chem., v. 67, p. 2169-2177, 1963.

22. BODENHEIMER, W.; HELLER, L. Sorption of Methylene Blue by Montmorillonite Satured with Different Cations. Isr. J. Chem., v. 6, p. 307-314, 1968.

23. GESSNER, F.; SCHIMITT,C.C; NEUMANN, M. G. Time-Dependent Spectrophotometric Study of the Interaction of Basic Dyes with Clays I: Methylene Blue and Neutral Red on Montmorillonites and Hectorites. Langmuir, v. 10, p. 3749-3753, 1994.

24. NEUMANN, M. G.; SCHIMITT, C. C; GESSNER, F. Time-Dependent Spectrophotometric Study of the Interaction of Basic Dyes with Clays II: Thiomine on Natural and Synthetic Montmorillonites and Hectorites. J. Colloid Interface Sci., v. 177, p. 165-169, 1996. 
25. NEUMANNN, M. G.; GESSNER, F.; CIONE, A. P. P.; SORTORI, A.; SCHIMTT, C. C. Interações entre corantes e argilas em suspensão aquosa. Quím. Nova, v. 23, p. 818$824,2000$.

26. FAUST, G. T. Staining of Clays Minerals as a Rapid Means of Identification in Natural and Beneficiated Products. U.S. Bur Mines. Rept. Inves., p. 3522, 1940.

27. PLESH, P. H.; ROBERTSON, R. H. S. Adsorption on to Ionogenic Surfaces. Nature, v. 161, p. 1020-1021, 1948.

28. YARIV, S.; LURIE, D. Metachromasy in Clay Minerals, 1. Sorption of Methylene Blue by Montmorillonite. Isr. J. Chem, v. 9, p. 537-552, 1971.

29. YARIV, S.; LURIE, D. Turbidity of Suspension of Cooper Montmorillonite Treated with Methylene-Blue. Isr. J. Chem, v. 9, p. 553-560, 1971.

30. SCHOONHEYDT, R. A. Clay adsorbed dyes - Methylene Blue on Laponite. Clay Miner., v. 27, p. 91-100, 1992.

31. CENENS, J.; SCHOONHEYDT, R. A. Spectroscopy of proflavine adsorbed on clays mineral. J. Chem. Soc. Faraday Trans., v. 82, p. 281-289, 1986.

32. SCHOONHEYDT, R. A. Spectroscopy and Chemistry in Small Domains. New York: Elsevier, 1994. p. 469.

33. ARBELOA, F. L.; MARTINEZ, J. M. H.; ARBELOA, T. L.; ARBELOA, I. L. The hydrophobic effect on the adsorption of rhodamines in aqueous suspension of smectites. The rhodamine 3B Laponite B system. Langmuir, v. 14, n. 16, p. 4566-4573, 1998.

34. CHARDHURI, R.; ARBELOA, F.L.; ARBELOA, I.L. Spectroscopy characterization of the adsorption of rhodamine 3B in hectorite. Langmuir, v. 16, n. 3, p. 1285-1291, 2000.

35. ARBELOA, F. L.; MARTINEZ, V. M.; PIETRO, J. P.; ARBELOA, I. L. Adsorption of Rhodamine 3B dye on Saponite Colloidal Particles in Aqueous Suspensions. Langnuir, v. 18, n. 7, p. 2658-2664, 2002.

36. ARBELOA, F. L.; CHAUDHURI, R.., ARBELOA, I. L.; ARBELOA, T. L, Aggregation of Rhodamine 3B adsorbed in Wyoming montmorillonite aqueous suspensions. J. Colloid Interface Sci., v. 246, p. 281-287, 2002. 
37. ARBELOA, F. L.; ARBELOA, I. L.; ARBELOA, T. L, Electronic Spectroscopy of Rhodamina Dyes Adsorbed at Clays Surfaces. In: KELLEY, M. (Ed.). Encyclopedia of Surface and Colloid Science. New York: Marcel Decker, 2002. p. 2007-2020.

38. BUDJÁK, J. Influence of the layer charge density of smectites on the interaction with methylene blue. J. Chem. Soc. Faraday Trans., v. 94,

p. 3487-3492, 1998.

39. BUDJÁK, J. Methylene blue interaction with reduced-charge smectites. Clays Clay Miner., v. 49, p. 244-254, 2001.

40. BUDJÁK, J.; KOMADEL, P. Interaction of methylene blue with reduced-charge montmorillonite. J. Phys. Chem. B, v. 101, p. 9065-9068, 1997.

41. BUDJÁK, J. Visible spectroscopy of cationic dyes in dispersion with reduced-charge montmorillonites. Clays Clay Miner., v. 50, p. 446-454, 2002.

42. CAVALHEIRO, C. C. S. Estudo das Interações entre corantes Catiônicos e Partículas de Argila em Suspensão. 1995. 208 f. Tese (Doutorado em Físico-Química) Instituto de Química de São Carlos, Universidade de São Paulo, São Carlos, 1995.

43. CARDOSO, M. Determinação do Ponto de Saturação de Argilas Através da Fluorescência de corantes Catiônicos. 1995. 96 f. Dissertação (Mestrado em FísicoQuímica1) - Instituto de Química de São Carlos, Universidade de São Paulo, São Carlos, 1995.

44. FERREIRA, A. J. Estudo das Interações entre Surfactantes e Partículas de Argila em Suspensão utilizando corantes Catiônicos. 1998. 118 f. Dissertação (Mestrado em Físico-Química) - Instituto de Química de São Carlos, Universidade de São Paulo, São Carlos, 1998.

45. CIONE, A. P. P. Fotoquímica e Fotofísica de Moléculas Orgânicas em Argilas. 2000. 121f. Tese (Doutorado em Físico-Química1) - Instituto de Química de São Carlos, Universidade de São Paulo, São Carlos, 2000.

46. MORAES, M. E., Estudo da Influência do Cátion Interlamelar nas Interações Corante- Argila. 2001. 170 f. Dissertação (Dissertação em Engenharia de Materiais) Instituto de Química São Carlos, Universidade de São Paulo, São Carlos, 2001.

47. CIONE, A. P.; NEUMANN, M. G.; GESSNER, F. Time-Dependent spectrophotometric study of the interaction of basic dyes with clays. Mixed dye aggregates on SWy-1 and Laponite. J. Colloid Interface Sci., v. 198, p. 106-112, 1998. 
48. NEUMANN, M. G.; GESSNER, F.; De OLIVEIRA, V. A. Formation of mixed dimmers in solution of dyes. J. Chem. Soc. Faraday Trans., v. 86, p. 3551-3555, 1990.

49. CIONE, A. P. P.; SCHIMITT, C. C.; NEUMANN, M. G.; GESSNER, F. The effect of added salt on the Aggregation of Clay Particles. J. Colloid Interface Sci., v. 226, p. 205209, 2000.

50. CIONE, A. P. P.; GESSNER, F.; NEUMANN, M. G., The Heavy-Atom Effect on the Photophysics of Aromatic Hydrocarbons in the Presence of Solid Clays. J. Colloid Interf. Sci., v. 240, p. 539-543, 2001.

51. SARTOTI, R. A. Estudo do Efeito da Densidade De Cargas nas Interações entre Corantes Catiônicos e Partículas de Argila em Suspensão. 1998161 f. Dissertação (Mestrado em Físico-Química) - Instituto de Química de São Carlos, Universidade de São Paulo, São Carlos, 1998.

52. NEUMANN, M. G.; GESSNER, F.; SCHIMITT, C. C.; SARTOTI, R. A., Influence of the layer charge and particle size on the interactions between the cationic dye methylene blue and clays in aqueous suspension. J. Colloid Interface Sci., v. 255, p. 254-259, 2002.

53. NEUMANN, G. M.; SCHIMITT, C. C.; GESSNER, F. Adsorption of dyes on clay surfaces. In: HUBBARD, A. T. (Ed.). Encyclopedia of Surface and Colloid Science. New York: Marcel Dekker, 2004. v. 1.

54. NEUMANN, G. M.; GESSNER, F. Adsorption of Dyes on clays Surfaces. In: HUBBARD, A. T. (Ed.). Encyclopedia of Surface and Colloid Science. New York: Marcel Dekker, 2002. v. 1.

55. YARIV, S. Termo-IR-spectroscopy analysis of interaction between organic pollutants and clay minerals. Therm. Acta. v. 274, p. 1-35, 1996.

56. FADALI, O. A. Effect of gas stirring on external mass transfer, intraparticle diffusion and energy consumption during adsorption. Adsorption, v. 21, p. 935-950, 2003.

57. HSU, Y. C.; CHIANG, C. C.; YU, M. F. Adsorption behavior of basics dyes on activated clay. Sep. Sci. Technol., v. 32, p. 2513-2534, 1997.

58. LU, L.; JONES, R. McBranch, D.; WHITTEN, D., Surface enhanced superquenching of cyanine dyes as J-aggregates on laponite clay nanoparticules. Langmuir, v. 18, p. 77067713, 2002.

59. VAN Olphen, H.; Fripiat, J. J. Data Handbook for Minerals and other NonMetallic Minerals. Oxford : Pergamon, 1979, p. 115-120. 
